\title{
Diretrizes metodológicas e validação estatística de dados para \\ a construção de data warehouses
}

\author{
Pedro Losco Takecian
}

\author{
TESE APRESENTADA \\ $\mathrm{AO}$ \\ Instituto de MatemáticA E Estatística \\ DA \\ Universidade De SÃo PaUlo \\ PARA \\ OBTENÇÃO DO TÍTULO \\ $\mathrm{DE}$ \\ DOUTOR EM CIÊNCIAS \\ Programa: Ciência da Computação \\ Orientador: Prof. Dr. João Eduardo Ferreira
}





\section{Diretrizes metodológicas e validação estatística de dados para \\ a construção de data warehouses}

Esta versão da tese contém as correções e alterações sugeridas pela Comissão Julgadora durante a defesa da versão original do trabalho, realizada em 14/08/2014. Uma cópia da versão original está disponível no Instituto de Matemática e Estatística da Universidade de São Paulo.

Comissão Julgadora:

- Prof. Dr. João Eduardo Ferreira (orientador) - (IME-USP)

- Prof ${ }^{a}$. Dr ${ }^{\mathrm{a}}$. Renata Wassermann - (IME-USP)

- Prof ${ }^{a}$. Dra . Ana Carolina Brandão Salgado - (UFPE)

- Prof. Dr. Márcio Katsumi Oikawa - (UFABC)

- Prof ${ }^{a}$. Dr ${ }^{a}$. Isabel Cristina Italiano - (EACH-USP) 

A minka querida avó Rachel. 



\section{Agradecimentos}

Este pequeno espaço é, pelo menos para mim, uma das partes mais importantes desta tese. É nele que se faz transparecer que este trabalho não é somente fruto de leituras, estudos e ideias solitárias acerca de uma área do conhecimento humano, mas sim resultado da interação prazeirosa com outras pessoas, de um processo recheado de muitas colaborações, incentivos e ajudas indispensáveis para a sua realização. A todos que participaram dessa trajetória, registro a minha mais profunda gratidão.

Ao IME-USP, no qual passo mais tempo do que em minha própria casa, e a todos que o formam, por propiciar um ambiente tão especial para o aprendizado e para a cooperação.

Ao professor Dr. João Eduardo Ferreira, meu orientador, pela paciência, compreensão e confiança em mim depositada. Tive a oportunidade de conhecê-lo ainda durante a minha graduação e, desde então, sua ajuda tem sido de inestimável valia durante todo esse percurso. Mais do que um orientador, um amigo com o qual sempre pude contar. Com sua simplicidade e humildade, estava sempre disponível para conversar, entendendo as minhas apreensões e dificuldades - que não foram poucas - e aconselhando-me da melhor forma possível.

Aos membros da banca, professores Drs. Renata Wassermann, Ana Carolina Salgado, Márcio Oikawa e Isabel Italiano, pela leitura atenciosa do texto e pelas valiosas sugestões e comentários, imprescindíveis para a finalização deste trabalho.

Aos professores Drs. Julio Singer, Junior Barrera e Carlos Bragança pelas importantes colaborações e ideias, sem as quais este trabalho não teria se concretizado. Fico muito grato pelo precioso tempo que gastaram comigo, sempre com muita paciência e gentileza. Ao professor Dr. Marco Gerosa pela bondade de me deixar usar sua sala por diversos meses em momento de necessidade.

Ao meu colega imeano Eduardo Dias, pelo auxílio na reta final deste trabalho e por acreditar na ideia aqui contida, tentando transformar um projeto de sistema em realidade.

Aos amigos Daniel Cordeiro e Kelly Braghetto, por estarem sempre próximos, pelos incentivos e conselhos, pelas conversas diárias, pelos almoços e lanches da tarde, sempre acompanhados de discussões muito proveitosas sobre os mais diversos assuntos.

Aos amigos do IME, à turma do BCC/2000, aos companheiros do Grupo Data e, em especial, aos amigos Danilo Sato, Eduardo Cotrin, André Schwerz, Rafael Liberato, João Josko, André Casimiro e Marcos Broinizi, que estiveram mais próximos durante a realização do meu doutorado, me incentivando e apoiando.

Aos meus pais Pedro e Rosemary, minha avó Rachel, meu irmão Alberto e minha cunhada Karina, por todo o carinho e apoio que só uma família é capaz de prover. Além disso, agradeço sempre que posso a meus pais por tudo o que fizeram nesta vida para que eu tivesse acesso a uma 
boa educação e bons estudos. Queria eu que todos tivessem essas mesmas oportunidades na vida.

À Cecília, minha companheira nesta vida, por todo o amor, carinho, paciência e compreensão nestes vários anos que estamos juntos. Acompanhar as apreensões e medos diários sobre as incertezas de um trabalho de doutorado não é fácil, e seu apoio incondicional foi fundamental nesse processo. Agradeço também ao Sr. Roberto e Roseli pelo apoio e compreensão.

A todas as outras pessoas que contribuíram e acompanharam, de diferentes formas, este trabalho. 


\section{Resumo}

TAKECIAN, P. L. Diretrizes metodológicas e validação estatística de dados para a construção de data warehouses. 112 p. Tese (Doutorado) - Instituto de Matemática e Estatística, Universidade de São Paulo, São Paulo, 2014.

Os sistemas de integração de dados que usam a arquitetura de data warehouse (DW) têm se tornado cada vez maiores e mais difíceis de gerenciar devido à crescente heterogeneidade das fontes de dados envolvidas. Apesar dos avanços tecnológicos e científicos, os projetos de DW ainda são muito lentos na geração de resultados pragmáticos. Este trabalho busca responder à seguinte questão: como pode ser reduzida a complexidade do desenvolvimento de sistemas de $D W$ que integram dados provenientes de sistemas transacionais heterogêneos? Para isso, apresenta duas contribuições: 1) A criação de diretrizes metodológicas baseadas em ciclos de modelagem conceitual e análise de dados para guiar a construção de um sistema modular de integração de dados. Essas diretrizes foram fundamentais para reduzir a complexidade do desenvolvimento do projeto internacional Retrovirus Epidemiology Donor Study-II (REDS-II), se mostrando adequadas para serem aplicadas em sistemas reais. 2) O desenvolvimento de um método de validação de lotes de dados candidatos a serem incorporados a um sistema integrador, que toma decisões baseado no perfil estatístico desses lotes, e de um projeto de sistema que viabiliza o uso desse método no contexto de sistemas de DW.

Palavras-chave: data warehouse, validação de dados, aprendizado de máquina, arquitetura modular, modelagem conceitual, análise de dados. 



\section{Abstract}

TAKECIAN, P. L. Methodological guidelines and statistical data validation for the construction of data warehouses. 112 p. Ph. D. Thesis - Instituto de Matemática e Estatística, Universidade de São Paulo, São Paulo, 2014.

Data integration systems that use data warehouse (DW) architecture are becoming bigger and more difficult to manage due to the growing heterogeneity of data sources. Despite the significant advances in research and technologies, many integration projects are still too slow to generate pragmatic results. This work addresses the following question: how can the complexity of $D W$ development for integration of heterogeneous transactional information systems be reduced? For this purpose, we present two contributions: 1) The establishment of methodological guidelines based on cycles of conceptual modeling and data analysis to drive construction of a modular data integration system. These guidelines were fundamental for reducing the development complexity of the international project Retrovirus Epidemiology Donor Study-II (REDS-II), proving suited to be applied in real systems. 2) The development of a validation method of data batches that are candidates to be incorporated into an integration system, which makes decisions based on the statistical profile of these batches, and a project of a system that enables the use of this method in DW systems context.

Keywords: data warehouse, data validation, machine learning, modular architecture, conceptual modeling, data analysis. 



\section{Sumário}

Lista de Abreviaturas e Siglas $\quad$ ix

Lista de Figuras $\quad$ xi

Lista de Tabelas $\quad$ xiii

1 Introdução 1

1.1 Motivação . . . . . . . . . . . . . . . . . . . . . . . . . . . 1

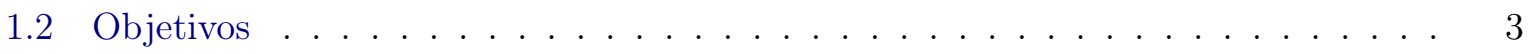

1.3 Justificativa . . . . . . . . . . . . . . . . . . . . . . . . . 3

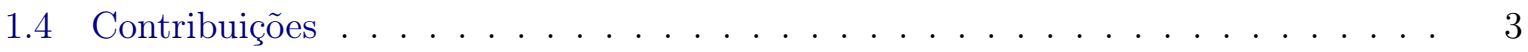

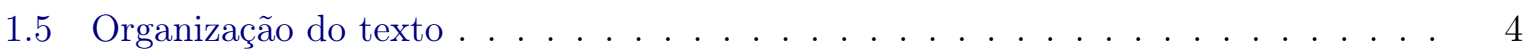

2 Fundamentos e Trabalhos Relacionados 5

2.1 Data warehouse . . . . . . . . . . . . . . . . . . . 5

2.1.1 Introdução e perspectiva histórica . . . . . . . . . . . . 5

2.1.2 Data warehouse e o panorama atual . . . . . . . . . . . . . . . . 6

2.1.3 Visualização e manipulação de dados em data warehouse . . . . . . . . . . 7

2.1.4 Metodologias de desenvolvimento de data warehouse . . . . . . . . . . . . 8

2.2 Integração de dados . . . . . . . . . . . . . . . . . . . . . . 9

2.2.1 Processo de integração de dados . . . . . . . . . . . . . . . . . . . 11

2.2.2 Correspondência entre esquemas . . . . . . . . . . . . . . . . 12

2.2 .3 Geradores de mapeamento . . . . . . . . . . . . . . . . . . . 13

2.2 .4 Qualidade dos dados . . . . . . . . . . . . . . . . . . . . . . . . . . . . . . . . . 14

2.3 Aprendizado de máquina: detecção de anomalias . . . . . . . . . . . . . . . 18

2.3.1 Deteç̧ão de anomalias . . . . . . . . . . . . . . . . . . . . . . . 19

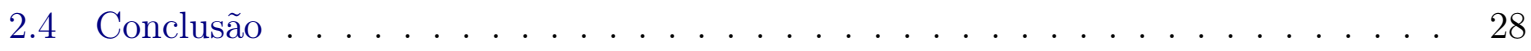

3 Projeto REDS-II 29

3.1 Introdução . . . . . . . . . . . . . . . . . . . . . . . . . . . . . . 29

3.2 Banco de dados normalizado e modelo conceitual . . . . . . . . . . . . . . . . 30

3.3 Arquitetura modular . . . . . . . . . . . . . . . . . . . . 32

3.4 Análises de dados . . . . . . . . . . . . . . . . . . . . . . . . . . . . 33

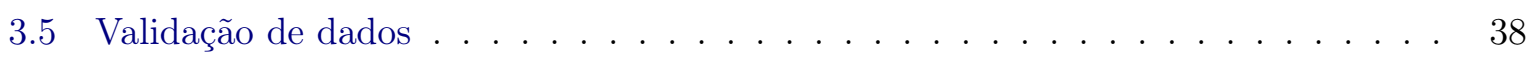

3.6 Projeto REDS-III . . . . . . . . . . . . . . . . . . . . . . . . . . . . . . . . 39 


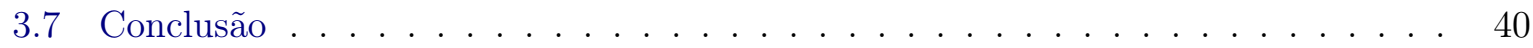

4 Diretrizes Metodológicas para a Construção de Data Warehouses 41

4.1 Diretrizes metodológicas . . . . . . . . . . . . . . . . . . . . . 41

4.2 Discussão . . . . . . . . . . . . . . . . . . . . . . . . . . . . 44

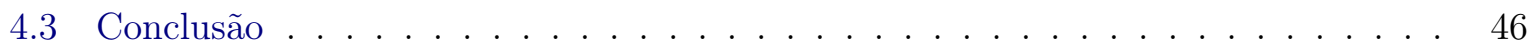

5 Validação Estatística Adaptativa de Lotes de Dados $\quad 47$

5.1 Descrição do problema . . . . . . . . . . . . . . . . . . . 47

5.2 Método de validação estatística utilizando deteç̧ão de anomalias . . . . . . . . . 50

5.2 .1 Uso de deteç̧ão de anomalias para a validação de lotes . . . . . . . . . . . . 51

5.3 Implementação do sistema de validação . . . . . . . . . . . . . . . . . . . . . . 59

5.3.1 Criação e configuração dos processos de validação . . . . . . . . . . . . . . 59

5.3 .2 Treinamento dos validadores . . . . . . . . . . . . . . . . . . . 64

5.3 .3 Validação de lotes . . . . . . . . . . . . . . . . . . . . 72

5.3 .4 Núcleo: detectores de anomalias . . . . . . . . . . . . . . . . . . 76

5.4 Conclusão . . . . . . . . . . . . . . . . . . . . . . . . . . 80

6 Conclusões $\quad 81$

6.1 Detalhes das principais contribuições . . . . . . . . . . . . . . . . . . 81

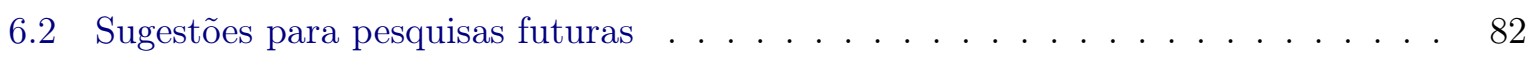

$\begin{array}{ll}\text { Referências Bibliográficas } & 85\end{array}$ 


\title{
Lista de Abreviaturas e Siglas
}

\author{
API Interface de Programação de Aplicações (Application Programming Inter- \\ face) \\ BD Banco de Dados \\ DTS Serviços de Transformação de Dados (Data Transformation Services) \\ DW Armazém de Dados (Data Warehouse) \\ ETL Extração, Transformação, Carga (Extract, Transform, Load) \\ NDS Banco de Dados Normalizado (Normalized Data Store) \\ OLAP Processamento Analítico Online (Online Analytical Processing) \\ REDS-II Estudo Epidemiológico de Retrovírus em Doadores - II (Retrovirus Epi- \\ demiology Donor Study - II) \\ REDS-III Estudo epidemiológico em receptores de sangue e avaliação de doadores \\ de sangue - III (Recipient Epidemiology and Donor Evaluation Study - \\ III) \\ SGBD Sistema Gerenciador de Bancos de Dados \\ SQL Linguagem de Consulta Estruturada (Structured Query Language)
}





\section{Lista de Figuras}

2.1 Abordagens de integração em diferentes níveis arquiteturais. Extraída de [ZD07] (tradução nossa) . . . . . . . . . . . . . . . . . . . . . . . . . . . 10

2.2 Arquitetura geral de um sistema integrador utilizando DW e as tarefas geralmente executadas em um sistema desse tipo. . . . . . . . . . . . . . . . . . . 11

3.1 Modelo conceitual do NDS (Modelo Entidade-Relacionamento estendido). . . . . 31

3.2 Arquitetura do data warehouse do projeto REDS-II. . . . . . . . . . . . . . . . 33

3.3 Visualização gerada a partir de um cubo OLAP com o cruzamento das variáveis Hemocentro $\times$ resultado de HCV . . . . . . . . . . . . . . . . . . . . 35

3.4 Outra forma de visualização possível considerando as mesmas variáveis da Figura 3.3. 36

3.5 Número de doações por mês de acordo com o tipo sanguíneo no hemocentro Hemope

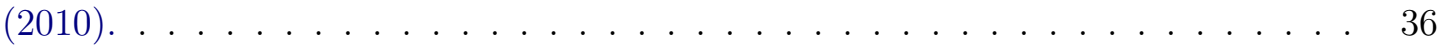

3.6 Número de doações por dia de acordo com o tipo sanguíneo no hemocentro Hemope

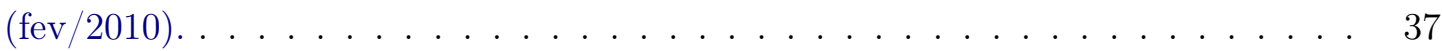

3.7 Exemplos de tipos de validação no processo de doação. . . . . . . . . . . . . . . . 38

5.1 Exemplo de validação de lote utilizando detectores de anomalias (simplificado). . 55

5.2 Exemplo de validação de lote utilizando detectores de anomalias considerando contextos (simplificado). . . . . . . . . . . . . . . . . . . 58

5.3 Sistema de validação: protótipo da tela de gerenciamento de processos de validação. 60

5.4 Sistema de validação: protótipo da tela de criação e edição de processos de validação. 61

5.5 Sistema de validação: protótipo da tela de criação e edição de estrutura de lotes. $\quad 62$

5.6 Sistema de validação: protótipo da tela de gerenciamento de estruturas de lotes. . 63

5.7 Sistema de validação: protótipo da tela de criação e edição de estrutura de arquivo presente no lote. . . . . . . . . . . . . . . . . . . . . . . . 64

5.8 Sistema de validação: protótipo da tela de criação e edição de validadores lógicos. $\quad 65$

5.9 Sistema de validação: protótipo da tela de criação de atributo contextual. . . . . 66

5.10 Fluxo de dados no treinamento dos detectores de anomalias considerando contextos (simplificado). . . . . . . . . . . . . . . . . . . . . 67 67

5.11 Sistema de validação: protótipo da tela de inserção de lote. . . . . . . . . . . . . 68

5.12 Sistema de validação: protótipo da tela de gerenciamento de lotes. . . . . . . . . . 69

5.13 Sistema de validação: protótipo da tela de gerenciamento de lotes reduzidos. . . . 70

5.14 Sistema de validação: protótipo da tela de sumário de lotes reduzidos. . . . . . . 72

5.15 Sistema de validação: protótipo da tela de submissão de lote para validação. . . . 75 
5.16 Exemplo de instâncias que excluem o uso de métodos gaussianos para detecção de anomalias. . . . . . . . . . . . . . . . . . . 77 


\section{Lista de Tabelas}

2.1 Cenários possíveis de erros e acertos na classificação de instâncias pelo detector de

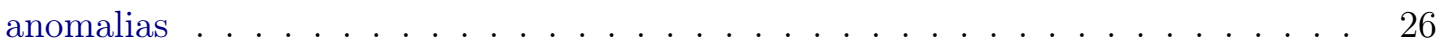

3.1 Exemplos de validações dos tipos ilustrados na Figura $3.7 \ldots \ldots$. . . . . . . . 38

5.1 Frequência dos tipos sanguíneos de doadores no lote exemplo L . . . . . . . . . . . 49

5.2 Proporções em um lote exemplo das categorias do atributo fator Rh sanguíneo . . 52

5.3 Proporções em um lote exemplo do atributo numérico faixa etária já categorizado. 52 



\section{Capítulo 1}

\section{Introdução}

\subsection{Motivação}

Com o passar dos anos, é notável o crescimento, tanto nas empresas como nas pesquisas científicas, do número de aplicações que necessitam integrar dados provenientes de diversas fontes distintas. Muitas vezes, o modelo que mais se encaixa na resolução do problema da integração de dados é a utilização de um data warehouse ${ }^{1}$ (DW) para unificar os dados em um único repositório. Entretanto, os sistemas de integração de dados envolvendo DW têm se tornado cada vez maiores e mais difíceis de gerenciar devido à crescente heterogeneidade das fontes de dados. Desse modo, os projetos desses sistemas envolvem pessoas com os mais diferentes perfis, formações e níveis de conhecimento tecnológico. Devido a esses fatores, vários projetos de integração são lentos para gerar resultados efetivos e muitas vezes são abandonados antes disso. De acordo com o Gartner Group [Gar05], ainda em 2005, quando os sistemas não tinham as dimensões de hoje, a previsão era de que cerca de $50 \%$ dos projetos de DW tendessem a falhar devido a problemas no projeto ou construção. Frequentemente, quando os sistemas de integração ficam finalmente disponíveis ao usuário final, as funcionalidades implementadas já estão obsoletas, enquanto as novas necessidades acabam sendo postergadas para futuras fases do desenvolvimento. Segundo Johnson [Joh03], mesmo quando esses grandes projetos são bem-sucedidos, a sua taxa de utilização é baixa, com menos de $40 \%$ das funcionalidades implementadas sendo usadas de fato. Isso ocorre por duas razões principais. A primeira delas é a falta de sincronismo entre os desenvolvedores e os usuários do sistema (médicos, empresários, pesquisadores). Devido ao grande tempo de desenvolvimento despendido nesses projetos, o alinhamento entre as necessidades do usuário e a solução implementada é afetado. A segunda razão refere-se ao processo tradicional de construção desse tipo de sistema, que não provê entregas rápidas e parciais das funcionalidades implementadas. De modo geral, o projeto somente estará disponível ao usuário após estar completamente implementado, o que pode levar meses ou até anos.

Uma vez que os sistemas integradores são implementados e entram no cotidiano das empresas e centros de pesquisa, existe um outro problema bastante comum que precisa ser enfrentado: a confiabilidade e a qualidade dos dados existentes neles. Dado que esses sistemas são muitas vezes utilizados para a tomada de decisões e para a criação de visões gerenciais do negócio, a qualidade

\footnotetext{
${ }^{1}$ Neste trabalho, o termo data warehouse não será traduzido para "armazém de dados" por ser amplamente consagrado e reconhecido nos trabalhos científicos da área na sua forma original, em inglês.
} 
dos dados usados dentro deles torna-se crítica para o seu uso. Entretanto, muitas validações não são implementadas devido à dificuldade inerente existente. Geralmente, observa-se que validações de caráter sintático são facilmente implementáveis, não precisando de ferramentas especializadas para isso. O mesmo se aplica para algumas validações semânticas. Entretanto, validações de caráter estatístico são usualmente negligenciadas por serem de difícil implementação, apesar de relevantes. Nesse tipo de validação pode-se, por exemplo, verificar se a distribuição dos valores das variáveis presentes nos lotes de dados que são candidatos a serem armazenados no DW estão de acordo com o esperado quando comparados com a distribuição dos valores das variáveis dos dados presentes em lotes previamente existentes e já validados por especialistas.

Dentre as diversas lacunas na integração de dados usando a arquitetura de DW que ainda necessitam de um maior aprofundamento científico, existem três grandes desafios que se mostram, no cotidiano da construção dessas soluções, grandes entraves para sua implementação. São eles:

1. a construção de uma ferramenta para automatizar a correspondência entre esquemas origem e destino da integração de dados e a geração de um mapeamento que traduza os dados entre os bancos de dados (BDs);

2. a especificação de uma metodologia para a construção evolutiva de um sistema integrador utilizando DW;

3. o desenvolvimento de um mecanismo para a validação estatística automatizada dos dados de entrada desses sistemas integradores.

No processo de integração de bancos de dados utilizando DW, um requisito essencial é o primeiro desafio apontado anteriormente: automatizar as correspondências e a geração de mapeamentos entre fontes de dados. Existem várias tentativas na literatura recente de automatizar a geração dos mapeamentos tendo em vista dois bancos de dados (origem e destino) e conceber as devidas correspondências entre os esquemas dos dois bancos. Entretanto, para casos que envolvem um maior grau de complexidade, não há evidências de que as ferramentas existentes funcionem adequadamente, estando sujeitas a falhas na geração dos mapeamentos.

Nesse cenário, a ferramenta ++ Spicy $\left[\mathrm{MMP}^{+} 11\right]$ tem se mostrado promissora. Ela é uma evolução das ferramentas Spicy [BMP ${ }^{+}$08b] e +Spicy [MPRB09]. Ela e suas antecessoras tiveram suas ideias e teorias publicadas em veículos científicos importantes da área de BD, tais como Very Large Data Bases (VLDB) [MPRB09, MMP10, $\left.\mathrm{MMP}^{+} 11\right]$, ACM Special Interest Group on Management of Data (SIGMOD) [BMP ${ }^{+}$08b, MPR09] e Extending Database Technology (EDBT) $\left[\mathrm{BMP}^{+} 08 \mathrm{a}\right]$. Lançada em 2011 e chamada pelos autores de "o primeiro exemplo de uma ferramenta de mapeamento de segunda geração", a ferramenta ++ Spicy é dita capaz de gerar códigos de mapeamento otimizados em SQL [DD97] ou XQuery [xqu] de modo automático. Entretanto, ainda não foi feito nenhum estudo a respeito das funcionalidades oferecidas pela ferramenta. Dessa forma, ainda não se conhece quais problemas foram, de fato, solucionados por ela.

Dado o grande avanço na resolução do problema da automatização do mapeamento entre fontes de dados, neste trabalho abordamos os outros dois desafios citados anteriormente, criando diretrizes metodológicas para a construção de sistemas integradores utilizando DW e projetando um sistema que visa aumentar a qualidade dos dados por meio de validações estatísticas. 


\subsection{Objetivos}

Este trabalho de doutorado busca ser uma resposta à seguinte pergunta: como pode ser reduzida a complexidade do desenvolvimento de sistemas de DW que integram dados provenientes de sistemas transacionais heterogêneos? Assim, ele aborda dois objetivos para reduzir tal complexidade, abrangendo os dois tópicos enfatizados na seção anterior da maneira descrita a seguir.

O primeiro objetivo deste trabalho é desenvolver, a partir da experiência adquirida durante o andamento do projeto REDS-II (Capítulo 3), diretrizes metodológicas para reduzir a complexidade da construção de sistemas de integração que envolvem dados provenientes de diversas fontes heterogêneas. Essas diretrizes baseiam-se em ciclos de modelagem conceitual e análise de dados para guiar a criação de um sistema modular de integração de dados.

O segundo objetivo é desenvolver um método de validação estatística de lotes de dados e projetar um sistema baseado nesse método, que possa ser utilizado no contexto de sistemas integradores, complementando-os. Esse sistema de validação será capaz de tomar decisões sobre a validade de lotes de dados candidatos a compor o DW baseado em medidas estatísticas extraídas dos lotes de dados previamente avaliados. Futuramente, o sistema de validação será integrado ao sistema Bloddis (Seção 3.6), desenvolvido a partir do projeto REDS-II.

\subsection{Justificativa}

Este trabalho de doutorado justifica-se principalmente pelos motivos apresentados nas seguintes sentenças, que visam resumir a essência do trabalho desenvolvido.

1. O uso das diretrizes metodológicas apresentadas neste doutorado viabiliza a integração de dados de fontes heterogêneas utilizando DW, conforme já experimentado com sucesso no projeto REDS-II. Essas diretrizes são construídas com base no uso cíclico de três técnicas (emprego do modelo conceitual, uso de análise de dados e arquitetura modular), criando um DW inicialmente pequeno, que se expande de maneira controlada, incorporando conceitos aos poucos e resultando em entregas rápidas e periódicas.

2. Nos sistemas atuais de integração de dados que usam DW, existem algumas ferramentas para facilitar a implementação de validações mais triviais (validações sintáticas e algumas validações semânticas). Entretanto, implementar validações mais elaboradas ainda é um grande desafio. Isso faz com que, em grande parte dos sistemas de DW, elas sejam negligenciadas. O projeto de um sistema de validação estatística de lotes de dados visa facilitar a implementação de validações complexas em sistemas de DW, com a finalidade de aumentar a qualidade dos dados armazenados, tornando-os mais confiáveis para a tomada de decisão e análises gerenciais.

\subsection{Contribuições}

As principais contribuições deste trabalho são as seguintes: 
- Especificação e descrição de diretrizes metodológicas para a construção de um sistema integrador de dados utilizando DW, tendo como base os aprendizados adquiridos durante a construção do sistema integrador do projeto REDS-II;

- Desenvolvimento de um método adaptativo de validação estatística de lotes de dados, que utiliza técnicas de classificação baseadas em deteç̧ão de anomalias, e de um projeto de sistema que visa a implantação desse método e a sua integração a sistemas de DW.

\subsection{Organização do texto}

O restante deste texto é organizado como se segue. O Capítulo 2 (Fundamentos e Trabalhos Relacionados) apresenta os assuntos que são fundamentos teóricos para o entendimento deste trabalho, como é o caso de Data warehouse (Seção 2.1), Integração de dados (Seção 2.2), e Deteç̧ão de Anomalias (Seção 2.3). Seu objetivo é o de fornecer apenas uma visão geral sobre esses assuntos, trazendo referências importantes para um possível aprofundamento e apontando os trabalhos que estão de alguma forma relacionados aos assuntos desta tese de doutorado. $\mathrm{O}$ Capítulo 3 (Projeto REDS-II) apresenta o projeto REDS-II, cujo DW é resultado deste doutorado, pois foi desenvolvido por meio das diretrizes propostas e cujo sistema resultante será integrado ao sistema de validação estatística de lotes de dados projetado neste trabalho. O Capítulo 4 (Diretrizes Metodológicas para a Construção de Data Warehouses) apresenta, com detalhes, as diretrizes desenvolvidas, de maneira algorítmica e com explicações textuais. O Capítulo 5 (Validação Estatística Adaptativa de Lotes de Dados) apresenta o método de validação de dados desenvolvido, baseado em detecção de anomalias e o sistema projetado para uso do método. Por fim, o Capítulo 6 (Conclusões) apresenta sucintamente os resultados deste trabalho, quais foram as suas contribuições e os possíveis trabalhos futuros. 


\section{Capítulo 2}

\section{Fundamentos e Trabalhos Relacionados}

Neste capítulo são apresentados os fundamentos deste trabalho. A Seção 2.1 introduz conceitos sobre data warehouse que são necessários para entender a Seção 2.2, sobre integração de dados e também o Capítulo 3, que apresenta o projeto REDS-II. A Seção 2.2 dá uma visão geral sobre o processo de integração, dissertando sobre os principais tópicos que constituem problemas relevantes na área. Por fim, a Seção 2.3, que trata de deteç̧ão de anomalias, caracteriza o problema da detecção de anomalias dentro do contexto de aprendizado de máquina. Tal contexto será importante para entender a solução do problema da validação estatística adaptativa de dados.

\subsection{Data warehouse}

\subsubsection{Introdução e perspectiva histórica}

Na segunda metade do século XX, o crescente sucesso dos sistemas gerenciadores de bancos de dados (SGBDs) foi responsável pela popularização do uso de bancos de dados em organizações de todo o mundo. Tal sucesso se deve, em grande parte, à introdução do modelo relacional e da linguagem declarativa SQL (na década de 70) nos SGBDs, o que facilitou a manipulação, manutenção e recuperação dos dados. Nos SGBDs, os bancos de dados (BDs) eram modelados (e ainda são) visando o processamento das transações rotineiras das empresas, sendo otimizados para tal fim. Os BDs transacionais, como são conhecidos, são amplamente utilizados nos mais diversos nichos empresariais, e o uso de SGBDs com essa finalidade tornou-se um "padrão de fato". Nesse mesmo período, com o aumento da competitividade entre empresas e com a procura incessante por melhorias nos processos de produção, intensificou-se a necessidade de obter visões analíticas e gerenciais sobre os dados armazenados nos BDs. Entretanto, os BDs transacionais não se mostravam adequados para prover tais visões que auxiliam a tomada de decisões, pois não eram desenvolvidos com essa finalidade. Assim, essa época é marcada por sucessivas e progressivas tentativas de companhias e pesquisadores que buscavam soluções apropriadas para desenvolver um BD analítico. A IBM foi uma dessas companhias, com diversos produtos desenvolvidos desde 1979 para atender às demandas por um ambiente analítico separado do ambiente transacional e que reduzisse o custo de processamento. No início da década de 90, surge o termo data warehouse, criado por William (Bill) Inmon [Inm02]. Ele o definiu como "uma coleção de dados orientada por assunto, integrada, variante no tempo e não volátil, para o apoio ao processo de tomada de 
decisão gerencial".

\subsubsection{Data warehouse e o panorama atual}

Atualmente, na literatura disponível, não existe precisão com relação ao conceito de data warehouse (DW), fato agravado pela sua utilização indiscriminada para aumentar o valor comercial dos produtos vendidos. Mesmo nos textos acadêmicos não há um consenso quanto ao seu significado, bem como ao que ele engloba. Algumas definições são restritivas. É o caso da definição de Inmon, vista na seção anterior, que limita o termo DW a uma coleção de dados. Em alguns textos mais recentes, é perceptível o aumento da abrangência do termo, que passa a englobar não somente coleções de dados, como também sistemas de apoio à extração e preparação dos dados que irão compor essas coleções. É essa visão mais abrangente de DW que será usada ao longo deste trabalho. Desta maneira, é possível interpretá-lo como um sistema que é projetado com o propósito de "dar apoio a extração, processamento e apresentação eficiente (dos dados) para fins analíticos e de tomada de decisão" [EN10]. Sob a mesma abrangência, Rainardi [Rai08] define DW como "um sistema que recupera e consolida dados periodicamente a partir dos sistemas de origem em um repositório de dados dimensional ou normalizado". Serão consideradas, ainda, algumas ferramentas e conceitos como pertencentes ao conceito de DW, pelo fato de suas funções estarem intrinsecamente ligadas. É o caso das ferramentas OLAP (online analytical processing) e dos cubos multidimensionais gerados a partir delas.

Assim como a definição de DW, existem também diversas abordagens para construí-lo. Em geral, suas diferenças se referem aos tipos de modelos empregados na construção dos BDs contidos nos DWs. Tais modelos são resultantes de diferentes combinações, em graus distintos, das abordagens defendidas por Inmon e por Ralph Kimball [Kim96]. Do mesmo modo que Bill Inmon, Ralph Kimball é um importante nome para o desenvolvimento da ideia de DW e sua consolidação. Entretanto, Kimball propôs uma outra abordagem metodológica da proposta por Inmon, contribuindo para o enriquecimento da diversificação dos paradigmas adotados na área. Para Inmon, um DW de uma organização deveria possuir um único repositório de dados. Nesse repositório, os dados deveriam ser armazenados de forma normalizada. Um banco de dados normalizado [EN10] é organizado de modo a evitar ao máximo redundâncias nos dados. A esse repositório de dados normalizado dá-se o nome de NDS (abreviação já consagrada do inglês para Normalized Data Store). Dele, subconjuntos de dados especializados em assuntos específicos seriam extraídos, desnormalizados (redundância de dados é introduzida nos BDs para aumentar o desempenho nas recuperações de dados) e indexados, dando origem a bancos de dados analíticos (conhecidos por data marts), que serviriam aos propósitos analíticos e gerenciais da organização. Já para Kimball, o DW de uma organização deveria ser formado por um conglomerado de data marts, desenvolvidos para atender a requisitos específicos. Nessa abordagem, os dados sempre são armazenados em bancos de dados analíticos, desnormalizados, que utilizam um modelo dimensional.

Em modelagem de banco de dados, um modelo (multi)dimensional é desenvolvido quando se busca eficiência na recuperação de dados provenientes de consultas analíticas. Entretanto, para obter essa eficiência, o modelo deve introduzir redundância de dados no BD. Essa introdução leva a uma necessidade de mais espaço para o armazenamento de dados e a uma maior dificuldade 
em garantir a integridade do BD. Um modelo multidimensional de BDs é basicamente composto de dois tipos de conceitos: fatos e dimensões. Um fato é uma medida de interesse para a análise. Essa medida deve ser armazenada com a granularidade apropriada para os fins pretendidos. Em um hemocentro, por exemplo, um fato de interesse poderia ser a quantidade de doações de sangue no período de um dia. Uma dimensão é um contexto de interesse relacionado a um fato. Como exemplo, é possível considerar o mês em que as doações ocorreram como uma dimensão relacionada ao fato acima. Uma vez que fatos podem ser analisados sob a perspectiva de diferentes contextos, o modelo pode ser chamado de multidimensional. Um modelo multidimensional pode ser implementado utilizando-se um SGBD relacional. Os dois tipos de implementação mais difundidos são conhecidos como modelo estrela e modelo floco de neve [EN10]. Em ambos os modelos, os fatos de interesse serão armazenados em tabelas fato, contendo atributos referentes a medidas e referências para tuplas das tabelas de dimensões. Para uma dimensão, os valores possíveis são armazenados em uma (ou mais) tabelas de dimensão, que podem ser ligadas às tabelas fato conforme for necessário para a análise em questão.

No cenário atual, existe espaço para o uso de todas as abordagens, dependendo do objetivo a ser atingido com a construção do DW. Muitas organizações estão mais próximas da ideia desenvolvida por Kimball, pois seus DWs surgem a partir da união de diversos bancos dimensionais desenvolvidos por departamentos em esforços independentes. Alguns autores e projetistas da área dizem ainda preferir uma abordagem integralmente dimensional pelo fato do modelo ser mais simples de ser entendido e interpretado por usuários finais. Entretanto, essa afirmação vem sendo questionada por alguns pesquisadores [SCT11]. O uso de uma abordagem mais próxima da proposta por Inmon é advogada pela facilidade de manutenção de uma base central e histórica quando ela é normalizada. A consistência dos dados é garantida mais facilmente dessa maneira. Conforme a necessidade, pode-se construir bancos dimensionais direcionados, sempre alimentados pelo banco normalizado central.

Neste doutorado, uma das maiores preocupações é facilitar a integração de dados provenientes de diversos sistemas transacionais heterogêneos, tendo sempre em mente a qualidade desses dados durante o processo de integração. Assim, decidimos adotar aqui a abordagem proposta por Inmon, priorizando a facilidade de manutenção dos dados, bem como a sua consistência.

\subsubsection{Visualização e manipulação de dados em data warehouse}

Tão importante quanto os bancos de dados de um DW são os componentes que manipulam os dados com a finalidade de torná-los aptos a popular o repositório. Um exemplo muito utilizado de componente com esse intuito são as ferramentas de ETL [KC04] (do inglês Extract, Transform and Load - Extração, Transformação e Carga), que têm como função facilitar os seguintes processos: extração de dados de diversos sistemas; transformação, validação e correção desses dados conforme necessário, adequando-os às necessidades do DW; e carga dos dados nos repositórios de dados normalizados ou analíticos. Existem diversos usos para tais ferramentas, inclusive fora do contexto de DW. Em particular, elas são usadas diretamente no processo de integração de dados utilizando DW e algumas das suas finalidades estarão melhor descritas na Seção 2.2.

No contexto de DW, além dos componentes para manipular os dados, outros componentes de grande importância são as ferramentas para visualização dos dados. Dentre elas, aquelas para 
manipulação dos cubos OLAP (Online Analytical Processing) se destacam pela sua versatilidade e facilidade de uso pelo usuário final. OLAP é uma abordagem no domínio da computação para responder a consultas analíticas multidimensionais. Um cubo OLAP é uma ferramenta desse tipo de abordagem, e é um conjunto de dados armazenado em um formato diferente do usual, de modo a facilitar a execução de consultas dinâmicas a informações sumariadas. De acordo com Italiano et al [IFT01], "os cubos são construídos de tal forma que, cada combinação de atributos das dimensões com uma métrica ou é pré-calculado ou é calculado muito rapidamente". Os dados que alimentam os cubos podem vir tanto de um modelo dimensional implementado em uma base relacional (cada uma dessas partes desnormalizadas são conhecidas como data marts), ou então vir de BDs multidimensionais, que já usam o formato de cubos para armazenar a informação. Um cubo pode, no momento da consulta pelo usuário, estar conectado ao BD origem dos dados, de modo que as consultas a ele serão feitas sobre os dados mais atuais existentes no DW, ou então estar desconectado da fonte original, gerando um formato portátil de arquivo que contém os dados que o $\mathrm{BD}$ origem continha no momento de sua geração. Existem várias ferramentas gráficas que permitem visualizar os dados dos cubos, como é o caso do visualizador de cubos para sistemas web de código aberto oferecido pela solução Pentaho ${ }^{\circledR}$ Mondrian ${ }^{\circledR}$ [mon], ou até mesmo simples e difundidos programas de escritório como o Microsoft ${ }^{\circledR}$ Excel ${ }^{\circledR}$ [exc]. Ferramentas OLAP têm sido usadas nos mais diversos domínios. Algumas delas foram adaptadas a ambientes biológicos [HPDW01, JKPT04]. A ideia de "OLAP científico" foi proposta [Huy01] para analisar dados em experimentos científicos controlados. Uma importante iniciativa de OLAPs científicos foi chamada de BIOLAP [bio12]. Essa abordagem procurou resolver algumas das limitações das abordagens OLAP clássicas, criando uma nova maneira de sumariar dados biológicos para domínios não numéricos. Outra abordagem é chamada de BIOSTAR, e busca evoluir de um esquema com fatos para um esquema quádruplo [WZR05].

\subsubsection{Metodologias de desenvolvimento de data warehouse}

Do ponto de vista do desenvolvimento de sistemas, as metodologias tradicionais que são usadas para o desenvolvimento de software (p. ex. cascata, espiral) [Pre10] também têm sido usadas para a construção de DWs. Mais recentemente, algumas metodologias ágeis também foram introduzidas nessa área [Amb03, AS06, Sad07]. As metodologias tradicionais não se mostraram capazes de tratar eficientemente da evolução dos sistemas de DW, que são muito dinâmicos e que requerem um constante acréscimo de requisitos e uma rápida correção de erros. Desde 2000, trabalhos como o desenvolvido por Ang \& Teo [AT00] têm mostrado as dificuldades inerentes em construir sistemas de DW usando as técnicas disponíveis. Tais dificuldades sugerem que uma abordagem incremental e a participação do usuário final devem ser incluídas no processo de desenvolvimento, mas esses trabalhos não mostram como isso pode ser feito. Dado esse cenário, as metodologias ágeis começaram a ser utilizadas no desenvolvimento de DW. Entretanto, nessas abordagens, não existe aprofundamento em como fazer um planejamento inicial. Desse modo, os problemas relacionados à evolução desses sistemas ainda persistem, dado que a essência conceitual subjacente a esses requisitos pode não ser capturada por essas metodologias. Mais recentemente, Giorgini et al. [GRG08] produziram uma excelente contribuição para a análise de requisitos, provendo sugestões de maneiras para coletar requisitos até que eles evoluam para um modelo 
conceitual. Eles também compararam os trabalhos existentes na área de desenvolvimento de DW usando um esquema de classificação para diferentes metodologias de desenvolvimento de acordo com a abordagem adotada para analisar os requisitos. Eles dividiram os trabalhos existentes em duas abordagens: orientada à oferta e orientada à demanda. Na abordagem orientada à oferta, os requisitos vêm de uma análise detalhada das fontes de dados. Na abordagem orientada à demanda, os requisitos são coletados dos usuários finais do DW. Entretanto, seu trabalho não considerou a necessidade de ciclos de desenvolvimento para a evolução dos sistemas.

A abordagem adotada neste trabalho abrange tanto a orientação à demanda quanto a orientação à oferta para capturar os requisitos. Por meio da abordagem desenvolvida, visamos capturar a essência conceitual por meio do uso de uma abordagem orientada à oferta, para desenvolver um modelo conceitual inicial que iria guiar o desenvolvimento do sistema. A partir disso, capturamos iterativamente os requisitos dos usuários de modo a gradualmente melhorar o sistema por meio da adição de características que seriam realmente úteis aos usuários finais, adaptando o modelo conceitual inicial para refletir esses requisitos. Portanto, neste trabalho, unimos o melhor de cada abordagem de uma maneira efetiva para construir um DW. Mais concretamente, a abordagem deste trabalho facilitou a resolução do problema da heterogeneidade por meio da aplicação integrada de três boas práticas: 1) a criação e manutenção de um modelo conceitual [EN10, GMR98]; 2) a aplicação de análise de dados [CD97, Kim96] para melhorar e corrigir o DW; e 3) o uso de uma arquitetura modular para conduzir, de maneira pragmática, o desenvolvimento do DW [Rai08].

\subsection{Integração de dados}

Integração de dados pode ser definida como uma subárea de Banco de Dados que estuda o problema de combinar dados que residem em diferentes fontes e prover ao usuário uma visão unificada desses dados [Len02]. Ela estuda também a automatização desse processo de integração. A automatização da integração de dados é uma tarefa complexa, principalmente em se tratando de fontes de dados heterogêneas. Apesar de ser um antigo problema em sistemas de computação e de haver muitos estudos significativos na área, ainda existem diversas lacunas a serem preenchidas. Com o passar do tempo, várias abordagens de automatização foram propostas, sendo que, até hoje, nenhuma delas resolveu completamente o problema e a escolha da melhor opção depende de cada caso e das necessidades envolvidas.

Segundo Ziegler e Dittrich [ZD07], o problema de integração de dados pode assumir múltiplas facetas, pois depende de muitas variáveis envolvidas, como é o caso da finalidade da integração, requisitos de desempenho, recursos disponíveis, tipo de informação a ser integrada, etc. Dessa forma, existem também diversas soluções possíveis para esse tipo de problema. Considerando-se uma perspectiva arquitetural, dependendo do nível de abstração no qual a integração é realizada, tem-se um tipo de solução possível (Figura 2.1). Na integração manual, a integração dos dados relevantes, provenientes de sistemas que apresentam interfaces heterogêneas, é feita de maneira manual pelos próprios usuários dos sistemas envolvidos. Na integração envolvendo interface comum de usuário, a integração ainda é feita pelo usuário, mas é facilitada pela existência de uma interface comum para acesso aos sistemas envolvidos. Na integração por aplicações, aplicações de integração são desenvolvidas para acessar diferentes fontes de dados e devolver resultados integrados aos 
usuários. Na integração por middleware, sistemas de middleware [DiM08] são utilizados para facilitar o trabalho de integração, retirando parte dessa funcionalidade das aplicações de integração. Na integração por acesso uniforme a dados, uma visão unificada e virtual dos dados é fornecida às aplicações. Essa integração é gerada no nível de acesso aos dados e em tempo de execução. Por fim, na integração por repositório de dados comum, a integração se dá pela geração de um novo repositório de dados que integrará fisicamente (e não virtualmente) os dados dos sistemas envolvidos.

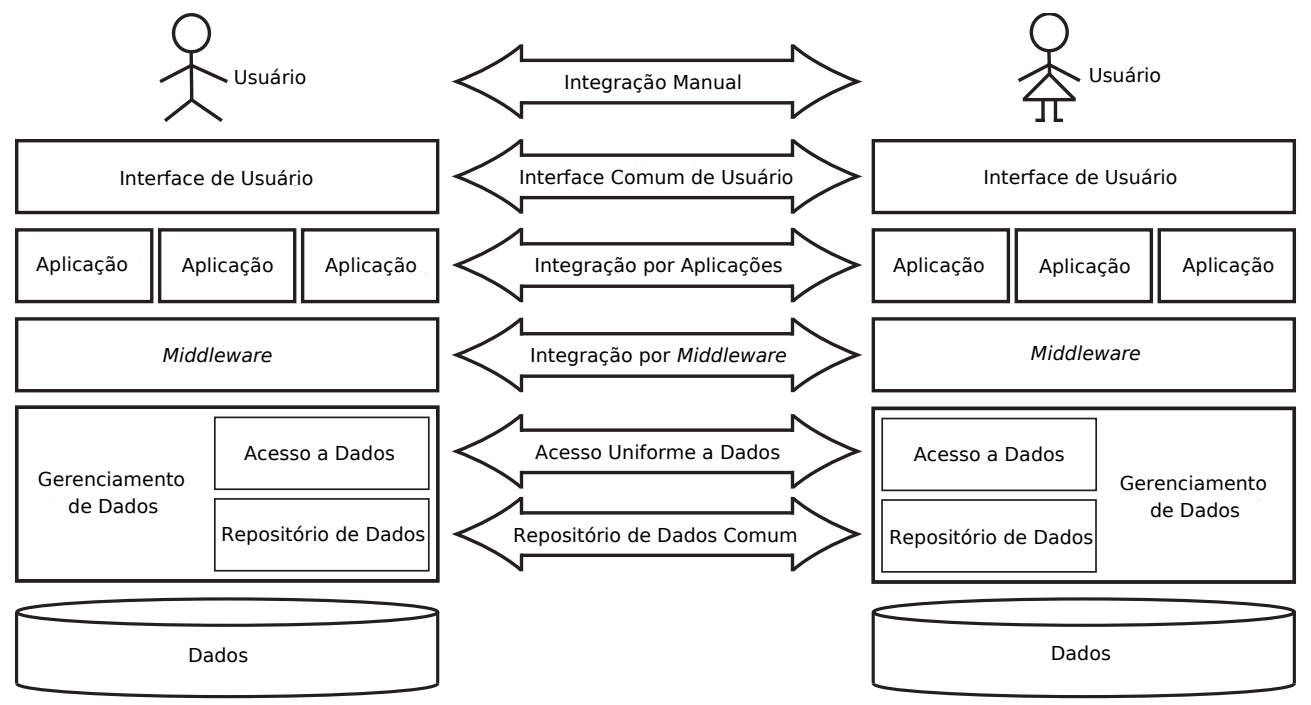

Figura 2.1: Abordagens de integração em diferentes niveis arquiteturais. Extraída de [ZD0`7] (tradução nossa).

Dentre as abordagens mais utilizadas para construir sistemas integradores, estão a arquitetura de data warehouse $(D W)$ - de acordo com a classificação anterior, uma implementação da integração por repositório de dados comuns - e a arquitetura de mediadores - integração por acesso uniforme a dados, de acordo com a mesma classificação.

$\mathrm{Na}$ arquitetura de DW, a integração se dá pela reunião dos dados provenientes das diversas fontes em um repositório único (que pode ser normalizado ou analítico, dependendo da abordagem adotada) e, portanto, regido por um único esquema. Um sistema de DW inclui rotinas que extraem, transformam e carregam os dados existentes em cada uma das fontes de dados, sendo que as consultas são feitas em uma única base e, portanto, respondidas eficientemente. Essa característica torna essa arquitetura ideal quando a integração visa a análise de grandes quantidades de dados. Caso esses dados estivessem espalhados por diversas bases, a quantidade de informação que teria que trafegar entre as bases toda vez que uma análise fosse feita a inviabilizaria. Entretanto, essa arquitetura não funciona bem nos casos em que um dos requisitos é ter os dados constantemente atualizados. Popular e atualizar a base central de um DW é uma tarefa custosa, que as organizações geralmente fazem com pouca frequência (diariamente, semanalmente, etc) em horários específicos, quando os sistemas transacionais que originam os dados têm a menor quantidade de utilização. Se a consulta a dados constantemente atualizados for um requisito indispensável, indica-se o uso da arquitetura de mediadores.

A arquitetura de mediadores é uma solução para o problema de integração que utiliza mediadores (e tradutores, se forem necessários). Um mediador é composto, basicamente, por um 
esquema de BD, por rotinas de decomposição de consultas e por rotinas de integração de respostas. Um esquema mediador é projetado de acordo com as necessidades de consulta dos usuários do sistema integrador. Feita uma consulta baseada no esquema mediador, ela é decomposta em outras consultas específicas, agora baseadas nos esquemas de cada uma das fontes de dados. Caso sejam necessários, tradutores podem ser utilizados para fazer a interface entre as fontes de dados e o mediador, diminuindo, assim, a complexidade do último. Em seguida, o mediador captura os dados devolvidos por essas consultas específicas, transformando-os e integrando-os para compor a resposta da consulta original, devolvendo os dados ao usuário requisitante da informação. Para mais informações sobre essa arquitetura, bem como sua utilização, as referências bibliográficas relacionadas ao assunto [Yan97, Len02, $\left.\mathrm{VdMP}^{+} 11\right]$ podem ser consultadas.

Neste trabalho, consideramos a arquitetura de data warehouse utilizando a abordagem de Inmon (utilizando um banco de dados normalizado central (NDS) - detalhes são apresentados na Seção 2.1) para abordar o problema de integração de dados. Essa decisão foi adotada a partir do interesse deste trabalho na integração de grandes quantidades de dados provenientes de fontes heterogêneas com a finalidade de análise. Tomamos como hipótese que, para as análises consideradas, não existe a necessidade de dados prontamente atualizados.

\subsubsection{Processo de integração de dados}

Em linhas gerais, a integração de dados utilizando a abordagem adotada neste trabalho pode ser dividida em algumas tarefas bem específicas. A Figura 2.2 mostra o posicionamento, em um diagrama representativo da arquitetura de um sistema integrador que utiliza a abordagem de DW, das tarefas que em geral são executadas em um sistema desse tipo. As tarefas, representadas por retângulos, serão sucintamente descritas a seguir, de acordo com a numeração que aparece na figura. Algumas delas, de maior importância e que constituem maior desafio no processo de integração, serão tratadas mais detalhadamente nas seções seguintes.

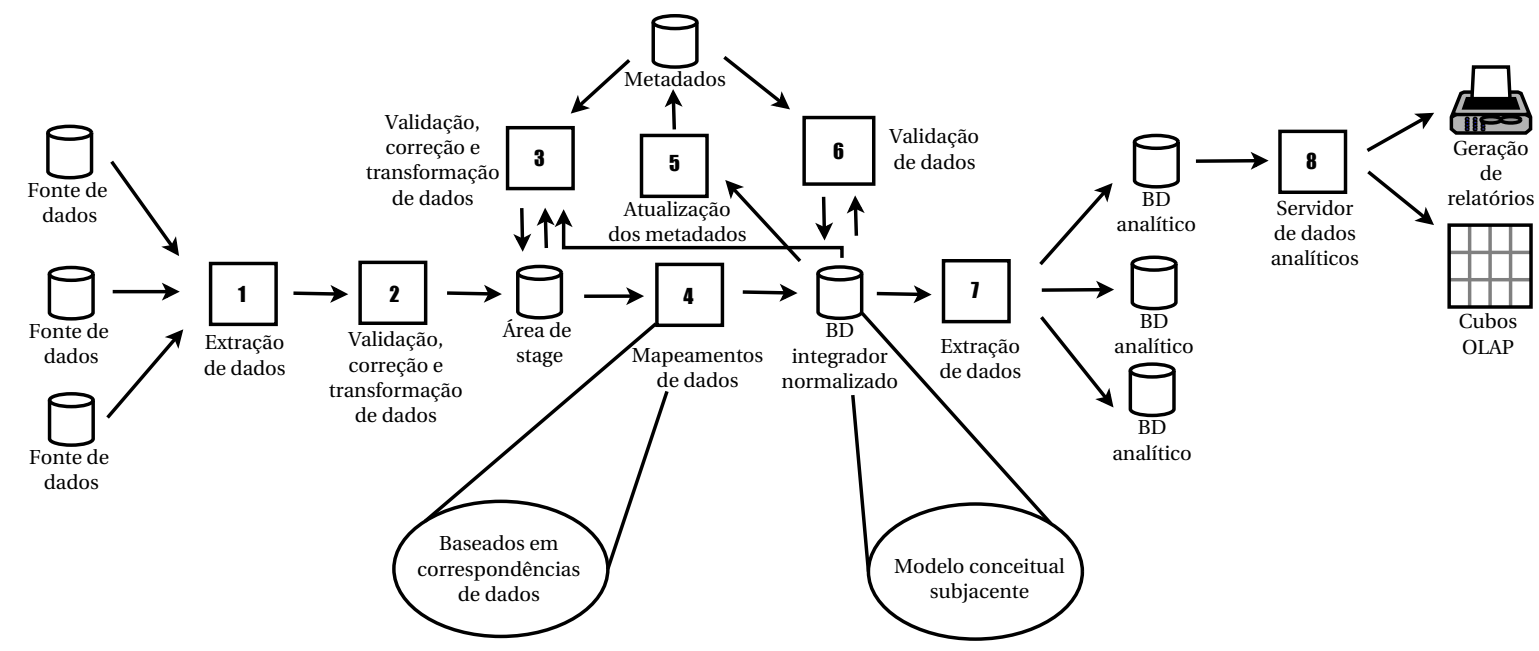

Figura 2.2: Arquitetura geral de um sistema integrador utilizando $D W$ e as tarefas geralmente executadas em um sistema desse tipo.

1. Extração de dados: extrai os dados das fontes de dados heterogêneas, trazendo-os para dentro do sistema integrador. 
2. Validação, correção e transformação de dados: recebe os dados provenientes da tarefa 1 , validando-os. Certas correções e transformações podem ser necessárias. Maiores detalhes estão na Seção 2.2.4 (validação dos dados de entrada). Após essa etapa, os dados são colocados em um banco de dados conhecido como área de stage ${ }^{1}$. De acordo com Rainardi [Rai08], um stage é "um repositório de dados interno usado para transformar e preparar os dados obtidos dos sistemas de origem, antes que eles sejam carregados em outros repositórios de dados em um DW".

3. Validação, correção e transformação de dados: aqui ocorre a segunda etapa de validações, correções e transformações de dados. Maiores detalhes podem ser encontrados na Seção 2.2.4 (validação cruzada dos dados de entrada).

4. Mapeamentos de dados: dadas as correspondências entre atributos dos BDs de origem dos dados (espelhados na área de stage) e o BD normalizado integrador (NDS - do inglês Normalized Data Store, detalhes na Seção 2.1), os mapeamentos que levam as instâncias dos bancos de origem para o banco destino são geradas automaticamente ou escritas manualmente. Elas automatizarão o transporte dos dados para o NDS. Detalhes são encontrados nas Seções 2.2.2 e 2.2.3.

5. Atualização dos metadados: os dados do NDS podem ser usados para popular um banco de metadados, que contém informações importantes - tais como a estrutura das tabelas e do próprio processo de integração - para a execução das outras tarefas.

6. Validação de dados: os dados do NDS ainda podem passar por uma terceira etapa de validação de dados, cujos detalhes estão explicados na Seção 2.2.4 (validação interna dos dados do DW).

7. Extração de dados: essa tarefa extrai os dados do NDS para popular BDs analíticos. É importante notar que, muitas vezes, somente uma parte dos dados é utilizada nos BDs analíticos, dependendo da visão que se quer gerar.

8. Servidor de dados analíticos: alimentados por bancos de dados analíticos, esses servidores são capazes de estruturar os dados de forma a permitir a geração de estruturas que facilitam a visualização dos dados, como é o caso dos cubos OLAP e dos relatórios gerenciais.

\subsubsection{Correspondência entre esquemas}

Uma vez especificado como será o banco de dados integrador, é necessário estabelecer as correspondências entre os esquemas de cada uma das fontes de dados para o esquema integrador. Para bancos de dados simples ou pequenos, as correspondências podem ser encontradas manualmente. Entretanto, o processo de especificação manual das correspondências é muito trabalhoso e tem a sua escalabilidade questionável quando utilizado para executar tarefas maiores [ $\mathrm{BMP}^{+} 08 \mathrm{a}$ ]. Diante desse fato, vários pesquisadores começaram a trabalhar com os chamados sistemas de casamento de esquemas, isto é, sistemas que automaticamente ou semi-automaticamente tentam descobrir atributos que casam nos esquemas origem e destino $\left[\mathrm{BMP}^{+} 08 \mathrm{a}\right]$. Entretanto, tal problema foi

\footnotetext{
${ }^{1}$ Não encontramos uma tradução consolidada desse termo para o português, optando pela sua versão em inglês.
} 
reconhecido como sendo de difícil solução [Gal06] e, até agora, não existe uma ferramenta que resolva satisfatoriamente todos os casos apresentados, sendo que, geralmente, a intervenção humana é requerida em algum ponto do processo, para validar o resultado gerado, para analisá-lo ou, até mesmo, para complementá-lo. Mais recentemente, uma ferramenta chamada Spicy $\left[\mathrm{BMP}^{+} 08 \mathrm{~b}\right]$ propôs automatizar por completo essa funcionalidade. Sucintamente, seu funcionamento é descrito a seguir.

Além dos esquemas dos bancos de dados origem e destino e das instâncias presentes no banco de origem, o algoritmo do sistema Spicy pressupõe que também está disponível pelo menos uma instância de dados do banco destino - chamada de instância canônica, que mostrará como os dados devem ser organizados. Dado um conjunto de correspondências (com um atributo da origem para cada atributo do destino), é possível executar rotinas automatizadas, oferecidas pela ferramenta (vide trecho que trata de geradores de mapeamento, neste mesmo capítulo), que levam instâncias da fonte para o destino. Com isso, é possível comparar o resultado obtido com a instância canônica dada como entrada, produzindo, assim, uma pontuação. Fazendo isso para cada conjunto de correspondências obtido, é possível classificá-los, descartando os piores - classificados como incorretos - e sugerindo aos usuários as alternativas de maior pontuação como possíveis mapeamentos corretos. Para calcular essa pontuação, os autores desenvolveram ainda um método chamado de análise estrutural, baseado no isomorfismo entre as estruturas dos esquemas das fontes de dados e de circuitos elétricos, explorado em outro artigo dos mesmos autores [BMP ${ }^{+} 08 \mathrm{a}$ ]. Os autores advogam que esse método produz melhores resultados de mapeamento se comparados a métodos de verificação a priori (na fase de escolha das correspondências) e também supera outros métodos de pontuação a posteriori baseados apenas na comparação dos atributos. Entretanto, não foram encontradas referências significativas à continuação do desenvolvimento dessa ideia e as próprias ferramentas sucessoras da Spicy, chamadas de + Spicy [MPRB09] e ++ Spicy $\left[\mathrm{MMP}^{+} 11\right]$ pareceram abandonar a ideia da sua precursora.

\subsubsection{Geradores de mapeamento}

Dado que as correspondências entre os BDs já estão definidas, é necessário gerar os mapeamentos para fazer a tradução dos dados entre os BDs. Mapeamentos podem ser considerados como "transformações executáveis que especificam como uma instância do repositório fonte deve ser traduzida em uma instância do repositório destino." [MPRB09]. Algumas ferramentas fornecem ao usuário uma interface gráfica para que ele especifique as correspondências entre os esquemas origem e destino (algumas correspondências costumam ser geradas automaticamente por igualdade de nomes de atributos) gerando, a partir daí, os mapeamentos em alguma linguagem de consulta (SQL é bastante usado). É o caso, por exemplo, de conhecidas ferramentas de ETL disponíveis no mercado, como o Microsoft ${ }^{\circledR}$ SQL Server ${ }^{\circledR}$. Entretanto, as ferramentas existentes em geral são capazes de gerar apenas mapeamentos triviais entre os esquemas, sendo que os detalhes mais complexos dos mapeamentos são deixados a cargo de uma identificação manual do usuário $\left[\mathrm{PHV}^{+} 02, \mathrm{PVH}^{+}\right.$02]. Algumas ferramentas vêm sendo desenvolvidas para lidar com essa questão de maneira mais profunda. Uma delas, chamada de Clio $\left[\mathrm{PHV}^{+} 02, \mathrm{PVH}^{+} 02\right]$, possui um algoritmo de mapeamento que se diz capaz de tratar mapeamentos complexos, gerando consultas correspondentes. Para isso, ele se baseia em um algoritmo composto de duas fases, que recebe do 
usuário um conjunto de correspondências em alto-nível (chamadas pelo autor de correspondências de valores e ditas mais expressivas do que simples correspondências no nível de atributos) entre os dois esquemas. A partir disso, o algoritmo captura a semântica implícita nessas correspondências, gerando um "mapeamento lógico", para, na segunda fase do algoritmo, ser convertido em uma consulta, preservando a semântica implícita na entrada. Maiores detalhes sobre o algoritmo e a ferramenta podem ser encontrados nas referências apontadas.

Em 2011, Marnete et al, em um artigo $\left[\mathrm{MMP}^{+} 11\right]$ que apresentou o seu trabalho chamado de ++ Spicy, classificou a ferramenta Clio, como também outras ferramentas de geração de mapeamento conhecidas, como a própria Spicy, antecessora da ++ Spicy, de sistemas de primeira geração, e afirmou que esses sistemas falharam na qualidade e expressividade dos mapeamentos gerados. Os autores afirmaram também que, apesar de outros algoritmos sofisticados (como é o caso do +Spicy) terem sido desenvolvidos com esse propósito, eles não seriam capazes de atender grandes BDs. Nesse cenário, eles então apresentaram a ferramenta ++ Spicy. ++ Spicy é baseada nos trabalhos teóricos da formalização do problema de troca de dados e é dita ser capaz de gerar códigos de mapeamento otimizados em SQL ou XQuery de modo automático, resolvendo os problemas dos algoritmos propostos até o momento (desde que as correspondências entre atributos dos BDs sejam fornecidas, entre outras interações mínimas com o usuário). Entretanto, ainda não foi feita nenhuma verificação a respeito das funcionalidades oferecidas pela ferramenta ++ Spicy. Dessa forma, ainda não se conhece quais problemas foram de fato solucionados e quais ainda exigem um maior estudo e aprofundamento, sendo uma provável fonte para pesquisas futuras.

\subsubsection{Qualidade dos dados}

A qualidade dos dados tem um papel crítico em muitas aplicações [BCFM09], sendo que ela foi identificada, no começo dos anos 90, como "uma questão intrínseca dos sistemas de informação." [SMR ${ }^{+94]}$. Os sistemas integradores que utilizam DW não fogem a essa regra. Como os DWs são utilizados no apoio à tomada de decisões, a confiabilidade dessas decisões está diretamente relacionada à confiabilidade das análises geradas usando esse tipo de sistema. A confiabilidade das análises, por sua vez, está intimamente ligada à qualidade dos dados presentes no sistema integrador. Ao construir sistemas de integração que envolvem dados provenientes de fontes heterogêneas, muitas vezes lida-se com dados gerados por diversos processos distintos. Como a qualidade dos dados está relacionada à qualidade dos processos envolvidos em sua geração, é possível inferir que as fontes de dados que precisam ser integradas possivelmente terão diferentes níveis de qualidade de dados. Nesse cenário, é preciso garantir que os dados que irão compor o DW do sistema integrador estejam corretos e adequados. Para isso, utiliza-se um processo de validação de dados.

No contexto de bancos de dados, é possível definir validação de dados como o processo pelo qual são submetidos os dados candidatos a integrar um BD (ou aqueles que já o integram) a fim de garantir que esse BD contenha apenas dados corretos e adequados para a finalidade desejada. Esse processo é composto por regras de validação, que são critérios utilizados para julgar se os dados estão de acordo com os requisitos. 
As validações usuais costumam ser classificadas em dois tipos: sintáticas e semânticas ${ }^{2}$. As validações sintáticas são responsáveis por conferir se os dados de entrada estão de acordo com os parâmetros dos tipos de campo que receberão os dados. Dentre as verificações possíveis, estão: detectar a existência de campos com caracteres não esperados para o tipo de campo que recebe a entrada (por exemplo, caracteres não numéricos em um campo numérico), detectar se o valor da entrada não está entre os valores esperados para o campo (por exemplo, detectar o valor 5 quando espera-se somente os valores de 10 a 100 em um campo numérico), detectar se o formato da entrada não está de acordo com o formato esperado (um e-mail ou ou CPF devem seguir certos formatos, que podem ser sintaticamente verificados). As validações sintáticas são geralmente simples e não são difíceis de implementar. As validações semânticas verificam os dados de acordo com regras cujo significado depende do domínio da aplicação. Por exemplo, considerando dados de doadores de sangue, se um campo indica que uma pessoa já esteve grávida, é necessário fazer a validação se essa pessoa é do sexo feminino. Apesar de algumas validações semânticas serem simples e triviais de implementar, outras podem ser bastante complexas, principalmente se envolverem dados históricos já armazenados no DW.

No processo de integração de dados, as validações de dados costumam ser aplicadas em momentos específicos e com uma finalidade determinada. É possível caracterizar três momentos distintos para os quais diferentes tipos de validações são aplicadas. São eles:

1. Validação dos dados de entrada: para cada fonte de dados que alimenta o DW, no processo de levar esses dados à área de stage ou com os dados já nessa área, é comum aplicar uma validação nesses dados de entrada. Nesse momento, não existe a consulta aos dados já presentes no DW. Entretanto, já é possível executar a quase totalidade das validações sintáticas e até mesmo algumas validações semânticas mais simples que dependem apenas dos dados de entrada. É possível também consultar dados externos para fazer a validação, o que pode ser feito trazendo-os localmente ou consultando-os de maneira remota.

2. Validação cruzada dos dados de entrada: passada a primeira fase de validação e ainda com os dados na área de stage, é possível fazer um outro tipo de validação mais sofisticada. Esse tipo de validação envolve cruzar as informações dos dados de entrada com as informações dos dados já presentes no DW do sistema integrador. Nessa fase, é possível aplicar validações semânticas mais complexas, garantindo que os dados que estão em via de serem colocados no DW não comprometerão a qualidade dele.

3. Validação interna dos dados do DW: quando os dados já estão incorporados ao DW, é importante aplicar, com uma certa periodicidade, algumas validações para garantir a contínua integridade dos dados. Tais validações, de caráter semântico, geralmente tendem a fazer algumas sumariações sobre os dados presentes do DW para garantir que eles estão livres de erros semânticos. Muitas vezes, essas validações têm caráter estatístico, que validam os dados do DW com uma visão mais global.

É importante notar que, mesmo implementando os três tipos de validações acima descritas, não é garantida a isenção de dados incorretos ou incompletos no DW. Isso acontece pois é impossível

\footnotetext{
${ }^{2}$ Neste trabalho, o termo "validação semântica" refere-se simplesmente àqueles casos em que a validação de um atributo depende do significado de outros atributos ou relações.
} 
prever todos os erros que podem acometer os dados que integram o DW. As validações servem geralmente para a prevenção de erros dos quais já se tem consciência de que podem existir. E é por esse motivo que a análise de dados tem um papel tão importante no descobrimento de novas validações que devem ser implementadas e, desse modo, é imprescindível para aumentar a qualidade dos dados.

As validações existem com o propósito de detectar problemas presentes nos dados. Entretanto, após a detecção, é preciso dizer ao sistema de integração o que fazer com o problema encontrado. Resumidamente, são três os tipos de ações que o sistema pode desempenhar ao encontrar um problema, cabendo ao projetista decidir qual deles é o mais indicado em cada caso. Eles estão descritos a seguir.

- Aceitar o dado: muitas vezes, é conveniente ao projetista de DW que o processo de integração não seja interrompido devido a erros que não têm muita importância no contexto geral. Dessa maneira, é importante capturar o erro, para que uma providência seja tomada como, por exemplo, a correção do problema inicial que gerou o erro, mas não parar a carga se for aceitável continuar desse modo. Esse também é o caso de situações para as quais o operador quer ser alertado, mas que não constituem propriamente um erro, mas sim um aviso. Por exemplo, um campo populado com um valor raro, porém teoricamente válido.

- Rejeitar o dado: dependendo do erro detectado, faz-se necessário rejeitar o dado em questão. Dependendo da importância do dado rejeitado, a rejeição pode ser pontual (simplesmente invalida-se o valor do campo do dado em questão), ou pode ser necessário rejeitar todos os registros relacionados ao dado problemático, ou até mesmo, em se tratando de campos-chave, abortar todo o processo de inclusão de dados em questão.

- Corrigir o dado: em certas circunstâncias, quer-se permitir a entrada de dados que estão a princípio errados em um sistema. Entretanto, para isso, torna-se necessário corrigi-los antes de serem integrados à base de dados. Isso acontece, por exemplo, quando o erro é conhecido, ainda não foi corrigido no sistema de origem e a sua solução, além de conhecida, é possível de ser feita nessa etapa. A correção de dados pode ser usada, também, quando não existe a possibilidade de correção dos dados na origem, sendo a única maneira de corrigi-los, ainda que tardiamente. Neste trabalho, o termo correção de dados será utilizado no lugar de limpeza de dados, bastante conhecido na literatura da área. O termo limpeza remete à retirada de imperfeições dos dados de entrada. Já o termo correção é mais abrangente, englobando o primeiro, e não se restringe somente à retirada de imperfeições, mas sim a qualquer tipo de correção que for necessário para tornar o dado válido. A aplicação da correção de dados na fase de validação deve ser feita de maneira criteriosa. Muitas vezes, um dado errado pode indicar um erro no processo ou ainda a falta de validação suficiente dos dados no sistema transacional de origem. De qualquer maneira, a simples correção do dado no DW não garante um amadurecimento do sistema que originou o dado. Assim, o mesmo erro continuará sendo gerado e poderá se refletir em outros sistemas (ou outras partes do mesmo sistema) que utilizam o dado. É por isso que as correções de dados devem ser utilizadas com cautela. O ideal é que, quando possível, as correções sejam utilizadas apenas temporariamente para possibilitar a carga. O processo que originou o erro deve ser 
corrigido o quanto antes, sanando o problema na sua origem.

Nesse ponto, vale a observação de que é importante não confundir transformação de dados com correção de dados. Algumas vezes, é necessário transformar dados para integrá-los. Por exemplo, supondo-se a seguinte situação: é preciso integrar dois sistemas distintos e que possuem um campo para guardar resultados de exames. Em um deles, os valores $P$ e $N$ indicam, respectivamente, exames com resultados positivos e negativos. No outro, para o mesmo exame, tem-se os valores $R$ e $N$, para indicar que os exames foram reagentes ou não reagentes. Para resultados negativos, não é preciso transformar os dados, já que $N$, para os dois casos, tem o mesmo significado e, portanto, pode ser utilizado. Já para o caso de resultados positivos, será preciso fazer uma transformação (de $R$ para $P$ ) para uniformizar a legenda entre os sistemas, armazenando-os de uma única forma. Casos como esses não devem ser tratados como erros e não devem gerar notificações, sendo parte do funcionamento normal do sistema de integração.

As ferramentas de ETL fornecem aos desenvolvedores do sistema de integração algumas ferramentas que facilitam tipos básicos de validação e correção de dados. Para isso, é possível especificar fluxos de dados por meio de ferramentas visuais e colocar, em determinados pontos, alguns filtros que fazem validações de dados e separam os dados corretos dos incorretos, dando destinos diferentes do usual aos dados incorretos. Entretanto, para as validações mais complexas, o desenvolvedor ainda é obrigado a projetar manualmente esses filtros validadores utilizando linguagens de programação ou linguagens de consulta, como é o caso de SQL, e tal tarefa é trabalhosa e de difícil manutenção. Dois fatores contribuem para que a implementação das validações tome muito tempo do desenvolvedor: o grande número de validações a serem implementadas, mesmo para integrar sistemas de pequeno porte; e a dificuldade da implementação eficiente de validações semânticas mais complexas. Esses fatores passam a ser muitas vezes responsáveis pelo atraso da entrega dos projetos de integração. Por esse motivo, diversos trabalhos têm sido desenvolvidos para facilitar o processo de validação e correção de dados. Galhardas et al [GFSS00, GFS ${ }^{+} 01$ ] possuem tentativas de desenvolver linguagens declarativas mais expressivas do que SQL para descrever as validações e correções, bem como algoritmos e modelos para executá-las, almejando assim diminuir a quantidade de código a ser escrito para implementar validações e correções complexas. Raman e Hellerstein desenvolveram uma ferramenta de correção de dados chamada Potter's Wheel [RH01], que propõe uma abordagem interativa de correção de dados, em que o sistema tenta identificar discrepâncias de dados e o usuário, por meio de um ambiente gráfico, pode ver as correções efetuadas, adicionando outras, refinando as já existentes ou desfazendo transformações conforme a necessidade. Mais recentemente, alguns projetos como o arcabouço LLUNATIC [GMPS13, GMPS14] e o sistema NADEEF $\left[\mathrm{DEE}^{+} 13, \mathrm{EEI}^{+} 13\right]$ tentaram facilitar o trabalho do desenvolvedor, provendo soluções genéricas que se propõem a tratar diversos tipos de inconsistências de dados de maneira unificada. Outros trabalhos (como SCAREd [YBEE13] e Eracer [MNP10]) se destacam pela utilização de técnicas de aprendizado de máquina e abordagens estatísticas para identificar e corrigir erros em dados. A identificação e remoção de dados duplicados também constituem um problema que já foi abordado por diversas pesquisas [Mon00, LLL00, KTR12, GDS14]. Apesar de existirem diversas ferramentas avançadas na área de validação e correção de dados como as apontadas aqui, a deteç̧ão de erros por meio da análise de lotes de dados de entrada, utilizando detecção de anomalias e o perfil estatístico dos dados presentes nos lotes ainda é inédita, e neste 
trabalho é chamada de validação estatística adaptativa de lotes de dados, constituindo um dos objetivos deste doutorado, conforme apresentado no Capítulo 5.

\subsection{Aprendizado de máquina: detecção de anomalias}

Aprendizado de máquina é um ramo da Inteligência Artificial que tem como objetivo o estudo de "programas de computador que aperfeiçoam seu desempenho em alguma tarefa por meio da experiência" [Mit97]. Segundo Tom Mitchell, para ter um problema de aprendizado bem definido, três aspectos precisam ser identificados: a classe de tarefas a serem aperfeiçoadas, qual será a medida de desempenho a ser melhorada e qual a fonte da experiência para o aperfeiçoamento. Tendo em vista esses três aspectos, o referido autor define o aprendizado do seguinte modo: "Diz-se que um programa de computador aprende com a experiência $E$, relacionado a uma classe de tarefas $T$ e medida de desempenho $P$, se seu desempenho em tarefas em $T$, quando medido por $P$, melhora com a experiência $E$ ".

Existem diversos modos de classificar os algoritmos ou técnicas de aprendizado de máquina. Uma das classificações mais importantes leva em consideração o tipo de experiência usada para o seu aprendizado. Assim, dentre as classes de técnicas existentes em aprendizado de máquina, as seguintes reúnem grande parte dos problemas da área e são alvos de intensa pesquisa: aprendizado supervisionado; aprendizado não supervisionado; aprendizado semissupervisionado e aprendizado por reforço. De modo sucinto, é possível descrevê-las do seguinte modo:

- Aprendizado supervisionado: nas técnicas de aprendizado supervisionado, a experiência é adquirida por meio do processamento dos chamados dados de treinamento. Os dados de treinamento são compostos por diversas instâncias de treinamento. Cada instância de treinamento é composta por um exemplo de entrada do problema e, associado a ele, um rótulo indicando o valor de saída esperado para essa entrada. O objetivo dos algoritmos de aprendizado desta classe é, a partir do comportamento observado nos dados de treinamento, extrapolá-lo para outras instâncias que não pertencem aos dados de treinamento. Assim, quando uma nova entrada não rotulada é oferecida, espera-se que o algoritmo consiga predizer o seu rótulo.

- Aprendizado não supervisionado: frequentemente, é preciso trabalhar com instâncias de treinamento não rotuladas. Tais situações ocorrem porque a rotulação de um grande conjunto de treinamento pode não ser factível, por demandar muito tempo ou esforço ou por ser impossível. Os algoritmos que trabalham com esse tipo de entrada constituem a classe de aprendizado não supervisionado. Existem diversos problemas práticos que se encaixam nessa classe. Como exemplo, tem-se a busca de padrões em dados - problema bastante conhecido no contexto de mineração de dados, separando-os em agrupamentos (clusters) consistentes. Desse processo, é possível descobrir similaridades e diferenças entre os padrões e extrair diversas conclusões úteis sobre os dados analisados.

- Aprendizado semissupervisionado: nessa classe, o conjunto de dados de treinamento utilizado costuma ser constituído tanto por dados rotulados quanto por dados não rotulados. Geralmente a quantidade de dados rotulados é menor do que a quantidade de dados não rotulados 
empregado nos algoritmos dessa classe. Tais técnicas podem resolver tanto problemas típicos dos algoritmos supervisionados, como é o caso da classificação, como problemas típicos dos não supervisionados, como é o caso de problemas de agrupamento.

- Aprendizado por reforço: nas técnicas de aprendizado por reforço (ou recompensa), um sistema aprende a partir da sua interação com o ambiente no qual está inserido. Cada ação no ambiente está associada a valores de reforço. Assim, o sistema age no ambiente e busca descobrir quais ações o levam a obter maiores valores de reforço, isto é, quais ações geram a maior recompensa e essa informação é assimilada para tomar decisões posteriores.

É possível separar os algoritmos de aprendizado supervisionado de acordo com o problema que eles se propõem a resolver: se o domínio dos rótulos associados às entradas das instâncias de treinamento for discreto, então tem-se um problema de classificação e os rótulos podem ser chamados de classes. Caso contrário, tem-se um problema de regressão e os rótulos são valores reais. Dentre os problemas existentes em aprendizado de máquina, os problemas de classificação têm grande destaque. Um problema de classificação pode ser definido do seguinte modo (definição baseada em [Moo07]):

Dado um objeto a ser classificado $x \in X$, em que $X$ é o espaço de objetos possíveis e um conjunto fixo de classes $C=\left\{C_{1}, C_{2}, \ldots, C_{n}\right\}$, determinar a classe de $x$, isto é, determinar $c(x)$, considerando $c$ uma função de classificação cujo domínio é $X$ e cuja imagem é $C$.

Para resolver tal problema, utiliza-se um classificador. Para poder exercer corretamente o seu papel, antes de ser utilizado, um classificador precisa ser treinado adequadamente. Seu treinamento pode ser definido do seguinte modo:

Seja $X$ e $C$ da definição anterior. Um exemplo ou instância de treinamento é um par $\langle x, c(x)\rangle$, em que $x \in X$ e $c(x) \in C$ é a classe correta para $x$, em que c é uma função de classificação desconhecida. Dado um conjunto $D$ de instâncias de treinamento, achar uma função hipotética de classificação $h$, tal que $\forall\langle x, c(x)\rangle \in D, h(x)=c(x)$.

Existe um grande número de algoritmos classificadores eficientes e precisos. Com isso, eles foram e são utilizados nos mais diferentes domínios. Apesar de os classificadores convencionais não serem diretamente usados neste trabalho, esta pequena introdução foi feita aqui devido a sua importância no contexto geral e para facilitar o entendimento de algumas partes do Capítulo 5 , que justifica a opção feita por uma técnica de deteç̧ão de anomalias para resolver o problema em questão em detrimento do uso de classificadores convencionais supervisionados.

No restante desta seção, segue um panorama geral sobre detecção de anomalias e duas técnicas existentes nessa área. Esse tópico é visto com maior destaque, pois as técnicas presentes aqui são usadas para a implementação do validador estatístico de lotes de dados descrito no Capítulo 5.

\subsubsection{Detecção de anomalias}

A detecção de anomalias busca identificar dados (observações, itens, eventos, dependendo do domínio) caracterizados como anômalos, diferenciando-os daqueles ditos "normais" dentro de um determinado contexto. Tais anomalias seguem um comportamento diferente do restante dos dados considerados. Segundo Chandola et al [CBK09], a deteç̧ão de anomalias é definida como o "problema de encontrar padrões em dados que não estão em conformidade com o 
comportamento esperado". O conceito de anomalia varia dependendo do domínio da aplicação considerado. Genericamente, é possível definir uma anomalia por "uma observação que se desvia tanto das outras observações a ponto de levantar suspeita de que ela foi gerada por um mecanismo diferente" [Haw80]. Ou ainda, em um contexto mais estatístico, tem-se a seguinte definição: "uma observação anômala é aquela que parece desviar-se acentuadamente dos outros membros da amostra em que ocorre" [BL94]. A ocorrência de anomalias costuma ser de grande interesse para os especialistas do domínio, pois geralmente está ligada a eventos importantes e que exigem atenção ou maiores análises.

A deteç̧ão de anomalias tem aplicações nos mais diversos domínios da computação e da estatística. Como exemplo de uso, pode-se citar:

- Em imagens radiográficas de pulmão, na separação de imagens sem maiores problemas, ditas normais, das imagens que apresentam alterações, como é o caso de tumores ou pneumonia, que constituem as anomalias;

- Em sistemas bancários, para detectar se as transações diárias realizadas por determinado cliente estão de acordo com os seus hábitos históricos ou se representam um comportamento anômalo, que pode indicar um possível roubo de cartão de crédito ou uma fraude em andamento;

- Em uma rede de computadores, o comportamento anômalo de um servidor pode indicar um possível ataque à rede, quando observa-se conjuntamente a largura de banda utilizada, o número de processos em execução e quantidade de memória RAM em uso, para exemplificar algumas características de interesse nesse caso;

- Em um DW, detectar se entre os dados armazenados existem erros (anomalias) que carecem de tratamento ou que indicam um possível erro sistêmico na inserção desses dados no BD;

- Em um sistema de monitoramento de aviões, detectar turbinas que estão prestes a falhar pelo comportamento anômalo que apresentam quando observadas algumas características, como, por exemplo, a sua potência e trepidação.

Nesses exemplos, é interessante observar a importância das anomalias nos contextos em que se apresentam. Todas elas são de extrema importância, como é o caso de indicativos de tumores, fraudes e roubos, ataques a redes, erros sistêmicos ou até mesmo falhas em motores de avião. Um outro ponto a observar é que em problemas nos quais a deteç̧ão de anomalias se aplica, as anomalias podem ser de diversos tipos, e não possuem um comportamento bem definido. Os comportamentos anômalos são assim caracterizados pelo fato de fugirem ao comportamento normal. Mas, muitas vezes, existem inúmeras formas de isso ocorrer. No caso das imagens radiológicas, por exemplo, diversas doenças pulmonares podem levar a uma alteração na imagem, sendo difícil caracterizar a causa da anomalia. Portanto, as anomalias geralmente precisam ser analisadas para que se chegue a uma conclusão sobre sua causa.

Um grande número de técnicas de detecção de anomalias foi desenvolvido. A escolha da técnica a ser utilizada depende basicamente das características impostas pelo domínio do problema que se quer resolver e pelos dados de entrada que serão fornecidos ao método. A seguir serão descritos 
alguns dos aspectos principais que devem ser levados em consideração no momento da escolha do método a ser utilizado. Tal descrição constitui um resumo do levantamento de diversos métodos de deteç̧ão de anomalias presentes na literatura feito por Chandola et al [CBK09].

O primeiro aspecto que deve ser considerado é a natureza dos dados que serão fornecidos como entrada para o método. Os dados de entrada são caracterizados por um conjunto de instâncias (por instância, entende-se cada uma das observações, eventos ou itens). As instâncias podem ser constituídas por uma ou mais características (também chamados de variáveis no contexto mais estatístico ou ainda de atributos ou dimensões em um contexto de bancos de dados). Se forem constituídas por apenas um atributo, elas são chamadas de univariadas. Caso contrário, são chamadas de multivariadas. Além do número de características das instâncias, devem ser observados também os seus tipos. As características podem ser quantitativas, representando quantidades, ou categóricas (ou qualitativas), representando categorias. No caso das características quantitativas, pode-se classificá-las ainda em discretas (só podem assumir valores pertencentes a um conjunto enumerável) ou contínuas (podem assumir quaisquer valores em um determinado intervalo). Para as características categóricas, é possível classificá-las em ordinais (se as características possuem uma ordem intrínseca) ou nominais, caso contrário.

O segundo aspecto a ser considerado é a natureza das anomalias que se deseja obter. As anomalias podem ser pontuais, contextuais, ou ainda coletivas. Uma instância é considerada uma anomalia pontual se ela for anômala quando comparada com o restante dos dados como um todo, independentemente de algum contexto. Por exemplo, ao considerar-se as características potência e vibração de uma turbina de avião, uma turbina anômala por apresentar alta trepidação e baixa potência quando comparada com as outras turbinas, será anômala independentemente de qualquer contexto. Já a anomalia contextual ocorre quando uma instância é anômala sob um determinado contexto, mas não sob outros. Como exemplo, é possível citar o caso de um site bancário, que controla o número de transações diárias efetuadas, tentando associar números muito altos ou baixos a possíveis falhas ou vulnerabilidades no sistema. Um número baixo de transações realizadas durante um dia útil, que caracteriza uma possível falha pode não caracterizá-la se for realizada no final de semana. Isto é, a caracterização de uma instância como anomalia depende do contexto, no caso, o dia da semana. Nas anomalias contextuais, as características usadas para determinar o contexto (o dia da semana, no exemplo dado) são chamadas de características contextuais. Já as características que não definem um contexto (o número de transações por dia, no exemplo), são chamadas de características comportamentais. A anomalia coletiva é o terceiro tipo de anomalia estudada, e é caracterizada pela análise coletiva das instâncias. É possível que uma instância individualmente não caracterize uma anomalia, mas, quando analisada juntamente com outras instâncias, fique caracterizada a ocorrência de uma anomalia. Como exemplo, é possível citar um sistema de deteç̧ão de fraudes, furtos e roubos utilizando transações bancárias de clientes individuais. Em um sistema desses, para um determinado cliente, uma transação que representa um saque pode não significar muita coisa. Entretanto, se uma sequência de saques for realizada para um cliente, isso pode significar que esse cliente tenha sido sequestrado e esteja agindo sob coação para efetuar diversos saques consecutivos.

O terceiro aspecto diz respeito à rotulação das instâncias utilizadas na fase de aprendizado do método. Em alguns casos, é possível associar a cada instância de treinamento utilizada, 
os rótulos de "anômala" ou "normal", que representam a saída esperada para essas entradas. Entretanto, nem sempre é possível rotular todas as instâncias de treinamento, seja porque é uma tarefa muito custosa ou ainda pela real impossibilidade inerente ao domínio. Dessa maneira, costuma-se dividir as técnicas de deteç̧ão de anomalias em três classes: supervisionadas, semissupervisionadas e não supervisionadas. As técnicas supervisionadas podem ser usadas quando tanto as instâncias de treinamento normais quanto as instâncias de treinamento anômalas estão devidamente rotuladas. As técnicas semissupervisionadas podem ser usadas quando tem-se apenas uma parte das instâncias de treinamento rotuladas, geralmente constituída por instâncias normais. Já as técnicas não supervisionadas podem ser usadas quando não há rótulos nas instâncias de treinamento. Geralmente parte-se da suposição de que a maioria das instâncias de treinamento são normais, minimizando os efeitos das instâncias anômalas que possam existir entre elas.

Existem ainda vários outros aspectos que devem ser levados em consideração no momento da escolha de um método de detecção de anomalias. Entre eles estão: o tipo de saída do método, que pode ser um rótulo ou então uma pontuação; aprendizado por meio de dados estáticos (offline) ou com dados que mudam continuamente (online); restrições inerentes ao domínio, por exemplo, de tempo; requisitos inerentes ao domínio. Existem diversos trabalhos [CBK09, ABA06, Zha13, BG10] que classificam as técnicas existentes de acordo com esses aspectos, auxiliando na tomada de decisão sobre qual detector usar. Esses trabalhos costumam agrupar tais técnicas de acordo com a abordagem que utilizam. Dentre as principais abordagens existentes estão:

- Baseada em classificadores: um classificador é treinado utilizando as instâncias de treinamento devidamente rotuladas. Utilizando-se esse classificador, rotula-se uma nova instância como "normal" ou "anômala", ou até mesmo em mais de duas classes com, por exemplo, diversas classes representando instâncias normais;

- Baseada em métodos estatísticos: assume ou encontra um modelo probabilístico ou uma distribuição para os dados em estudo. A classificação de uma instância em anômala ou normal se dará baseada na sua adequação ao modelo ou distribuição resultante do método.

- Baseada em distâncias: ao considerar cada instância com $n$ características como um ponto em um espaço $n$-dimensional, é possível, por meio de diversas métricas, calcular a distância entre eles. Utilizando a ideia de proximidade ou o conceito de "vizinhança", uma nova instância é classificada como anômala ou normal.

- Baseada em densidade: ao considerar cada instância com $n$ características como um ponto em um espaço n-dimensional, é possível considerar regiões de maior ou menor densidade de pontos nesse espaço. A classificação de uma nova instância é feita baseada na densidade da região em que se localiza.

Nas seções seguintes serão apresentados dois métodos de detecção de anomalias que serão usados no processo de validação estatística descrito no Capítulo 5. Tais métodos são baseados na teoria estatística das densidades probalilísticas das curvas gaussianas para separar as instâncias anômalas das normais. O primeiro método, mais simples e rápido, baseia-se na premissa da independência estatística entre as características para gerar um modelo baseado em uma função de densidade probabilística conjunta, que será usado na classificação de novas instâncias. Já o segundo, 
mais complexo e custoso, leva em consideração a dependência entre as características, sendo baseado em uma função de densidade probabilística de uma distribuição gaussiana multivariada para classificar as novas instâncias.

Apesar de a teoria estatística neles envolvida já estar consolidada e ser utilizada nos mais diversos domínios da matemática e computação, os métodos utilizados aqui são de autoria de Andrew Ng, professor e pesquisador de inteligência artificial da Universidade de Stanford, EUA, e foram apresentados em seu curso de aprendizado de máquina $[\mathrm{Ng}]$ ministrado por meio da plataforma Coursera [cou].

De acordo com os aspectos apresentados anteriormente nesta seção, é possível dizer que os dois métodos descritos caracterizam-se por:

- Serem capazes de tratar instâncias com mais de uma característica (multivariadas). As características devem ser quantitativas e contínuas, isto é, pertencentes ao domínio dos números reais.

- Reconhecerem anomalias pontuais. Esses métodos não tratam diferentes contextos ou anomalias coletivas.

- Serem semissupervisionados. Durante a fase de treinamento desses métodos, utiliza-se dois conjuntos de dados: um deles, somente com instâncias não rotuladas, tem o propósito de servir como base para o desenvolvimento de um modelo estatístico para as instâncias; o outro, somente com instâncias rotuladas, é utilizado para calcular um limiar de separação para posterior classificação de novas instâncias.

- Terem seu aprendizado realizado de maneira off-line.

- Terem sua abordagem baseada em métodos estatísticos.

Seguem os dois métodos em questão:

\section{Método da distribuição gaussiana}

O método da distribuição gaussiana parte da premissa de que as características das instâncias seguem, separadamente, distribuições normais ou gaussianas. Utilizando um conjunto de instâncias não rotuladas (mas supostamente não anômalas em sua quase totalidade) na sua fase de treinamento, ele estima as médias e as variâncias dessas distribuições, uma a uma. Com base nas distribuições estimadas e partindo do pressuposto que as características são estatisticamente independentes entre si, calcula-se a função de densidade de probabilidade conjunta $p$ multiplicando-se as funções de densidade de probabilidade individuais provindas das distribuições univariadas.

Além da função de densidade de probabilidade conjunta $p$, por meio de uma fração devidamente rotulada das instâncias de treinamento, o método encontra também um limiar $\varepsilon$ para separar o espaço das características em duas regiões distintas, que serão utilizadas para classificar uma nova instância $z$ em normal ou anômala. Se $p(z)<\varepsilon$, a instância será uma anomalia. Caso contrário, será normal. Dada uma visão geral do funcionamento do método, segue abaixo o seu detalhamento. 
Seja $X=\left\{x^{(1)}, x^{(2)}, \ldots, x^{(m)}\right\}$ um conjunto de $m$ instâncias de treinamento não rotuladas. Apesar de serem não rotuladas, é importante que essas instâncias sejam normais (não anômalas) em sua quase totalidade, minimizando, assim, os efeitos de possíveis anomalias presentes nesse conjunto. Tal suposição é comum nesse tipo de treinamento e deixa o método mais robusto para ser usado na prática, já que o seu funcionamento correto ainda ocorre mesmo que algumas anomalias se infiltrem no conjunto $X$, situação que ocorre com frequência em casos reais. Cada uma das instâncias desse conjunto é um vetor $\left[x_{1}, x_{2}, \ldots, x_{n}\right]$ de $n$ características, todas contínuas. Assim:

$$
x^{(i)} \in \mathbb{R}^{n}, \text { e } x^{(i)}=\left[x_{1}^{(i)}, x_{2}^{(i)}, \ldots, x_{n}^{(i)}\right]
$$

Supõe-se que cada uma das características segue uma distribuição normal. Dessa maneira, tem-se que:

$$
\forall i \in \mathbb{Z}, 1 \leq i \leq n, x_{i} \sim \mathcal{N}\left(\mu_{i}, \sigma_{i}^{2}\right)
$$

em que $\mu_{i}$ é a média da distribuição da característica $i$, e $\sigma_{i}^{2}$ a sua variância. Para estimar as médias das distribuições gaussianas, utilizam-se as $m$ instâncias de $X$, da seguinte forma:

$$
\mu_{i}=\frac{1}{m} \sum_{j=1}^{m} x_{i}^{(j)}
$$

As variâncias são estimadas utilizando-se o mesmo conjunto e utilizando as médias já estimadas, do modo a seguir:

$$
\sigma_{i}^{2}=\frac{1}{m} \sum_{j=1}^{m}\left(x_{i}^{(j)}-\mu_{i}\right)^{2}
$$

Para cada característica $x_{i}$, por seguir uma distribuição normal $\mathcal{N}\left(\mu_{i}, \sigma_{i}^{2}\right)$, é possível descrever a sua função densidade de probabilidade por:

$$
p\left(x_{i} ; \mu_{i}, \sigma_{i}^{2}\right)=\frac{1}{\sigma_{i} \sqrt{(2 \pi)}} e^{-\frac{1}{2}\left(\frac{x_{i}-\mu_{i}}{\sigma_{i}}\right)^{2}}
$$

Seja $\mathbf{x}=\left[x_{1}, x_{2}, \ldots, x_{n}\right]$ uma instância. Partindo do pressuposto que as características são estatisticamente independentes, a função densidade de probabilidade conjunta é dada por:

$$
p(x)=p\left(x_{1} ; \mu_{1}, \sigma_{1}^{2}\right) p\left(x_{2} ; \mu_{2}, \sigma_{2}^{2}\right) \ldots p\left(x_{n} ; \mu_{n}, \sigma_{n}^{2}\right)
$$

que também pode ser escrita da seguinte forma:

$$
p(x)=\prod_{j=1}^{n} p\left(x_{j} ; \mu_{j}, \sigma j^{2}\right)=\prod_{j=1}^{n} \frac{1}{\sigma_{j} \sqrt{2 \pi}} e^{-\frac{1}{2}\left(\frac{x_{j}-\mu_{j}}{\sigma_{j}}\right)^{2}}
$$

Esta função atribui uma densidade de probabilidade a uma instância. Resta agora achar um limiar que dividirá o espaço $n$-dimensional dos vetores instâncias em duas regiões distintas. Seja $\varepsilon$ esse limiar. Uma instância $x$ será classificada como anômala se $p(x)<\varepsilon$. Caso contrário, será 
classificada como normal.

Resta saber como calcular o limiar $\varepsilon$. Entretanto, para o seu cálculo, o próprio algoritmo de detecção de anomalias deve ser utilizado. Portanto, ele será apresentado resumidamente a seguir (Algoritmo 1), para facilitar o entendimento:

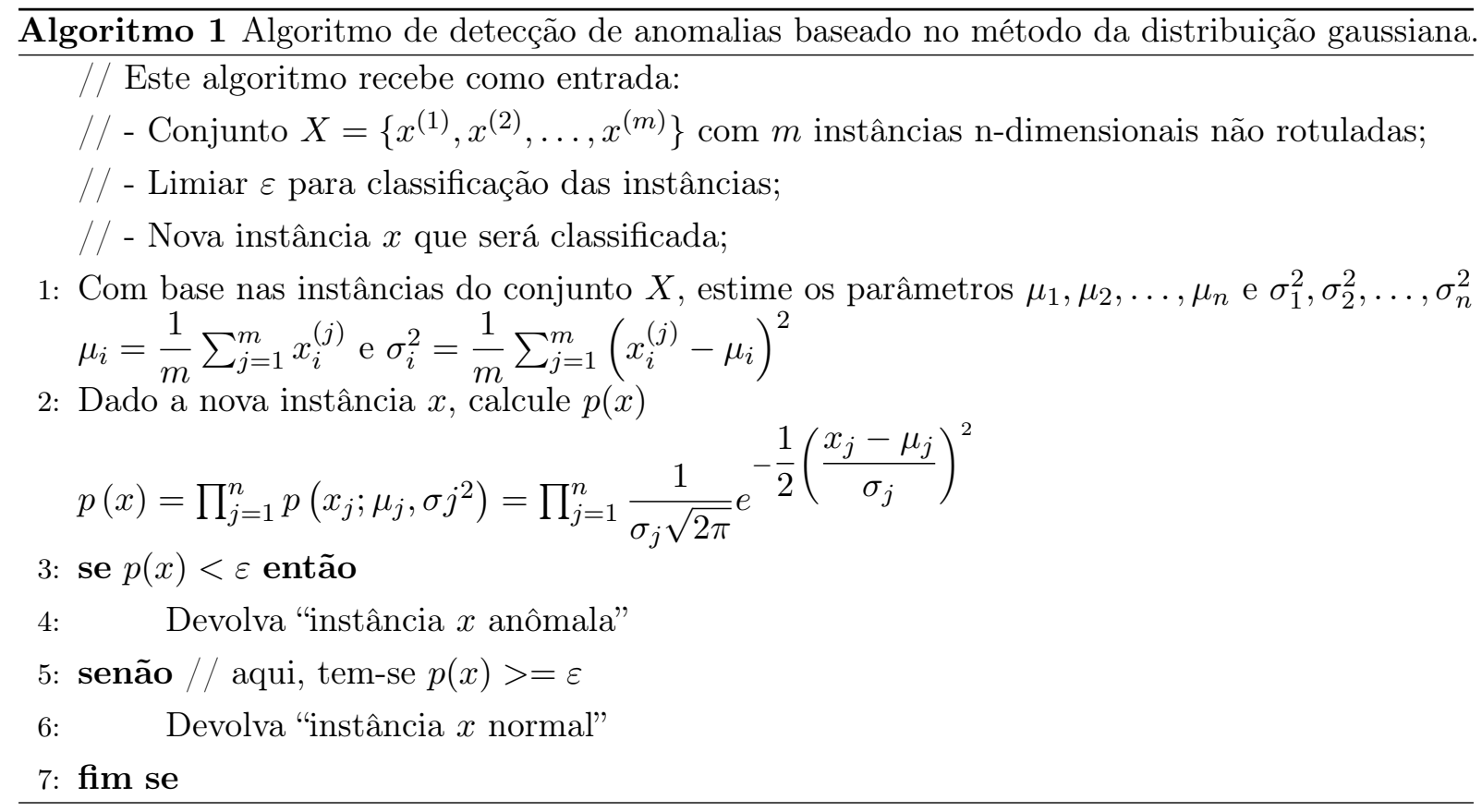

Sobre o Algoritmo 1, é importante notar que o passo 1 nem sempre é necessário ser executado. O treinamento pode ser executado de maneira separada do resto dos passos e com menor frequência, o que garante um melhor desempenho na execução do método. Outra observação importante é que o método pode receber, em vez de apenas uma instância $x$ para ser classificada, um conjunto de instâncias, o que facilita a sua utilização para classificar grandes quantidades de instâncias ou até mesmo para calcular o valor de $\varepsilon$, como será visto a seguir.

Seja $V=\left\{v^{(1)}, v^{(2)}, \ldots, v^{(r)}\right\}$ um conjunto de $r$ instâncias rotuladas, de modo que haja tanto instâncias normais quanto instâncias anômalas nesse conjunto. A cada instância $v^{(i)}$ estará associado, portanto, um rótulo $y^{(i)}$, e o par será representado por $\left(v^{(i)}, y^{(i)}\right)$. Esse rótulo contém a real classificação da instância, representada por 1 (no caso de anomalia) e 0 (do caso de normalidade). Para escolher qual o melhor limiar, adota-se a abordagem de escolher o $\varepsilon$ que maximiza a eficiência do algoritmo. Para medir a eficiência do algoritmo, é necessário escolher uma métrica que quantificará a eficiência do método quando executado sobre o conjunto $V$ e um limiar $\varepsilon$. Essa medição é possível pois já é sabido a priori, para essas instâncias, qual é o resultado correto e, portanto, esperado como saída do algoritmo de detecção. Como métrica, foi utilizado o já consagrado índice F1-Score [MRS08], muito utilizado em diversas áreas da computação, como em aprendizado de máquina e em recuperação de informação. Segue, portanto, como calcular o índice F1-Score e o $\varepsilon$ :

Dado o conjunto $X$ de instâncias não rotuladas, um limiar $\varepsilon$, execute o Algoritmo 1 para classificar as instâncias de $V$. Em seguida, compare as respostas do algoritmo com os rótulos das instâncias de $V$. Classifique-os de acordo com os seguintes cenários:

- Verdadeiros positivos (VP): número de instâncias anômalas que foram corretamente classifi- 
cadas como anomalias;

- Falsos positivos (FP): número de instâncias normais que foram incorretamente classificadas como anomalias;

- Falsos negativos (FN): número de instâncias anômalas que foram incorretamente classificadas como normais;

- Verdadeiros negativos (VN): número de instâncias normais que foram corretamente classificadas como normais.

\begin{tabular}{l|cc} 
& Realmente anômalas & Realmente normais \\
\hline Classificadas como anômalas & VP & FP \\
Classificadas como normais & FN & VN
\end{tabular}

Tabela 2.1: Cenários possíveis de erros e acertos na classificação de instâncias pelo detector de anomalias

A métrica F1-Score é calculada pela média harmônica dos conceitos de precisão e cobertura. A precisão é calculada pela divisão entre o número de instâncias corretamente classificados como anômalas (VP) e o número total de instâncias que foram classificadas pelo método como anômalas $(\mathrm{VP}+\mathrm{FP})$. Já a cobertura é calculada pela divisão entre o número de instâncias que foram corretamente classificadas como anômalas (VP) e o número de instâncias que são de fato anômalas. Assim:

$$
\text { F1-Score }=\frac{2 * \text { precisão } * \text { cobertura }}{\text { precisão }+ \text { cobertura }}
$$

em que

$$
\text { precisão }=\frac{V P}{V P+F P}, \text { e cobertura }=\frac{V P}{V P+F N}
$$

O cálculo da métrica F1-Score deve ser feito para diversos valores de $\varepsilon$ com a granularidade desejada. O limiar que maximizar a métrica deve ser adotado antes da utilização do método para classificar novas instâncias. Ao fazer um novo treinamento, o $\varepsilon$ deve ser também recalculado.

\section{Método da distribuição gaussiana multivariada}

Este método funciona de maneira análoga ao anterior. Entretanto, nele, as funções de densidade de probabilidade não são modeladas separadamente, considerando as características como independentes. Para considerar todas as características de uma única vez, utiliza-se uma função densidade de probabilidade gaussiana multivariada, que já considera, inclusive, a dependência existente entre as características. Tal fato faz com que esse método seja mais sofisticado, adequando-se melhor aos dados em questão. Contudo, essa sofisticação faz com que o método seja computacionalmente mais custoso e requeira um número suficiente de instâncias de treinamento para que ele funcione (número de instâncias deve ser maior do que o número de características). Segue o seu detalhamento. 
Seja $X$ o mesmo conjunto de instâncias não rotuladas do método anterior, em que cada instância é um vetor de $n$ características. Da mesma forma, supõe-se que cada uma das características segue uma distribuição normal.

Em vez de ser necessário calcular a média e a variância de cada uma das distribuições, será preciso estimar o vetor média $\mu \in \mathbb{R}^{n}$ da função multivariada e calcular a matriz de covariância $\Sigma \in \mathbb{R}^{n \times n}$ do seguinte modo:

$$
\mu=\frac{1}{m} \sum_{i=1}^{m} x^{(i)}
$$

em que $x^{(i)}$ é um vetor instância de treinamento. Logo a soma apresentada é uma soma de vetores. Em seguida é realizada a multiplicação do vetor resultante pelo escalar $1 / m$. O resultado disso é um vetor de médias das características.

$$
\Sigma=\frac{1}{m} \sum_{i=1}^{m}\left(x^{(i)}-\mu\right)\left(x^{(i)}-\mu\right)^{T}
$$

em que $\left(x^{(i)}-\mu\right)$ é um vetor n-dimensional e $\left(x^{(i)}-\mu\right)^{T}$ é esse mesmo vetor transposto. A sua multiplicação resultará em uma matriz $n \times n$. A somatória resultará em uma matriz de mesmo tamanho, que será multiplicada pelo escalar $1 / \mathrm{m}$.

Obtidos os parâmetros necessários e dado $x$ uma instância, a função densidade de probabilidade multivariada é dada por:

$$
\left.p(x ; \mu, \Sigma)=\frac{1}{(2 \pi)^{n / 2}|\Sigma|^{1 / 2}} e^{\left(-\frac{1}{2}(x-\mu)^{T} \Sigma^{-1}(x-\mu)\right.}\right)
$$

No Algoritmo 2 é possível ver a semelhança entre os dois métodos, mudando somente os parâmetros que precisam ser calculados e a função densidade de probabilidade utilizada.

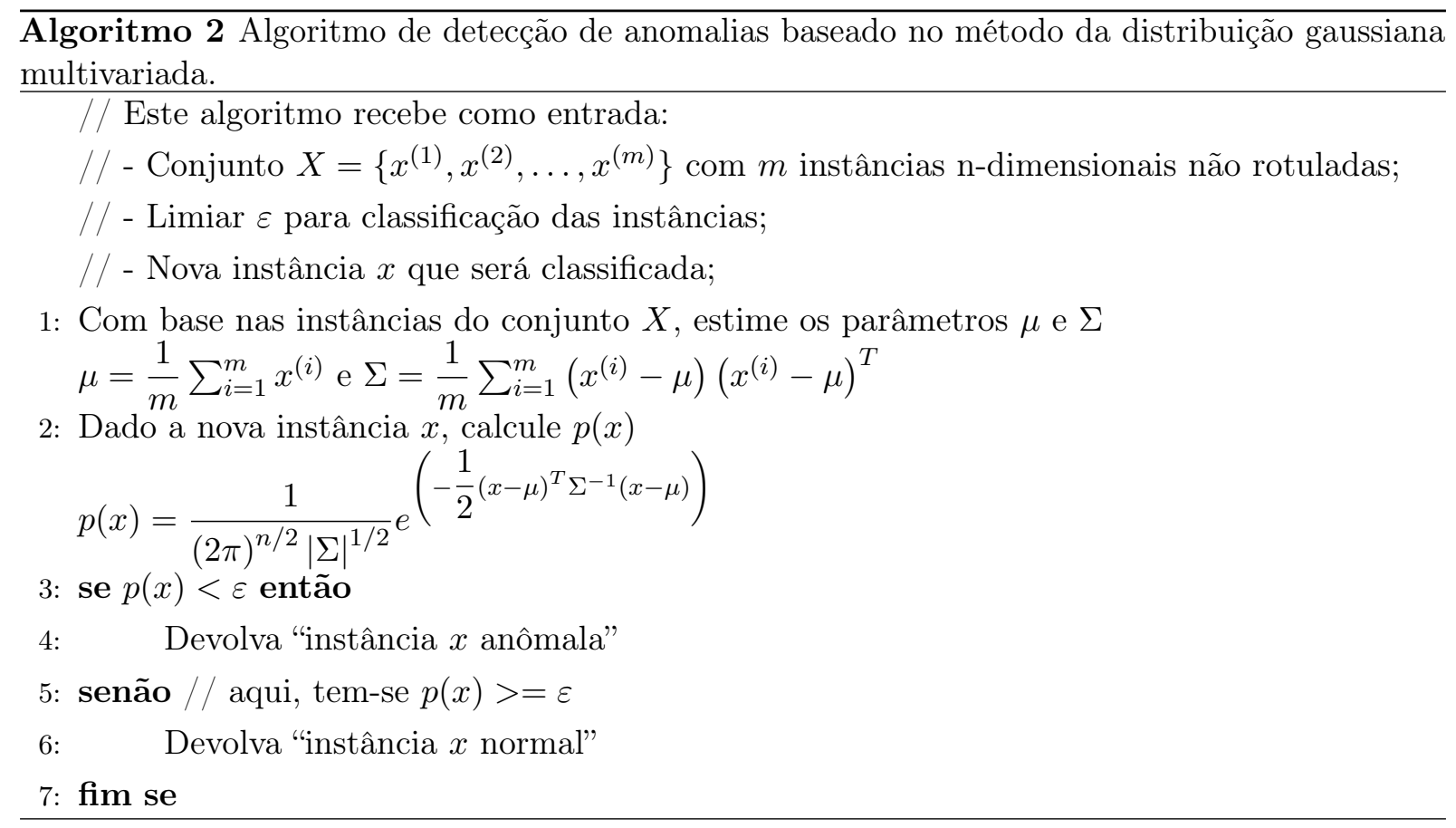


As observações feitas no Algoritmo 1 também valem para o Algoritmo 2. O cálculo do limiar também é realizado da mesma maneira, executando o algoritmo diversas vezes sobre diferentes valores do limiar até achar aquele que maximize a métrica utilizada.

\subsection{Conclusão}

Neste capítulo, dissertamos sobre os principais fundamentos necessários para o entendimento deste trabalho. Primeiramente, fornecemos um panorama geral sobre data warehouses, com ênfase em alguns aspectos que julgamos mais relevantes. Foi descrito, então, como utilizar DWs para implementar sistemas integradores, assunto necessário para o acompanhamento dos Capítulos 3 e 4. Por fim, uma introdução ao aprendizado de máquina, com ênfase em detecção de anomalias foi apresentada, de modo a facilitar a compreensão do Capítulo 5. No capítulo seguinte, apresentaremos o projeto REDS-II, sistema de integração de dados fruto da utilização das diretrizes metodológicas descritas neste trabalho e candidato para integrar-se com o validador estatístico de lotes apresentado neste trabalho. 


\section{Capítulo 3}

\section{Projeto REDS-II}

O projeto descrito nesta seção é o primeiro resultado deste doutorado. Seu desenvolvimento foi norteado por uma intuição de que os métodos aqui empregados facilitariam o desenvolvimento de um sistema de DW, expondo um conjunto de boas práticas que, se utilizadas conjuntamente, agilizariam a construção do sistema, tornando-o factível considerando as severas restrições de tempo dos projetos atuais. Com o término bem sucedido do seu desenvolvimento, comprovando a intuição inicial, surgiu a necessidade de generalizar o método utilizado, retirando-o do contexto inicial, para que ele pudesse ser utilizado em outros domínios, culminando em diretrizes metodológicas a serem seguidas em projetos similares, explicitadas no capítulo seguinte. Além das diretrizes, o projeto REDS-II (mais especificamente o sistema resultante dele, chamado Bloddis - detalhes na Seção 3.6) servirá como o primeiro sistema de DW a ter incorporado o sistema de validação estatística projetado neste trabalho (Capítulo 5). Colocadas essas observações, segue uma introdução do projeto (Seção 3.1) e o detalhamento dos seus principais pontos que serão explorados pelas diretrizes: Seção 3.2, seu banco de dados normalizado e modelo conceitual; Seção 3.3, sua arquitetura modular; e Seção 3.4, as análises de dados realizadas. Além disso, para melhor contextualizar o validador estatístico, seguem: Seção 3.5, que trata do processo de validação de dados no projeto; e a Seção 3.6, que explica o sistema Bloddis, no qual o validador será aplicado.

\subsection{Introdução}

O projeto Retrovirus Epidemiology Donor Study - II (REDS-II) foi financiado pelo National Hearth Lung and Blood Institute (NHLBI - EUA) e iniciou com uma rede de hemocentros norte americanos, cujo intuito era desenvolver projetos de pesquisa com enfoque em segurança transfusional. Em 2005, o National Institutes of Health (NIH-EUA) abriu uma chamada de propostas para incluir hemocentros estrangeiros interessados em participar desta rede. Três grandes hemocentros brasileiros foram inseridos: Fundação Pró-Sangue (hemocentro de São Paulo), Fundação Hemominas (hemocentro de Minas Gerais) e Hemope (hemocentro de Pernambuco). Nesse contexto, o grupo DATA (Database Modeling, Transactions, and data Analysis) do Instituto de Matemática e Estatística da Universidade de São Paulo (IME-USP) ficou responsável por montar a infraestrutura de organização dos dados dos hemocentros brasileiros envolvidos no projeto, bem como a geração de estruturas para análise desses dados.

Dois fatores foram determinantes para o envolvimento do grupo DATA neste projeto: o primeiro 
deles é a dificuldade inerente ao fato de que cada hemocentro participante tem seu próprio sistema transacional, adequado para as necessidades e requisitos locais, não havendo uma uniformização dos dados entre os hemocentros; o segundo fator é a ausência de sistemas apropriados nos hemocentros para análise dos dados. Assim, ficamos responsáveis por coletar, corrigir, homogenizar e guardar os dados referentes ao processo de doação sanguínea dos hemocentros. Além disso, geraríamos relatórios para análises estatísticas e estruturas para análises multidimensionais que possibilitariam aos hemocentros obter rapidamente visões gerenciais do processo de doação de sangue, permitindo, assim, melhorá-lo em diversos aspectos.

Integrar os dados, cuidando da sua qualidade sempre foi uma das principais preocupações durante o desenvolvimento da solução de DW para o projeto REDS-II. Devido a esse fato, a abordagem de construção de DW proposta por Inmon (explicada na Seção 2.1) mostrou-se mais adequada, pois proveria ao sistema um BD centralizador normalizado, que facilita a integração dos dados e a manutenção da sua consistência.

O NDS do projeto REDS-II é o nosso elemento de armazenamento para os dados provenientes de diversos anos de doações de todos os hemocentros participantes. Ele é a nossa fonte organizada de dados para todas as questões analíticas e relacionadas a pesquisas. Além do banco de dados central, temos também outros bancos analíticos, populados a partir do primeiro, que servem para prover visões específicas sobre os dados dos hemocentros. As estruturas desses bancos são otimizadas para agilizar a geração dessas visões quando forem necessárias e para facilitar a construção de estruturas de dados gerenciais auxiliares, como é o caso de cubos OLAP (sua definição encontra-se na Seção 2.1.3). Para popular os BDs, foram usadas rotinas de recepção, correção, validação e transformação de dados. Tais rotinas, que foram escritas usando DTS (Data Transformation Services - conjunto de ferramentas e objetos do Microsoft ${ }^{\circledR}$ SQL Server ${ }^{\circledR} 2000$ para manipulação de dados) também compõem o nosso DW e serão melhor descritas na Seção 3.3, que apresenta a arquitetura do sistema.

O sistema de integração de dados do projeto REDS-II proporcionou a realização de várias análises feitas por diversos pesquisadores, e os resultados obtidos até o momento podem ser encontrados nas referências $\left[\mathrm{CPSS}^{+} 10, \mathrm{SSS}^{+} 10, \mathrm{dANLW}^{+} 11, \mathrm{GSS}^{+} 12, \mathrm{PdANL}^{+} 12, \mathrm{SGCP}^{+} 12\right]$.

\subsection{Banco de dados normalizado e modelo conceitual}

Apesar de os hemocentros participantes do estudo terem o mesmo domínio de doação de sangue, cada um deles implementa e opera o seu processo a sua maneira. Essa circunstância leva à existência de vários modelos de dados distintos. Entretanto, analisando os dados provenientes dos hemocentros, nós concluímos que, apesar das diferenças existentes, os conceitos principais utilizados eram os mesmos. O modelo conceitual [EN10] nos ajuda a extrair esses conceitos-chave, auxiliando a nos restringirmos ao que é realmente importante para o sistema. Ele não só ajuda a identificar entidades essenciais envolvidas, como também ajuda a identificar o relacionamento entre essas entidades. O modelo, uma vez desenvolvido, foi usado para construir o NDS. Além disso, era essencial manter o modelo conceitual atualizado, de tal forma que as mudanças estruturais no DW fossem apenas um reflexo das mudanças feitas anteriormente no modelo conceitual. Assim, nosso NDS, que é responsável por guardar dados históricos de todos os hemocentros, foi desenvolvido baseado em nosso modelo conceitual descrito na Figura 3.1. O modelo descrito a seguir foi o 
resultado de várias iterações que envolveram análises de dados e, baseado nelas, subsequentes melhorias ao modelo inicialmente desenvolvido.

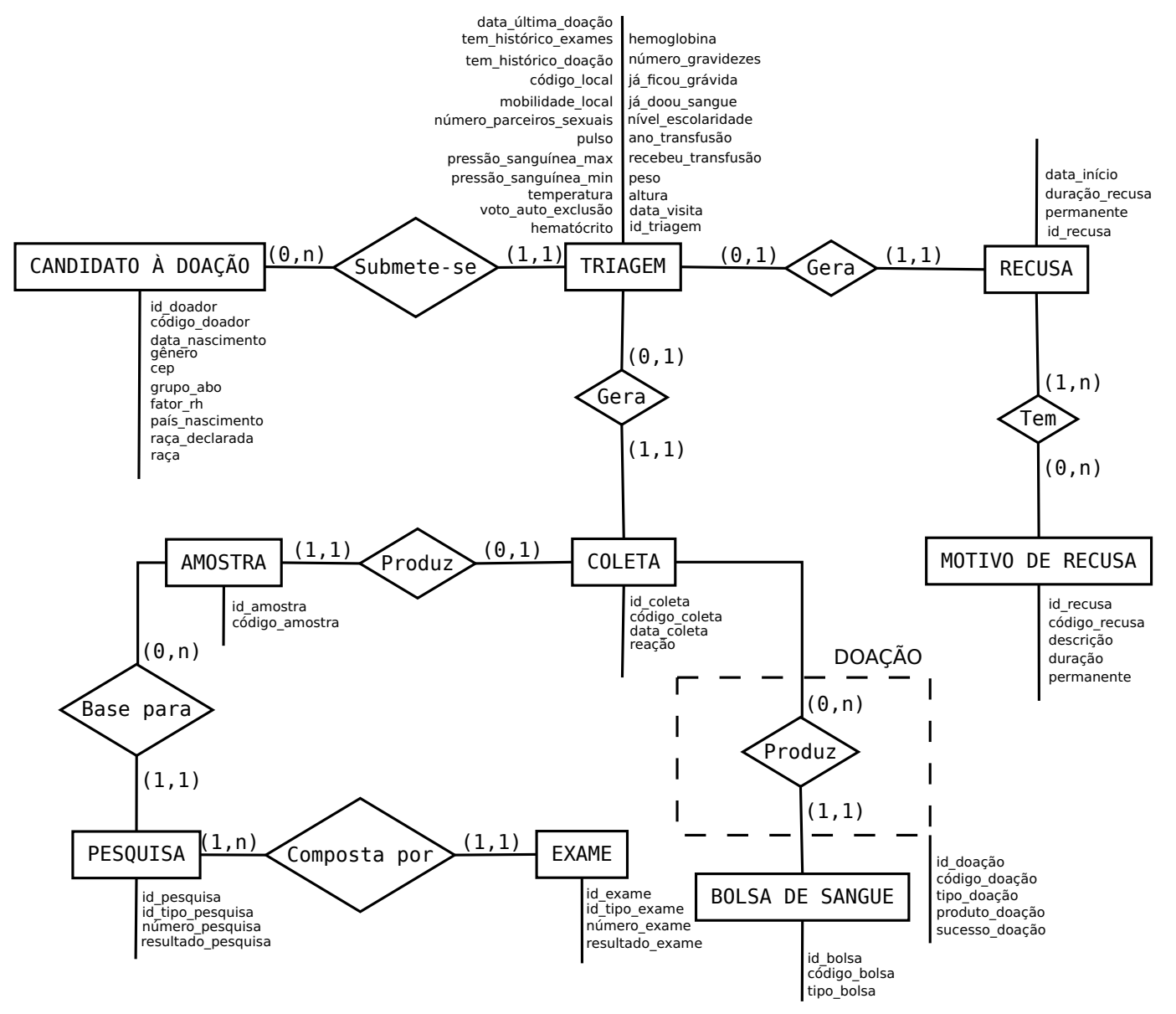

Figura 3.1: Modelo conceitual do NDS (Modelo Entidade-Relacionamento estendido).

Triagem é uma das entidades identificadas. Ela representa o primeiro contato entre o candidato à doação e o hemocentro. Basicamente, uma triagem constitui-se dos dados provenientes das entrevistas, questionários, e exames clínicos (como pressão sanguínea, altura, pulso) obtidas no começo de cada visita. Dependendo das regras de cada hemocentro, uma triagem pode evoluir para uma coleta (se o candidato for aprovado) ou para uma recusa (se o candidato for rejeitado). É importante notar que uma triagem nunca produzirá as duas situações ao mesmo tempo, dado que elas são mutuamente exclusivas. Se uma recusa for produzida, ela será ligada ao(s) motivo(s) que levaram a essa rejeição (motivo de recusa). Por outro lado, se uma coleta for produzida, dois produtos podem ser obtidos: uma ou mais bolsas de sangue e uma amostra para os exames laboratoriais. Ao agregado de relacionamentos entre uma coleta e suas respectivas bolsas, dá-se o nome de doação. A amostra é a base para diversas pesquisas investigativas, cujos resultados irão determinar o destino dado às bolsas de sangue associadas à coleta em questão. Uma pesquisa, por sua vez, é composta por exames, que serão avaliados individualmente e, baseado em seus resultados, um resultado para a pesquisa será determinado. Como exemplo, pode-se considerar uma pesquisa para HIV, composta por dois exames diferentes. A pesquisa somente será considerada com resultado positivo se ambos os exames forem reativos. 


\subsection{Arquitetura modular}

Quebrar um sistema em módulos não somente melhora a sua organização como também facilita a sua manutenção, uma vez que esta prática define os limites de cada uma de suas partes, separando os seus papéis e funcionalidades e estabelecendo interfaces bem definidas para interagir com cada uma delas. A modularização facilita o reuso dos seus componentes e ajuda o sistema a evoluir mais facilmente. Pelos motivos apresentados, optamos por usar uma arquitetura modular. O modelo arquitetural utilizado foi baseado em uma das técnicas de construção propostas por Vincent Rainardi [Rai08] e é dividido em quatro módulos distintos (e três níveis de BDs) que são ilustrados pela Figura 3.2. São eles:

1. O Módulo 1 é responsável por receber e temporariamente armazenar dados transacionais provenientes de cada sistema dos hemocentros em uma área de stage (o primeiro nível de BD). Entretanto, apesar do fato de os hemocentros lidarem basicamente com o mesmo processo, cada um deles modela seus dados de uma maneira diferente, gerando bancos de dados bastante distintos uns dos outros. Assim, esta área deve conter diferentes bancos de dados para acomodar diferentes formatos. Para cada hemocentro, temos um banco de dados. Neste nível, optamos por não fazer validações, correções e transformações de dados. Optamos por fazê-las no Módulo 2, com os dados já no interior do sistema.

2. O Módulo 2 realiza a validação e correções de possíveis erros nos dados, bem como a sua homogenização. Conforme esperado, dados de entrada provenientes de fontes heterogêneas frequentemente usam diferentes valores ou codificações para os mesmos atributos, o que requer certo trabalho de uniformização. Como exemplo, um hemocentro pode representar um resultado positivo de exame como $P$ enquanto outro hemocentro o representa como $Y$. Para esses casos, aplicam-se transformações de dados. Além disso, os dados são validados e algumas correções são feitas para evitar a passagem de dados errados ao próximo módulo. Essas tarefas ainda ocorrem na área de stage.

3. O Módulo 3 é responsável por captar os dados da área de stage e inserí-los (ou atualizá-los) em um banco de dados normalizado histórico (o segundo nível de BD). Uma vez corretos e padronizados, os dados devem ser armazenados definitivamente e unidos àqueles já existentes no sistema. Com essa finalidade, nós temos um banco de dados normalizado histórico (NDS) no sistema. Esse NDS foi criado com base no modelo conceitual descrito na Seção 3.2 e armazena os dados provenientes de todos os centros. Nesse módulo, algumas validações semânticas entre os novos dados e os dados que já existiam no NDS devem ser executadas com o intuito de garantir a consistência do NDS.

4. O Módulo 4 é direcionado à visualização dos dados, análises e exportação. Nele, nós construímos bancos de dados analíticos (o terceiro nível de BD) para facilitar a geração de cubos OLAP e o processamento de consultas mais elaboradas. Nossos bancos de dados dimensionais são compostos por tabelas fato e tabelas de dimensões. As tabelas fato contêm, em geral, medidas numéricas que são os elementos básicos usados para a análise das doações. As tabelas de dimensões representam um conjunto de perspectivas sobre o sistema que nós temos interesse em estudar, como é o caso de resultados de exames, gênero, data de 
nascimento, data da doação, entre outros. Dessas bases, é possível extrair alguns cubos OLAP. Usando os cubos, usuários não especialistas podem descobrir relacionamentos entre diferentes atributos usando ferramentas que são familiares a eles (como o Microsoft ${ }^{\circledR}$ Excel $\left.{ }^{\circledR}\right)$. Esse módulo também contém componentes para a construção de visões do NDS, geradores de planilhas, e processos que selecionam dados para programas de mineração.

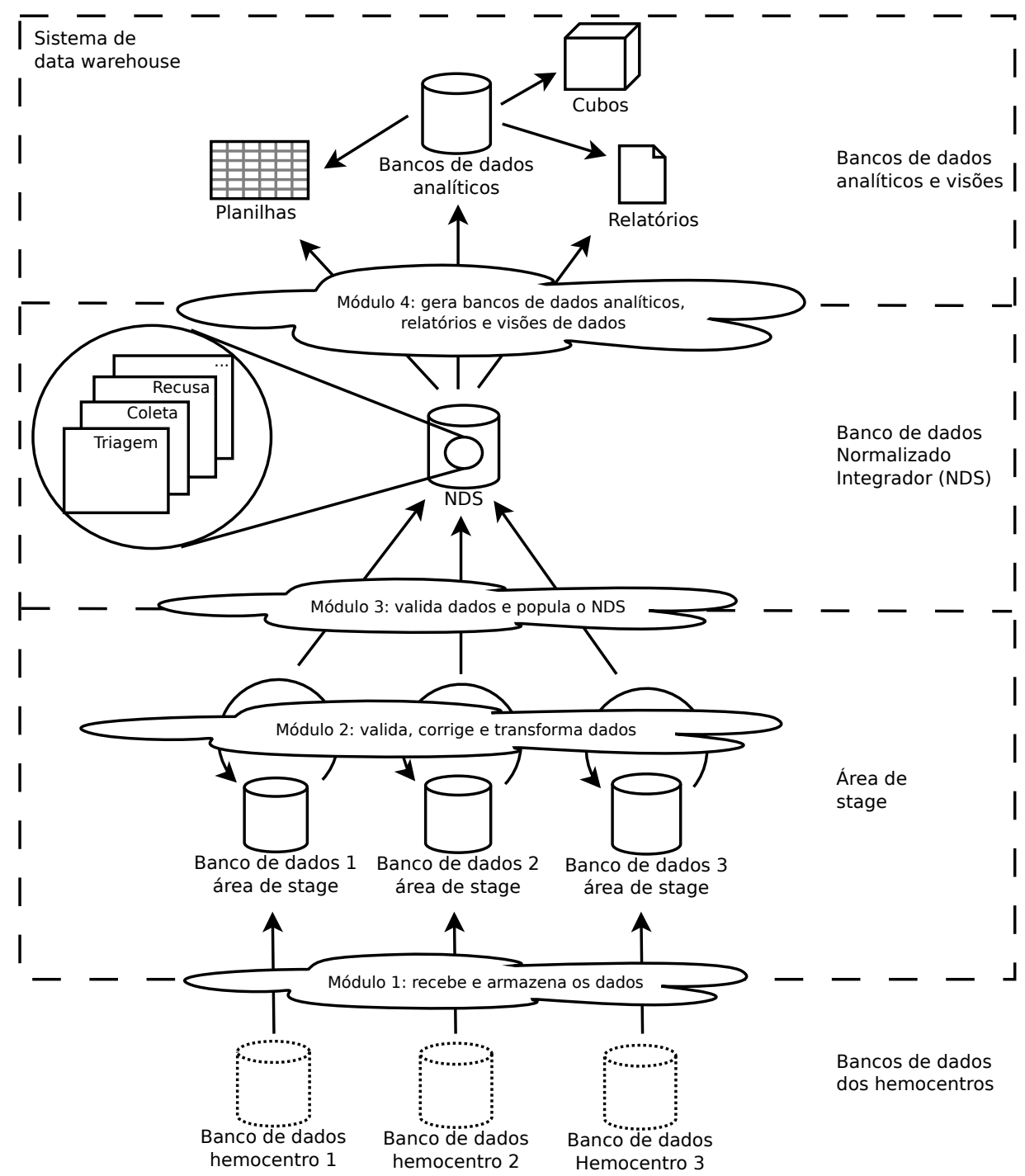

Figura 3.2: Arquitetura do data warehouse do projeto REDS-II.

\subsection{Análises de dados}

Depois de construir uma versão do DW, obtém-se um arcabouço poderoso para gerar estruturas com visões gerenciais que nos permitem fazer análises de dados [CD97, Kim96]. O DW também provê uma visão global de todo o processo de transformação dos dados, desde os sistemas transacionais de origem até as formas sintéticas analíticas finais. Neste caso específico, o DW nos provê dois benefícios importantes: verificação de consistências e apoio a tomada de decisões. Antes de explorá-los, seguem algumas visualizações possíveis geradas a partir de um cubo OLAP construído a partir do DW REDS-II. 
A Figura 3.3 ilustra uma consulta extraída de um cubo gerado a partir de uma de nossas bases analíticas. Por se tratar de um projeto internacional, as imagens extraídas do sistema desenvolvido para o REDS-II encontram-se em inglês. Esta figura está dividida em duas partes: uma lista de variáveis e uma área de manipulação de dados. A lista de variáveis indica as diferentes visões que as informações dos hemocentros podem assumir. A área de manipulação de dados indica a região em que o usuário pode manipular livremente as variáveis, criando várias classificações sobre os dados originais. As variáveis podem ser combinadas com o intuito de gerar visões mais complexas. A visão do exemplo abaixo provê as seguintes variáveis: grupo ABO, idade, data de nascimento, hemocentro, país de nascimento, raça declarada, procedimento de doação, data de doação, tipo de doação, escolaridade, histórico de doação prévia, indicativo de doação fixa ou móvel, gênero e número de gravidezes. Além disso, no cubo também estão inclusos resultados de exames, como doença de Chagas, hepatite B (HBSAG e HBCAB), hepatite C (HCV), HIV, sifilis, vírus T-linfotrópico humano (HTLV) e seus respectivos resultados de exames confirmatórios.

A nossa estratégia de análise inclui o oferecimento de cubos como o descrito anteriormente aos usuários finais. Usando um cubo, o usuário pode rapidamente combinar essas variáveis, porque nesse tipo de estrutura, os valores de todas as possíveis combinações de dimensões são pré-calculadas durante a construção do cubo. Esta característica provê agilidade para o usuário final, que pode tentar várias opções de consulta até determinar qual é a mais apropriada para a análise desejada.

A Figura 3.3 e a Figura 3.4 são exemplos de consultas considerando as variáveis hemocentro e resultado do exame HCV. O cubo constrói automaticamente uma tabela em que os dados são classificados considerando o hemocentro e, internamente, o resultado do exame HCV. Os valores possíveis para os hemocentros são Fundação Pró-Sangue, Hemominas e Hemope. Os valores possíveis para os testes de HCV são: negativo, positivo, não testado, indefinido e amostra não coletada.

A Figura 3.5 mostra outra opção de visualização construída a partir de um cubo, ilustrando a capacidade de apoio analítico desse tipo de ferramenta. Nela, o número de doações no hemocentro Hemope de acordo com o tipo sanguíneo é desenhado em um gráfico para um ano. Esse gráfico pode ser facilmente expandido para ver os detalhes das doações diárias em um mês específico (Figura 3.6). Usando esse gráfico, é fácil, por exemplo, visualizar o impacto do Carnaval (13 a 16 de fevereiro) no número de doações de sangue no Brasil.

Um bom modo de detectar a presença de erros conceituais ou de implementação é analisar os dados disponíveis de um ponto de vista global. Várias verificações podem ser feitas dessa maneira, como é o caso da verificação de consistências. A análise de dados contribui de diversas maneiras para a verificação de consistências. Um exemplo simples de verificação é a identificação de erros no campo número_gravidezes (número de gravidezes), associando-o com o campo já_ficou_grávida, que indica se a doadora já engravidou alguma vez. A presença do valor não nesse último campo deve ser seguido por um valor não aplicável no campo anterior. Como nesse exemplo, especialistas podem identificar diversas associações complexas que podem indicar se houve algum engano na implementação do sistema (erros nas transformações, correções, validações, etc.).

As análises de dados também facilitam o apoio a tomada de decisões. Em muitos casos, as análises decorrentes dos dados do DW podem apontar para observações válidas, porém não 


\begin{tabular}{|lr|}
\hline Row Labels & Count \\
\hline Fundacao Pro-Sangue - SP & 404,901 \\
\hline Negative & 400,713 \\
Not tested & 2,390 \\
Positive & 966 \\
Undefined & 404 \\
Unit not collected & 428 \\
Hemominas - MG & 211,769 \\
\hline Negative & 208,151 \\
Not tested & 3,295 \\
Positive & 211 \\
Undefined & 112 \\
Hemope - PE & 313,040 \\
\hline Negative & 307,625 \\
Not tested & 3,285 \\
Positive & 571 \\
Undefined & 713 \\
Unit not collected & 846 \\
\hline Grand Total & 929,710 \\
\hline
\end{tabular}

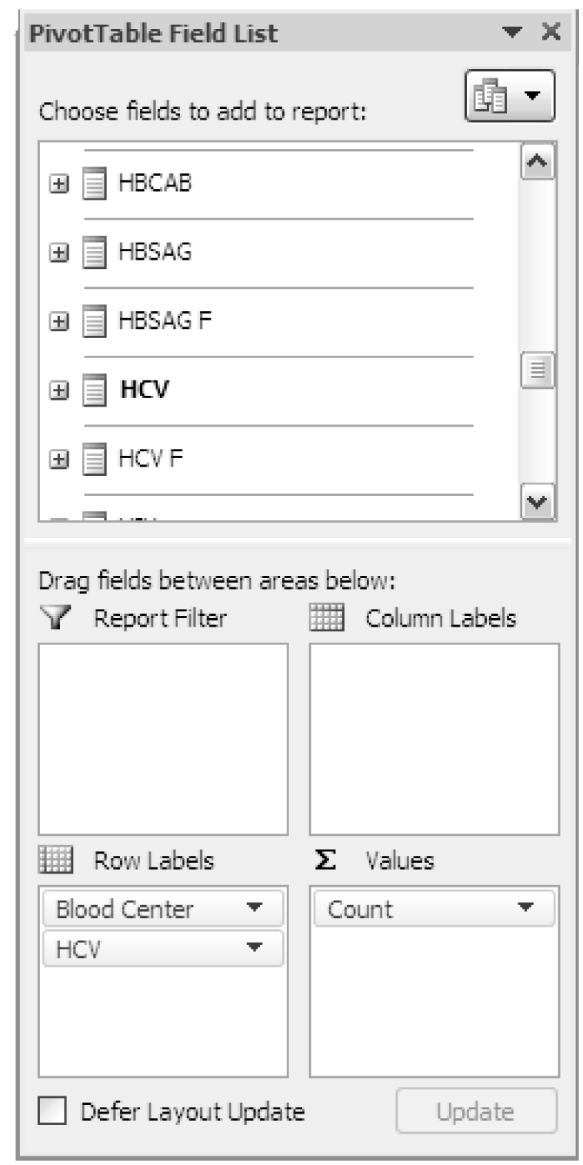

Figura 3.3: Visualização gerada a partir de um cubo OLAP com o cruzamento das variáveis Hemocentro $\times$ resultado de $H C V$.

esperadas, como é o caso do aumento de casos de HIV em doações de reposição se comparadas às doações voluntárias gerais. Essas situações, descartadas as possibilidades de haver erro no sistema, costumam indicar comportamentos especiais de nichos particulares entre os doadores. Nesse caso, o DW apóia os especialistas na condução de pesquisas mais rigorosas usando informações de seu próprio banco de dados. 


\begin{tabular}{l|lrrr|}
\hline Count & Column Labels & & & \\
\hline Row Labels & Fundacao Pro-Sangue - SP & Hemominas - MG & Hemope - PE & Grand Total \\
\hline Negative & 400,713 & 208,151 & 307,625 & 916,489 \\
Not tested & 2,390 & 3,295 & 3,285 & 8,970 \\
Positive & 966 & 211 & 571 & 1,748 \\
Undefined & 404 & 112 & 713 & 1,229 \\
Unit not collected & 428 & & 846 & 1,274 \\
\hline Grand Total & 404,901 & 211,769 & 313,040 & $\mathbf{9 2 9 , 7 1 0}$
\end{tabular}

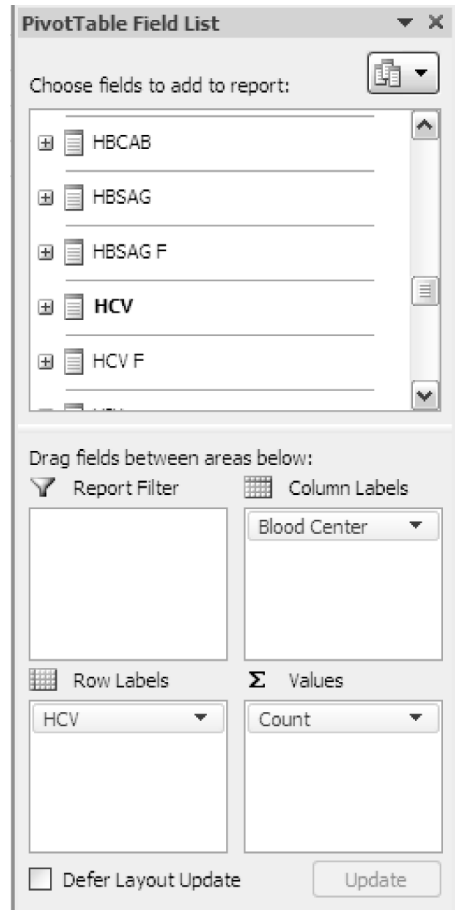

Figura 3.4: Outra forma de visualização possível considerando as mesmas variáveis da Figura 3.3.

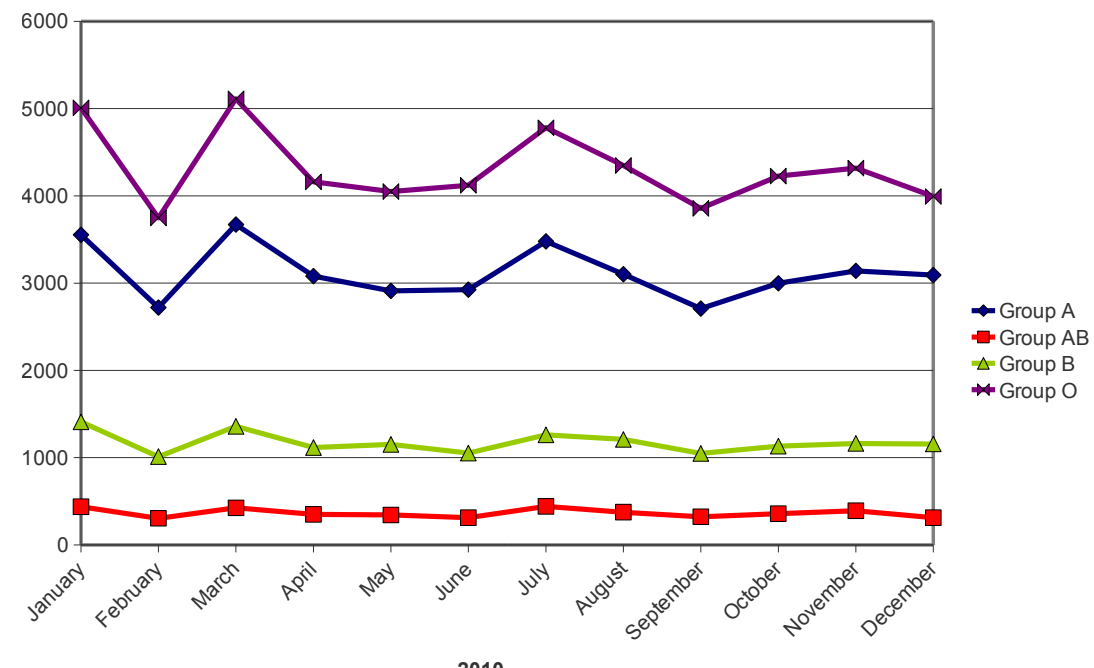

Figura 3.5: Número de doações por mês de acordo com o tipo sanguíneo no hemocentro Hemope (2010). 


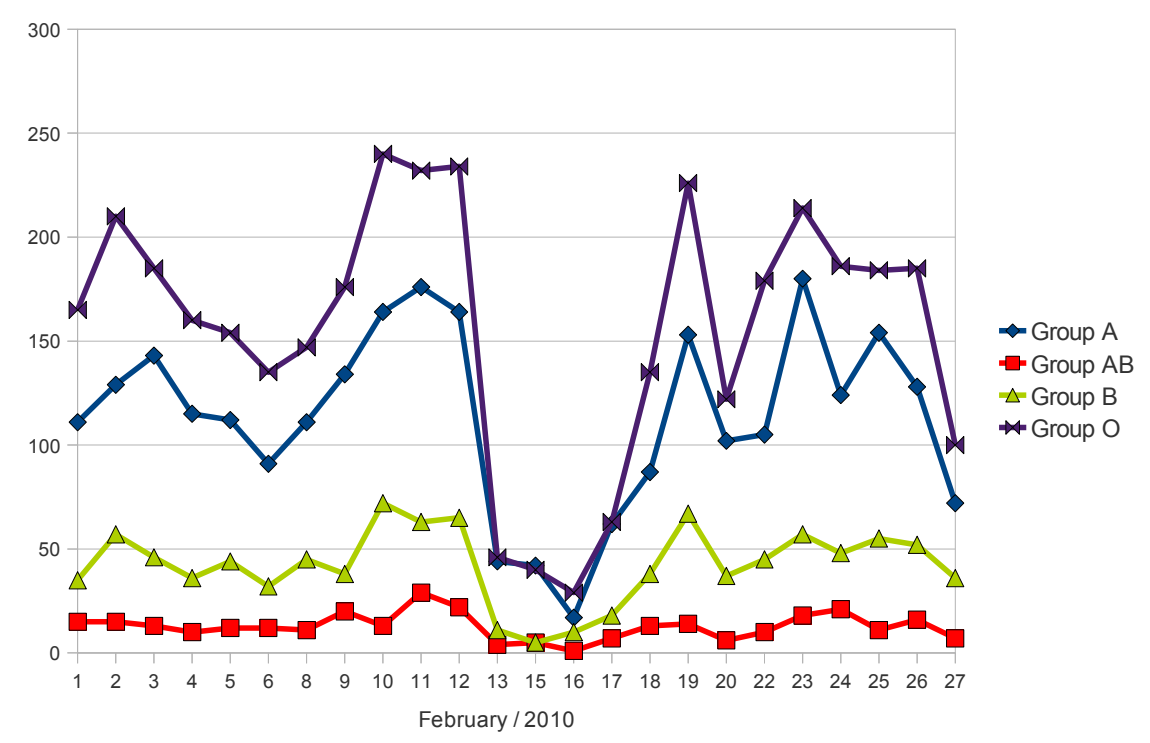

Figura 3.6: Número de doações por dia de acordo com o tipo sanguíneo no hemocentro Hemope (fev/2010). 


\subsection{Validação de dados}

As inserções de dados feitas no NDS do sistema devem ser realizadas com cautela. A inclusão a esmo de novas entradas pode levá-lo a um estado inconsistente ou até mesmo inutilizá-lo. Para evitar tais situações, antes de permitir que mudanças definitivas sejam feitas nessa base, nós asseguramos que diversas rotinas de validação sejam executadas, mantendo a consistência e integridade de nossas bases. Para ilustrar alguns tipos de validação que são empregados em nossas rotinas, exemplos estão representados na Figura 3.7. Esses exemplos estão descritos na Tabela 3.1.

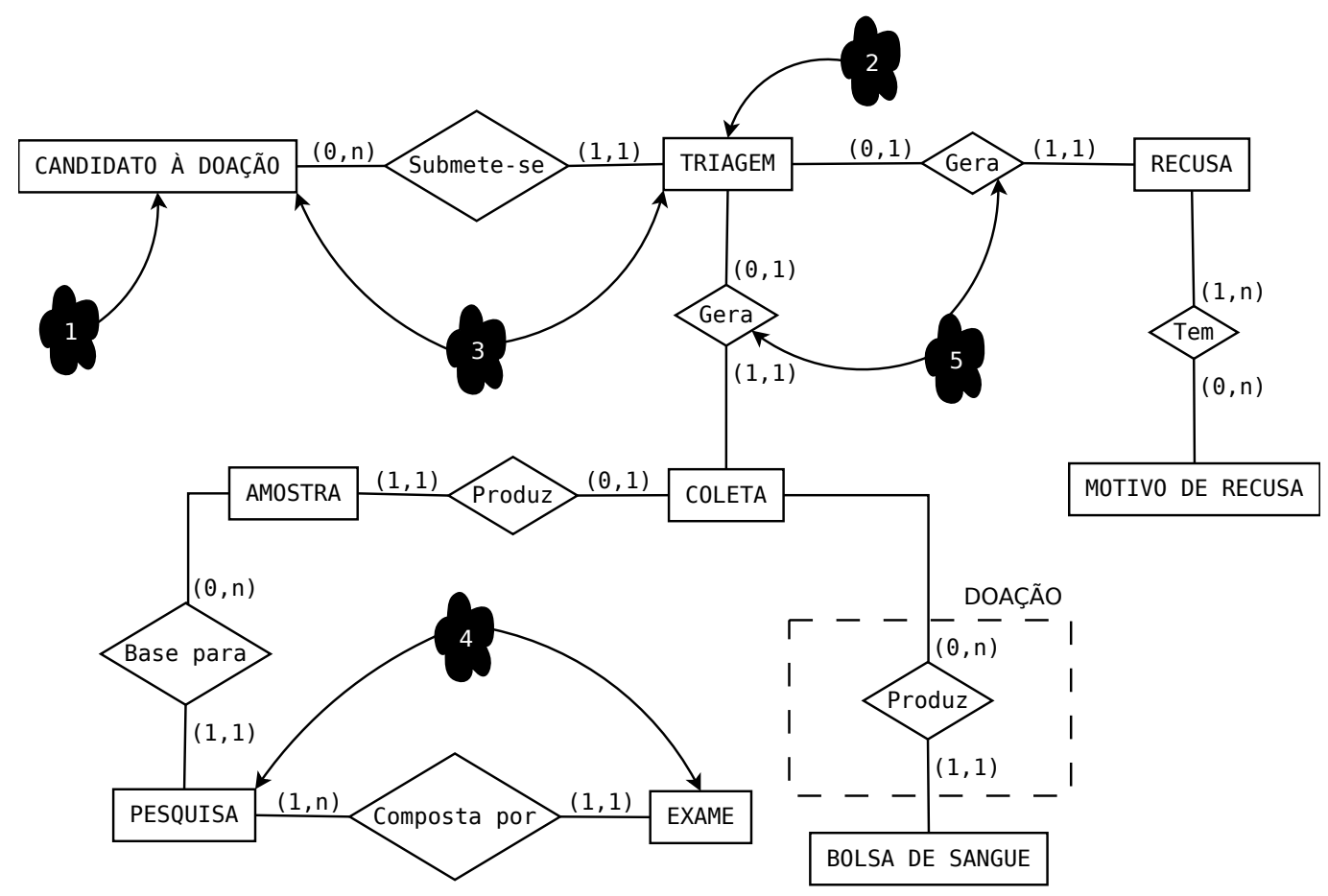

Figura 3.7: Exemplos de tipos de validação no processo de doação.

\begin{tabular}{|l|l|l|}
\hline$\#$ & Tipo de validação & Exemplo \\
\hline $\mathbf{0}$ & Validação sintática de campo & $\begin{array}{l}\text { Campo gênero admite somente os valores masculino e } \\
\text { feminino }\end{array}$ \\
\hline $\mathbf{2}$ & $\begin{array}{l}\text { Validação entre campos de } \\
\text { uma mesma entidade }\end{array}$ & $\begin{array}{l}\text { Se já_ficou_grávida tem valor não (candidata à doação } \\
\text { nunca ficou grávida), nós verificamos a presença do valor } \\
\text { náo aplicável no campo número_gravidezes (número de } \\
\text { gravidezes). }\end{array}$ \\
\hline $\mathbf{3}$ & $\begin{array}{l}\text { Validação entre campos de en- } \\
\text { tidades distintas }\end{array}$ & $\begin{array}{l}\text { Se o campo gênero tiver valor masculino, nós verificamos } \\
\text { se o campo já_ficou_grávida possui o valor nấo aplicável. }\end{array}$ \\
\hline $\mathbf{4}$ & $\begin{array}{l}\text { Validação para garantir inte- } \\
\text { gridade referencial }\end{array}$ & $\begin{array}{l}\text { Todo exame deve estar vinculado a uma e somente uma } \\
\text { pesquisa. }\end{array}$ \\
\hline $\mathbf{6}$ & Validação da disjunção & $\begin{array}{l}\text { Uma triagem pode gerar uma recusa, uma coleta ou mesmo } \\
\text { nenhuma das duas, mas não as duas ao mesmo tempo. }\end{array}$ \\
\hline
\end{tabular}

Tabela 3.1: Exemplos de validações dos tipos ilustrados na Figura 3.7.

No projeto REDS-II, foram implementadas validações sintáticas e semânticas (maiores detalhes estão na Seção 2.2.4). Essas validações são aplicadas nos lotes de dados recebidos pelo sistema e 
ocorrem em duas fases distintas. Antes de explicá-las, é necessário explicitar o que é um lote de dados no contexto do sistema. Cada lote de dados recebido pelo sistema deve ser autocontido, devendo conter as triagens do período considerado (geralmente referente a um mês), bem como todos os dados relacionados a essas triagens (os doadores que se submeteram às triagens e as doações, exames e recusas geradas a partir delas - a Seção 3.2 explica esses relacionamentos). A primeira fase de validações é feita ainda no Módulo 2 (explicado na Seção 3.3), considerando somente o lote de dados que será inserido no sistema (sem considerar os dados do NDS). Nessa fase, é possível fazer praticamente todas as validações sintáticas necessárias e algumas validações semânticas que não requerem ligações com dados não contidos no próprio lote. Como exemplo de validações desse tipo, é possível citar a primeira validação da Tabela 3.1. Na segunda fase, temos as validações que, por algum motivo, não puderam ser feitas no Módulo 2. Nessa fase,que ocorre no Módulo 3, fazemos todas as validações que requerem acesso aos dados presentes no NDS. Isso ocorre pois, na primeira fase, ainda não temos acesso aos dados do NDS. Nessa fase, estão localizadas algumas validações semânticas como é o caso do último exemplo da Tabela 3.1.

Caso o lote de dados não passe nas validações, sua carga é interrompida para que os dados de entrada sejam corrigidos. Isso evita a inclusão permanente de dados errados no sistema.

No projeto REDS-II não existe nenhuma espécie de validação estatística dos lotes de entrada de dados no sistema. Com isso, alguns lotes de dados errados entram no DW, diminuindo a confiabilidade dos dados presentes nele e dos relatórios gerados por ele. O único modo de detectar tais dados problemáticos é por meio da análise dos cubos, feita a posteriori. Caso seja detectado algum problema nos cubos, todo um trabalho de reprocessamento é necessário, o que é bastante custoso e demanda muito trabalho. Por esse motivo decidimos implementar o validador estatístico de dados, assunto do Capítulo 5, que será aplicado no projeto.

\subsection{Projeto REDS-III}

No início do ano de 2011, com o sucesso do projeto REDS-II, o National Institutes of Health (NIH) e um de seus institutos chamado National Heart, Lung, and Blood Institute (NHLBI) decidiram dar continuidade à parceria, criando um novo projeto, chamado de Recipient Epidemiology and Donor Evaluation Study III (REDS-III), promovendo novos estudos baseados no DW construído durante o projeto REDS-II. Além da continuação da participação dos hemocentros que já compunham o REDS-II, houve a adesão de pelo menos quatro novos centros ao novo projeto, que está em franca expansão. Tais centros também estão colocando os seus dados no DW desenvolvido por nós e o sistema de integração passou a ter novas exigências com relação a usabilidade, interface com o usuário e rapidez de processamento dos dados.

Para nos adequar a esses novos requisitos, desde o início de 2011, o grupo DATA está desenvolvendo um novo sistema para integração dos dados. Tal sistema, denominado Bloddis (Blood Donation Data Integration System), está sendo desenvolvido utilizando componentes gratuitos e de código aberto. A sua parte relacionada à integração de dados está inteiramente baseada no que foi desenvolvido durante o projeto REDS-II, que foi uma etapa essencial para ganharmos maturidade no funcionamento do mecanismo integrador, possibilitando, assim, concentrarmos a nossa atenção nos outros requisitos sistêmicos nessa nova fase. É importante notar que tanto a modularização, quanto o modelo conceitual do NDS, as validações e as análises de dados 
foram herdados do sistema anterior. Na nova abordagem, por se tratar de um sistema web, integralmente automatizado, o arcabouço Ruby on Rails [rai], atrelado à linguagem Ruby [rub] está sendo utilizado no desenvolvimento. Para o armazenamento de dados, optamos pelo SGBD PostgreSQL [pos], de código aberto e de ampla aceitação tanto na área acadêmica, como também na indústria.

Os dados já existentes no nosso repositório de dados foram migrados para esse novo sistema, que já está em produção e substituiu o anterior. Nesse novo sistema será implementada a validação estatística de lotes de dados, que impedirá, com o mínimo de interferência dos desenvolvedores, a entrada de lotes que fogem do comportamento usual, evitando assim o trabalho de reprocessamento de dados incorretos. Tal processo de validação será melhor explicado no Capítulo 5. Como outras tarefas ainda pendentes para esse novo sistema, estão a implantação de um bom componente de geração de visualizações de dados via web e a automatização de análises estatísticas mais complexas sobre os dados para dar apoio aos pesquisadores dos hemocentros.

\subsection{Conclusão}

Neste capítulo foi apresentado o projeto REDS-II. Na descrição feita, procuramos destacar os pontos relevantes do projeto que levaram à concepção das diretrizes metodológicas descritas no próximo capítulo. Tais pontos são a existência de um modelo conceitual guiando o desenvolvimento do DW; a geração de análises de dados como um meio para avaliar a qualidade do sistema ao mesmo tempo que apóia o usuário final na tomada de decisões; e a existência de uma arquitetura modular para facilitar a evolução sistêmica. Além disso, a validação de dados também é citada como tópico importante a ser considerado nesse contexto. No próximo capítulo serão descritas as diretrizes metodológicas que guiaram a construção do REDS-II, porém de maneira independente de domínio, possibilitando a sua aplicação em outros cenários de integração de dados. 


\section{Capítulo 4}

\section{Diretrizes Metodológicas para a Construção de Data Warehouses}

Neste capítulo é apresentada a contribuição proveniente do primeiro objetivo deste doutorado: desenvolver diretrizes metodológicas para reduzir a complexidade da construção de sistemas de integração que envolvem dados provenientes de diversas fontes heterogêneas. No capítulo anterior, foram apresentadas as seguintes práticas: o uso de uma arquitetura modular, o desenvolvimento de um modelo conceitual e a geração de análises de dados. É importante notar que esses tópicos, quando considerados separadamente, são bastante conhecidos dentro da área de sistemas de bancos de dados e foram amplamente utilizados em diversos projetos. Entretanto, as diretrizes metodológicas que constituem uma real contribuição deste trabalho de doutorado são baseadas no uso combinado dessas práticas. O uso dessas práticas de maneira cíclica e interativa é inovador, possibilitando a redução da complexidade do desenvolvimento de sistemas de DW. Além disso, este capítulo apresenta essas diretrizes sem que estejam vinculadas a algum domínio específico, sendo que o método pode ser aplicado de maneira genérica no desenvolvimento de sistemas integradores que utilizam DW. Um artigo com as diretrizes apresentadas aqui foi aceito em um importante veículo de publicação acadêmica $\left[\mathrm{TOB}^{+} 13\right]$.

\subsection{Diretrizes metodológicas}

Ao trabalhar em um domínio complexo que inclui muitas variáveis (como é o caso do domínio de doações de sangue), é importante, a princípio, concentrar-se nas partes essenciais do processo, em vez de tentar construir uma versão final e completa do sistema nessa etapa. Somente após a obtenção de uma versão estável, o sistema deve devagar e progressivamente ser expandido para incluir as variáveis restantes e os conceitos de menor importância. De outro modo, existe uma maior propensão a cometer erros. Esta estratégia é detalhada por meio das diretrizes apresentadas a seguir, e constituem uma maneira factível de desenvolver de modo efetivo um DW. Essas diretrizes são apresentadas de maneira algorítmica (Algoritmo 3), com o intuito de enfatizar a ordem dos passos que devem ser seguidos. As ideias apresentadas nesse algoritmo são explicadas textualmente para complementá-lo e facilitar o seu entendimento.

Tipicamente, existem dois cenários nos quais há a necessidade de construir DWs que compilam dados provenientes de fontes heterogêneas. O primeiro deles ocorre quando existem vários sistemas 


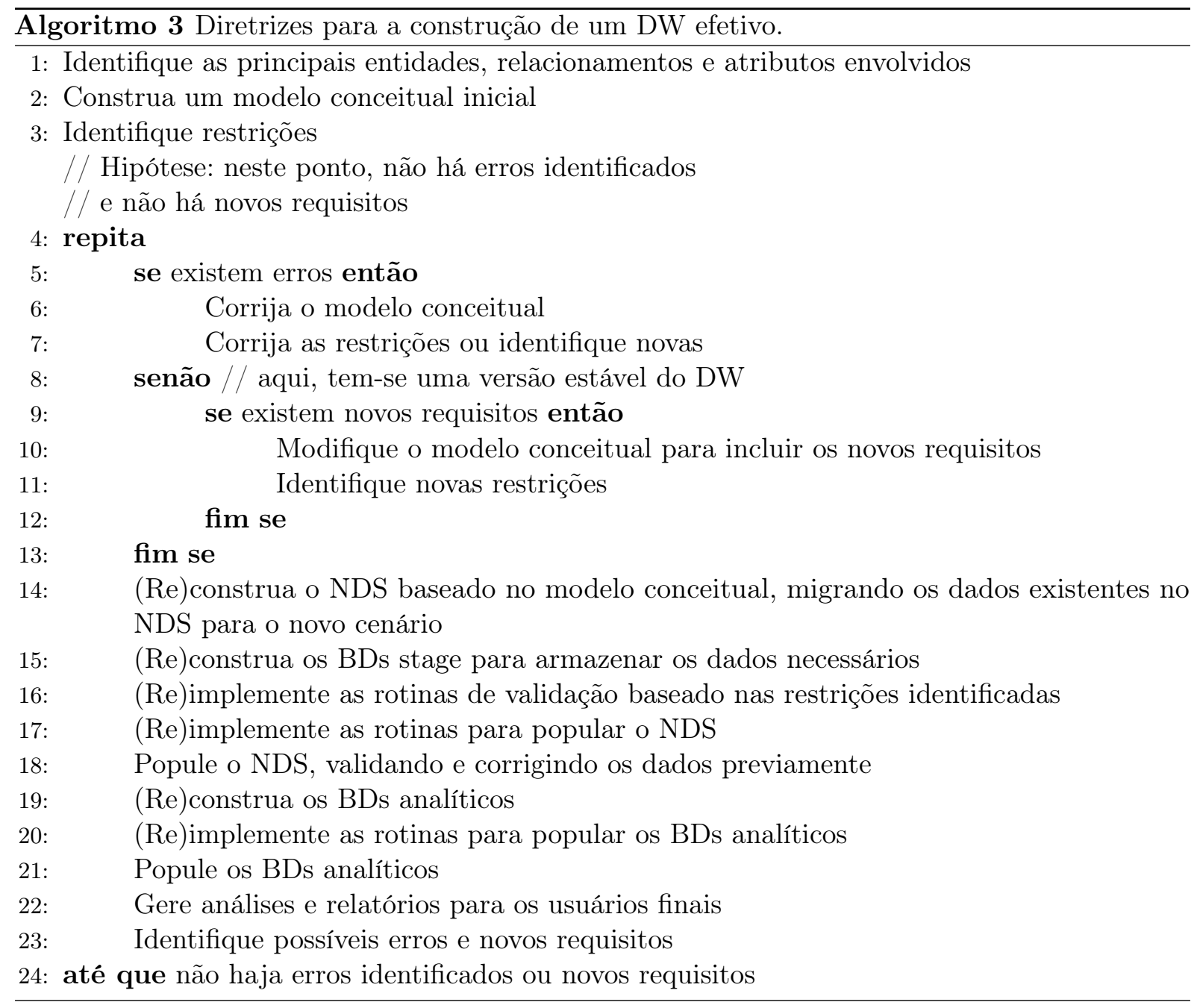

distintos, mas que implementam o mesmo processo. Os sistemas transacionais de bancos de sangue são um exemplo dessa situação, na qual o processo implementado é a doação de sangue. O segundo cenário é constituído por sistemas heterogêneos que implementam processos diferentes, porém relacionados. Em qualquer um dos cenários considerados, é importante o enfoque nos processos implementados pelos sistemas. Olhando para os processos, é possível ver claramente o que os sistemas têm em comum e como eles estão conectados entre si. Desse modo, partes do sistema que não são importantes, que foram introduzidas durante a sua fase de implementação, e que seriam uma potencial distração ao desenvolvedor do sistema de DW, poderiam ser identificadas: por exemplo, é o caso de diferentes interfaces que implementam os mesmos conceitos. A finalidade de concentrar-se nos processos que estão implícitos nas implementações dos sistemas é conseguir um modo factível de identificar as principais entidades que precisam ser modeladas em um DW, como elas estão relacionadas e quais são os seus atributos. Esta identificação constitui a linha 1 dessas diretrizes. Embora algumas abordagens para a identificação dessas entidades já tenham sido concebidas, não é uma tarefa fácil perceber todos os detalhes dos processos envolvidos em uma fase inicial do desenvolvimento. É importante, portanto, que a evolução do sistema seja gradual.

Depois que as principais entidades e os relacionamentos foram estabelecidos, é possível construir o modelo conceitual que será usado para desenvolver o banco de dados normalizado, 
dando origem, assim, à primeira versão do DW (linha 2). O modelo conceitual será essencial para representar os dados (entidades) que serão integrados e os relacionamentos entre eles. Além disso, ele ajudará também com relação a outro importante ponto na construção de um sistema de DW: na identificação de restrições a serem colocadas nos dados (linha 3). As restrições dão informações a respeito das validações que precisam ser implementadas. Por sua vez, as validações são responsáveis por garantir a qualidade dos dados em um DW. Entretanto, devido a limitações semânticas, nem todas as restrições podem ser inferidas a partir do modelo conceitual. Essas limitações são o motivo pelo qual a análise de dados (linha 22) também tem um papel essencial para melhorar a qualidade dos dados. Em um primeiro momento, as linhas 5 a 13 não serão executadas, porque a condição para isso não é inicialmente satisfeita. Desse modo, elas serão explicadas mais adiante no texto. A existência do loop "repita / até que" (linhas 4 e 24) também será explicada mais adiante.

Uma vez que o modelo conceitual tenha sido produzido, o sistema de DW pode ser implementado. Neste ponto, a primeira coisa a fazer é construir o NDS seguindo o modelo conceitual que foi desenvolvido (linha 14). Existem algumas ferramentas [pow12, erw12] amplamente utilizadas capazes de automatizar essa tarefa, gerando uma rotina de construção do banco de dados com base no modelo dado. Uma vez que o NDS tenha sido construído, são conhecidos os dados que devem ser extraídos dos sistemas de origem. Portanto, é o momento de construir os bancos de dados stage para receber esses dados (linha 15). Baseado nas restrições identificadas, as rotinas de validação e correção de dados podem ser implementadas (linha 16). Baseado nos bancos de dados de stage e no NDS, as rotinas para popular o NDS podem ser desenvolvidas (linha 17). Utilizando essas rotinas, se existirem novos dados disponíveis no stage, eles já podem popular o NDS (linha 18). É importante que esses dados sejam validados e corrigidos previamente. Para isso, é preciso utilizar as rotinas de validação e correção de dados atualizadas. Tanto a fase de validação dos dados de entrada como a fase de validação cruzada de dados (Seção 2.2.4) devem acontecer antes da inclusão dos dados no NDS. A validação estatística de dados, contribuição deste trabalho (Capítulo 5), também deve ser executada juntamente com as demais rotinas de validação cruzada de dados. Depois que um NDS funcional for estabelecido, os bancos de dados analíticos podem ser construídos (linha 19) e as rotinas para populá-los podem ser implementadas (linha 20). Os bancos de dados analíticos populados (linha 21) podem ser usados para gerar visões e relatórios (linha 22). As análises dessas visões serão cruciais para a detecção de erros no sistema e para a sua expansão. Nos sistemas de integração, a qualidade dos dados e o desenvolvimento de sistemas são conceitos intimamente relacionados. Por meio das análises, os usuários são capazes de encontrar inconsistências que indicam a existência de possíveis erros no sistema (linha 23). Se existir um erro na implementação do sistema ou no modelo conceitual, ele pode ser corrigido pelos desenvolvedores antes que a próxima versão seja entregue. Entretanto, o erro pode estar nos dados. Isso significa que os dados foram colocados erroneamente no sistema, o que pode indicar uma falha no processo de validação. Tais falhas revelam que ou há erros nas validações já existentes ou ainda que novas validações precisam ser implementadas. Assim, a análise de dados contribui para aumentar a qualidade dos dados. Olhando para esse fato por outra perspectiva, é possível dizer que quanto mais confiavel são os dados no sistema, maior é a confiança que se tem nas análises. Em outras palavras, a qualidade dos dados melhora as análises que, por sua vez, 
melhoram a qualidade dos dados.

Além de ajudar na detecção de inconsistências no sistema, as análises são importantes para determinar quais entidades e atributos devem ser incluídos com a finalidade de expandir o sistema (linha 23). Partindo de suas necessidades reais, os usuários finais estarão aptos a dizer quais são os próximos passos no desenvolvimento do sistema, o que garante que horas de desenvolvimento não serão gastas com partes do sistema que nunca serão utilizadas na prática.

Com as análises, é possível construir uma nova versão do modelo conceitual, contendo correções (linhas 5 a 7) dos erros encontrados. Depois de vários ciclos de análise e desenvolvimento, é esperado que se obtenha uma versão razoavelmente estável do DW (linha 8). Nesse estágio, é possível começar a trabalhar para expandir o modelo conceitual, de maneira a cobrir mais entidades e atributos (linhas 9 a 12), assim começando novamente o ciclo de análises e correções. Além da evolução do sistema, os dados já armazenados no NDS precisam ser levados em consideração, uma vez que esses dados devem evoluir da mesma maneira. Entretanto, essa não é uma tarefa difícil, dado que todos os componentes que acessam os dados do repositório estão sob controle único do desenvolvedor do DW, o que permite a criação de rotinas corretivas para serem usadas no NDS sem maiores consequências. Já existem vários trabalhos [AS06, Sad07] que usam técnicas de evolução de dados quando ocorrem mudanças nos esquemas de dados. Tais trabalhos provaram-se funcionais e, portanto, esse assunto não será tratado neste texto.

A característica cíclica destas diretrizes é representada por meio do laço "repita / até que" da linha 4 até a linha 24. É importante notar que, nesse laço, correções de erros têm precedência sobre o crescimento do sistema, e o sistema não será expandido até que uma versão estável tenha sido atingida. Outro ponto importante a notar é o fato de que depois do primeiro ciclo, todos os bancos de dados e rotinas precisarão apenas de pequenas adaptações para funcionarem com a evolução dos cenários, e a implementação dessas adaptações será facilitada com o uso de uma arquitetura modular.

Considerando o contexto no qual o desenvolvimento se dá em diversos ciclos, os vários estágios de refatoração, correção e expansão aos quais o sistema deverá ser submetido requerem ao mesmo tempo alta flexibilidade e baixo acoplamento. Para garantir essas características, é importante a adoção de uma arquitetura modular bem definida que ajuda na organização do sistema. Em um sistema de larga escala, é muito fácil os desenvolvedores se perderem em meio a um grande número de linhas de código com centenas ou milhares de validações. Modularizar o sistema de modo que as suas partes sejam agrupadas de acordo com as suas características funcionais foi uma maneira encontrada para acelerar eficientemente o desenvolvimento dos sistemas e facilitar a sua manutenção.

\subsection{Discussão}

Sucintamente, é possível resumir a ideia das diretrizes da seguinte forma: em se tratando de sistemas de DW cujos dados provêm de fontes heterogêneas, "não se pode ferver o oceano". É uma tarefa difícil entender todos os detalhes dos dados disponíveis que vêm de múltiplas fontes de uma única vez. Para facilitar o desenvolvimento de tais sistemas, é importante enfocar nas principais entidades. Por meio dessas entidades, tem-se um ponto de partida para construir o modelo conceitual inicial e, a partir dele, começar a construir o DW. Depois que a primeira versão 
do DW for desenvolvida, ele já pode ser populado e algumas visões e relatórios podem ser gerados. As análises dessas visões serão muito úteis na verificação da existência de erros dos conceitos modelados até o momento. Então, será possível desenvolver uma nova versão do modelo conceitual, contendo correções para os erros detectados. Depois de completar suficientes ciclos de análises e desenvolvimento até que se atinja uma versão estável do DW, será possível trabalhar em uma expansão do modelo conceitual, de modo que cubra mais entidades ou atributos, recomeçando assim o ciclo de análises e correções. Todas essas mudanças serão facilmente realizadas se for usada uma arquitetura modular com alta flexibilidade e baixo acoplamento.

O uso combinado das práticas (arquitetura modular, modelagem conceitual e análise de dados) que foi apresentado nessa seção com uma perspectiva cíclica e interativa permite a redução da complexidade do desenvolvimento de um DW. Em outras palavras, seguindo essas boas-práticas apresentadas, consegue-se obter, de maneira rápida e eficiente um DW que contém as entidades mais importantes e com a possibilidade de gerar visões e relatórios a partir desses dados. Dessa maneira, resolve-se a principal causa de falhas no desenvolvimento de sistemas de DW: a demora na entrega de um sistema funcional. Entretanto, pode-se levantar a seguinte questão: o que aconteceria se apenas um subconjunto dessas práticas fosse usada em um projeto? Para tentar responder essa questão, segue abaixo a análise do que aconteceria se cada uma das práticas fosse excluída do cenário de desenvolvimento:

- Sem arquitetura modular: a evolução do modelo conceitual por meio da avaliação das análises geradas pelos usuários finais leva a constantes mudanças na implementação do sistema. Essas mudanças são necessárias para corrigir os erros encontrados ou expandir o sistema. A falta da modularização do sistema faria com que essas mudanças sejam mais difíceis de implementar, e as iterações de desenvolvimento levariam mais tempo para serem finalizadas. Isto levaria à perda da agilidade do método proposto, com um substancial aumento do tempo gasto para entregar novas versões.

- Sem modelo conceitual: é bem conhecido que a ausência de um modelo conceitual em um projeto de banco de dados é tão catastrófico quanto a falta de uma planta na construção de um prédio. Bancos de dados complexos precisam ser planejados com cuidado antes de sua implementação. Os modelos conceituais também provêm um meio de pensar sobre os sistemas e documentar o que será construído. Sem eles, seria extremamente difícil implementar o sistema ou saber quais mudanças no sistema seriam necessárias para corrigí-lo ou expandí-lo.

- Sem análises de dados: as análises são a maneira que os usuários têm para avaliar a qualidade do sistema e uma base comum para a discussão entre esses usuários e os desenvolvedores. Atualmente, a importância da participação do usuário final no processo de desenvolvimento é bastante conhecida. Se essa interação não está disponível, não é possível saber o estado do sistema. Perguntas como "O que precisa ser corrigido?" ou "Quais são os aspectos que precisam ser implementados a seguir?" só são possíveis pela geração de estruturas analíticas e sua análise pelos usuários.

No projeto REDS-II, essas diretrizes mostraram-se funcionais, gerando os resultados pretendidos. Atualmente, o DW do projeto REDS-II armazena mais de 2 milhões de triagens de cerca de 
1 milhão de candidatos, com mais de 1,5 milhão de doações e 500 mil recusas. Das amostras de sangue, mais de 12 milhões de resultados de exames foram obtidos até agora. Todos esses dados são provenientes de sistemas transacionais heterogêneos de doação de sangue e agora são parte desse DW, que foi construído usando as práticas discutidas neste trabalho.

\subsection{Conclusão}

Neste capítulo foram apresentadas, de maneira algorítmica e textual, diretrizes metodológicas para reduzir a complexidade da construção de sistemas de integração que envolvem dados provenientes de diversas fontes heterogêneas. Para isso, as práticas utilizadas durante o desenvolvimento do projeto REDS-II foram abstraídas do seu cenário original e combinadas de uma maneira cíclica e interativa, possibilitanto a sua aplicação em domínios diferentes daquele nas quais foram concebidas. No próximo capítulo, será abordada a segunda contribuição desse trabalho, que é o desenvolvimento de uma solução para facilitar a implementação de validações estatísticas de lotes de dados. 


\section{Capítulo 5}

\section{Validação Estatística Adaptativa de Lotes de Dados}

Este capítulo apresenta a contribuição relacionada ao segundo objetivo deste doutorado: desenvolver uma solução para a validação estatística de lotes de dados que possa ser utilizado no contexto de sistemas integradores. Na Seção 5.1, é apresentado o problema de validação a ser enfrentado. A Seção 5.2 desenvolve um método para o problema descrito utilizando detecção de anomalias. A Seção 5.3 descreve os principais pontos para o entendimento de como implementar um sistema que utiliza o método apresentado para resolver o problema da validação e que pode ser integrado a sistemas de DW.

\subsection{Descrição do problema}

Em sistemas de integração de dados que utilizam a arquitetura de DW, o DW precisa ser populado com os dados dos diferentes sistemas transacionais integrados por ele. Existem duas formas de fazer essa tarefa: 1) o sistema integrador pode extrair ativamente os dados dos sistemas transacionais ou; 2) o sistema integrador pode passivamente receber esses dados. Na primeira forma, o sistema integrador possui um amplo controle do processo de extração. Desse modo, ele é capaz de dar maiores garantias a respeito da qualidade dos dados extraídos, pois seu mecanismo de extração pode ser inspecionado utilizando diversas técnicas. Entretanto, para o seu funcionamento, o sistema integrador deve, em primeiro lugar, ter acesso aos diferentes sistemas transacionais, o que muitas vezes se torna uma tarefa complexa, por razões políticas ou comerciais. Em segundo lugar, supondo que o acesso aos sistemas transacionais é concedido, tais sistemas costumam ser complexos, e entender as suas implementações a ponto de poder extrair os seus dados costuma ser uma tarefa difícil de ser concretizada. É por esse motivo que em sistemas reais de grande porte a segunda forma é utilizada. Nela, a responsabilidade de fornecer os dados necessários, de maneira correta e precisa, fica com as organizações responsáveis pelos sistemas transacionais. Para implementar essa solução, contratos devem ser estabelecidos com as companhias detentoras dos dados, estabelecendo um formato de envio e um sistema de envio das informações. Por meio do formato de envio são especificados quais são os dados que serão enviados, bem como as regras sintáticas e semânticas às quais eles devem se submeter. Já o sistema de envio determina como esses dados deverão ser passados ao integrador. Haverá um sistema que recebe arquivos 
texto com os dados no formato especificado? Haverá um serviço web ao qual as companhias poderão se conectar e enviar esses dados? É importante notar que o formato de envio deverá ser planejado de acordo com o sistema de envio pretendido. Ao adotar a recepção passiva de dados, a implementação do sistema integrador simplifica-se drasticamente, pois a implementação dos sistemas transacionais fica encapsulada pela interface do formato de envio contratado. Entretanto, perde-se o controle do mecanismo de geração desses dados e, com isso, perde-se garantias sobre a qualidade dos dados que estão sendo enviados ao sistema.

Devido a sua importância prática, este capítulo aborda a integração de dados por meio de seu recebimento pelo sistema integrador. Uma maneira simples e eficiente de implementar esse tipo de envio de dados é a utilização de arquivos texto para o envio periódico de dados e um sistema web para receber tais arquivos e processá-los. Por meio de um conjunto de arquivos texto é possível enviar qualquer conjunto de dados que possa ser armazenado em um banco de dados relacional. Basta, para isso, utilizar algum caractere separador de campo predefinido para criar, dentro de um arquivo, uma estrutura que remete a uma tabela. Cada linha do arquivo corresponde a uma tupla (ou registro) dessa tabela. A um conjunto de arquivos com dados extraídos de um sistema transacional e referentes a um período predeterminado de execução desse sistema, com a finalidade de alimentar um sistema integrador, daremos o nome, neste trabalho, de lote de dados. Assim, os lotes de dados contêm conjuntos de dados, muitas vezes relacionados por meio de atributos (ou campos) que são chaves primárias e estrangeiras [EN10] e que seguem regras sintáticas e semânticas determinadas. Para ilustrar a ideia de lote, segue um exemplo: se um hospital precisa passar semanalmente os dados das transfusões de sangue realizadas durante a semana, bem como os pacientes que receberam as transfusões e as bolsas de sangue transfundidas, ele pode fazer isso por meio de três arquivos. O primeiro deles, chamado paciente, contém os dados de todos os pacientes que realizaram alguma transfusão de sangue durante a semana (número identificador do paciente, nome do paciente, tipo sanguineo do paciente); o segundo arquivo, de nome bolsa de sangue, contém os dados de todas as bolsas de sangue que foram transfundidas na semana (número identificador da bolsa, quantidade de sangue na bolsa, tipo sanguíneo da bolsa); já o terceiro, chamado transfusão, contém os dados das transfusões realizadas na semana (identificador do paciente, identificador da bolsa, hora da transfusão), e se relaciona com os outros dois por meio das chaves (identificadores). Cada arquivo terá três campos distintos, separados por vírgula. Este trabalho adota os lotes de dados como a abordagem para recebimento dos dados pelo sistema integrador.

Quando um sistema integrador recebe lotes de dados e os processa, ele não pode simplesmente confiar na corretude desses dados. O sistema integrador não tem controle sobre o mecanismo de geração desses dados e não pode garantir a sua qualidade. Desse modo, antes de os dados presentes nos lotes integrarem o DW, eles precisam passar por um processo de validação. $\mathrm{O}$ processo de validação usualmente compreende um conjunto de regras de validação, de caráter sintático ou semântico. Tais regras garantem que o contrato estabelecido pelo formato de envio seja respeitado. Entretanto, isso não é garantia de que o mecanismo de extração de dados foi implementado corretamente, e alguns erros graves podem estar ocultos. Segue um exemplo que esclarece esse tipo de situação.

Seja $L$ um lote com dados mensais de doadores de sangue de um hemocentro brasileiro. Esse 
lote é gerado pelo hemocentro e enviado por um sistema web para um sistema integrador. Tal lote contém um arquivo texto com 10.000 linhas, referentes aos dados de 10.000 doadores de sangue distintos. Segue um pequeno trecho do arquivo, cujos campos referem-se a, respectivamente: número identificador do doador, nome do doador, tipo sanguíneo, fator Rh.

103001,Severino de Freitas,O,+

103004,José Aparecido Humm,AB,+

102506,Maria Alda Terezina,A,+

105654,Pedro de Lima Darte,B,-

...

Ao analisar o campo referente ao tipo sanguíneo das 10.000 linhas, nota-se que todas as linhas possuem um dos quatro tipos aceitos: $O, A, B$ ou $A B$. Por essa perspectiva, não há, portanto, qualquer erro nesse atributo que invalide os dados presentes no lote. Entretanto, em uma análise global do lote, nota-se o seguinte fato:

\begin{tabular}{|r|r|}
\hline Tipo sanguíneo & Frequência relativa no lote \\
\hline \hline $\mathrm{A}$ & $42 \%$ \\
$\mathrm{~B}$ & $10 \%$ \\
$\mathrm{O}$ & $3 \%$ \\
$\mathrm{AB}$ & $45 \%$ \\
\hline
\end{tabular}

Tabela 5.1: Frequência dos tipos sanguíneos de doadores no lote exemplo L.

Para um analista do domínio, ter $45 \%$ dos doadores de sangue do tipo AB e apenas $3 \%$ dos doadores com tipo $\mathrm{O}$ mostra uma situação improvável de acontecer. Muito provavelmente, o mecanismo de extração dos dados trocou o tipo sanguíneo $\mathrm{O}$ por $\mathrm{AB}$ e $\mathrm{AB}$ por $\mathrm{O}$ no momento da geração dos arquivos, dado que o sangue do tipo $\mathrm{O}$ é muito frequente e o sangue do tipo $\mathrm{AB}$, raro.

Esse tipo de erro exemplificado pode ter sérias consequências para a qualidade dos dados do DW por dois motivos: 1) é um erro indetectável pelos validadores sintáticos e semânticos convencionais; 2) não se trata de um erro pontual, mas sim de um erro que afeta os dados globalmente.

Alguns sistemas integradores tentam detectar erros nos mecanismos de extração de dados por meio de levantamentos estatísticos realizado a posteriori sobre os dados já armazenados no DW (também chamado de validação interna dos dados do DW - Seção 2.2.4). Entretanto, tais estudos não impedem a entrada de dados errados no DW e, até que o erro seja descoberto, diversas decisões equivocadas podem ter sido tomadas.

Para ser possível implementar um validador capaz de detectar erros nos sistemas de extração de dados antes da entrada dos dados no DW, a utilização da ideia de lotes de dados é fundamental. Os lotes de dados fornecem uma visão mais global dos dados gerados, e permite, assim, desenvolver uma estratégia de deteç̧ão de erros nos mecanismos de extração utilizando o perfil estatístico dos dados presentes dos lotes. Obviamente, não é possível detectar todos os tipos de erros que podem existir em um sistema de extração de dados olhando somente para os dados gerados por ele. Entretanto, encontrar um método que detecta parte desses problemas já é suficientemente 
importante por garantir um aumento na qualidade dos dados dos sistemas integradores. A esse tipo de validação que usa medidas estatísticas dos lotes de dados para detectar possíveis erros nos mecanismos de extração, tentando impedir dessa forma a entrada de lotes de dados inválidos no DW, demos o nome de validação estatística de lotes de dados.

De maneira mais sintética, apesar de um lote ser formado por um conjunto de arquivos, esses arquivos representam uma estrutura relacional, sendo possível considerar um lote $l$ como um conjunto de relações. Uma relação pode ser definida da seguinte forma (baseada na definição de Elmasri \& Navathe [EN10]): uma relação é descrita por um esquema $R\left(A_{1}, A_{2}, \ldots, A_{n}\right)$, em que $R$ é o nome da relação e $A_{1}, A_{2}, \ldots, A_{n}$ são uma lista de atributos que a compõe. A relação descrita por esse esquema é denotada por $r(R)$, e é um conjunto de n-tuplas $r=\left\{t_{1}, t_{2}, \ldots, t_{m}\right\}$. Cada n-tupla é uma lista ordenada de $n$ valores $t=\left\langle v_{1}, v_{2}, \ldots, v_{n}\right\rangle$, em que cada valor $v_{i}, 1 \leq i \leq n$, é um elemento do domínio de $A_{i}$. O i-ésimo valor da tupla $t$ corresponde a um valor do atributo $A_{i}$, e pode ser representado por $t\left[A_{i}\right]$. Dado um lote $l$, cujas tuplas já foram validadas pelo sistema de DW, procura-se uma função de validação $V$ tal que:

$$
V(l)= \begin{cases}0, & \text { se algum erro for detectado em } l \\ 1, & \text { caso contrário }\end{cases}
$$

\subsection{Método de validação estatística utilizando detecção de ano- malias}

$\mathrm{Na}$ abordagem adotada por este trabalho, para detectar erros em um lote de dados e, por consequência, nos mecanismos que o geram, é preciso tomar decisões baseadas no perfil estatístico do lote, isto é, em algumas medidas estatísticas que tentam descrever o perfil dos dados contidos nele. Entretanto, como é possível saber, sem recorrer a um especialista no domínio, qual é o perfil esperado em um lote corretamente gerado? O que diferencia um lote correto (isto é, válido) de um lote incorreto (inválido)? Para responder a essas perguntas, utilizaremos os outros lotes já recebidos pelo sistema e que já foram classificados como válidos ou inválidos, realizando assim uma validação cruzada de dados (Seção 2.2.4).

Essa abordagem de modelar o perfil dos lotes por meio dos lotes já validados, isto é, fazer o computador aprender uma tarefa, melhorando o seu desempenho de classificar novos lotes conforme o acúmulo de dados na forma de lotes, caracteriza o cenário como um problema de aprendizado de máquina.

Existem três características importantes a respeito do problema de classificação dos lotes em válidos ou inválidos que irão afetar diretamente na solução adotada para resolvê-lo. São elas:

- Desbalanceamento entre tipos de lotes: em um sistema validador dessa natureza, é esperado que haja muito mais lotes válidos do que inválidos. Isso ocorre pois erros de extração não deveriam ser frequentes. Em um sistema em produção não é razoável esperar que no processo de extração de dados existam muito mais erros do que acertos. Dessa forma, lotes inválidos são eventos "raros";

- Importância dos lotes inválidos: apesar de raros, quando ocorrem, os lotes inválidos devem 
ser tratados com cautela, pois saber qual a origem do erro e corrigir o sistema extrator para evitar novos erros é uma medida de extrema importância;

- Heterogeneidade dos lotes inválidos: existem inúmeros problemas que podem ocorrer em um sistema extrator. Todos esses problemas podem ser refletidos nos dados de um lote das mais diferentes formas. Assim, não é possível caracterizar, de maneira bem definida, um lote inválido de acordo com o seu perfil. Geralmente, a sua classificação é feita pela não caracterização do lote na classe oposta, isto é, por não se enquadrar como um lote válido.

Os algoritmos de classificação supervisionada clássica partem do pressuposto de que existe um balanceamento entre as ocorrências das instâncias de todas as classes em questão, existindo instâncias suficientes de todas as classes para o correto aprendizado do algoritmo e supondo que todas as instâncias possuem importâncias equivalentes, independentemente de sua classe. Além disso, esses algoritmos supõem que instâncias futuras a serem classificadas serão similares àquelas fornecidas durante o treinamento. Pelas características do problema de classificação de lotes de dados apontados anteriormente, descarta-se, portanto, a classificação supervisionada clássica como solução adequada. Por essas mesmas características, constata-se que a classificação de lotes é melhor caracterizada como um problema de detecção de anomalias (Seção 2.3).

\subsubsection{Uso de detecção de anomalias para a validação de lotes}

Um validador estatístico de lotes de dados se propõe a utilizar o perfil estatístico de lotes previamente analisados para tomar uma decisão a respeito da validade de novos lotes. Entretanto, o perfil estatístico de um lote é um conceito bastante abrangente. Existem inúmeras medidas estatísticas que podem ser extraídas de um lote. Pode-se ter, por exemplo, medidas de contagem, médias, medianas, modas, medidas de dependência (como correlações e covariâncias), histogramas, etc. Para prosseguirmos com o trabalho, faz-se necessário, portanto, delimitar com quais medidas trabalharemos aqui. Nesta abordagem do problema, o perfil estatístico de um lote de dados será caracterizado pelas proporções no lote dos valores que os atributos de interesse podem assumir. Por atributos de interesse, entende-se "aqueles atributos que se quer validar utilizando o validador estatístico". Para alguns atributos, não faz sentido trabalhar com proporções de seus valores. É o caso dos atributos identificadores ou chaves. Para esses atributos, esse tipo de análise não é adequada, visto que cada entrada terá um valor exclusivo, que pode ser validado da maneira convencional. Não trataremos aqui também, de atributos cujos valores possíveis podem assumir um número muito grande de opções que não podem ser agrupadas em categorias ou intervalos numéricos. Dentre os atributos que podem ter seus valores contabilizados em proporções, é possível dividi-los em categóricos e numéricos.

Os atributos categóricos terão como medidas as proporções nos lotes das categorias que eles podem assumir. Assim, por exemplo, o atributo fator Rh sanguíneo, em um lote de doadores de sangue, terá como medidas as proporções no lote das categorias positivo, negativo e indeterminado, conforme exemplificado pela Tabela 5.2. É importante notar que, mesmo que uma categoria não ocorra em um lote específico, isso não quer dizer que ela não deva ser considerada como medida. Nesse caso, a categoria que não aparece em nenhuma instância do lote ganha uma proporção zerada nesse lote. No caso de atributos categóricos que aceitam muitas categorias 
distintas, se o especialista de domínio achar mais conveniente, é possível agrupá-las em algumas poucas características mais significativas para a análise.

\begin{tabular}{|r|r|}
\hline Fator Rh sanguíneo & Proporções no lote \\
\hline \hline Positivo & 0,46 \\
Negativo & 0,45 \\
Indeterminado & 0,09 \\
\hline
\end{tabular}

Tabela 5.2: Proporções em um lote exemplo das categorias do atributo fator Rh sanguíneo

Os atributos numéricos devem ser tratados de acordo com as características que apresentam. Se o atributo apresentar alguns poucos valores numéricos como possíveis, basta tratá-los como se fossem categorias, recaindo no caso de atributos categóricos. Entretanto, no caso de atributos com valores contínuos ou naqueles casos em que haja muitas possibilidades de valores distintos, é necessário fazer a categorização do atributo de acordo com o estabelecimento de intervalos, conforme exemplificado na Tabela 5.3, que categoriza o atributo faixa etária em um lote exemplo. É importante notar que a categorização deve ser feita por um especialista de domínio para que seja significativa. Atributos que armazenam datas também podem ser tratados da mesma forma que os outros atributos numéricos. Com a categorização de todos os tipos de atributos, é possível utilizar no restante do texto a palavra categoria para se referir aos valores que serão contabilizados nos lotes, independentemente do tipo de atributo considerado. No caso de agrupamento de categorias, os grupos definidos também serão considerados como novas categorias, substituindo as categorias agrupadas por eles.

\begin{tabular}{|c|r|}
\hline Faixa etária & Proporções no lote \\
\hline \hline idade $<18$ & 0,00 \\
$18 \leq i d a d e<28$ & 0,25 \\
$28 \leq i d a d e<38$ & 0,22 \\
$38 \leq i d a d e<48$ & 0,23 \\
$48 \leq i d a d e<58$ & 0,19 \\
$58 \leq i d a d e<68$ & 0,10 \\
$68 \leq i d a d e$ & 0,01 \\
\hline
\end{tabular}

Tabela 5.3: Proporções em um lote exemplo do atributo numérico faixa etária já categorizado.

Levar em conta somente as proporções das categorias dos atributos não resolve todos os problemas no sentido de capturar erros presentes nos lotes de dados. Entretanto, essa abordagem resolve problemas significativos e recorrentes em casos práticos existentes em sistemas de DW (caso do exemplo de erro possível apresentado na seção anterior - Tabela 5.1). É por esse motivo que tais medidas foram escolhidas para uma primeira abordagem desse problema no contexto de DW.

Considerando as proporções das categorias dos atributos de interesse, seria possível modelar a validação estatística de lotes de dados como um problema de detecção de anomalias em que cada lote daria origem a uma instância constituída por um vetor de características cujas dimensões seriam as proporções encontradas no lote em questão das categorias dos atributos de interesse. Entretanto, mesmo para lotes constituídos por poucos atributos, um problema relevante que surge 
é a alta dimensionalidade dos vetores de características resultante desse tipo de modelo. Para exemplificar esse problema, é possível imaginar pequenos lotes cuja estrutura é composta por um único arquivo, de doadores de sangue, que contém os seguintes atributos de interesse, com suas respectivas categorias possíveis:

- Tipo sanguíneo: $A, B, O, A B$, desconhecido;

- Gênero: $M$ (masculino), F (feminino), outros;

- Escolaridade: superior completo, superior incompleto, ensino médio completo, ensino médio incompleto, ensino fundamental completo, ensino fundamental incompleto, alfabetizado, analfabeto;

- Estado civil: casado, solteiro, divorciado, viúvo, outros.

Tal estrutura, mesmo que pequena para padrões de sistemas de DW, já resultaria em um problema de deteç̧ão de anomalias com entradas contendo 21 dimensões (uma dimensão para cada uma das proporções dos valores dos atributos descritos). A alta dimensionalidade resultante indica que possivelmente não seria uma boa ideia utilizar esse tipo de abordagem (um único detector de anomalias para validar integralmente os lotes), devido aos seguintes motivos:

- Quanto maior a dimensionalidade do problema de deteç̧ão de anomalias, maior o número de instâncias (lotes) de treinamento necessário para fazer com que o validador funcione de maneira apropriada. Muitas vezes, dependendo do tipo de lote de dados, não existem tantas instâncias assim, inviabilizando o método.

- No caso de o detector de anomalias indicar um lote anormal, não haverá uma resposta específica sobre qual atributo foi o responsável pelo comportamento anômalo. Essa informação, em se tratando de um validador de dados, é importante de ser obtida, pois será utilizada para corrigir o sistema que o gerou e tal correção só será possível se o erro estiver bem localizado.

Devido aos fatores apontados acima, decidimos dividir o problema de validação de lotes em diversos problemas de validação. Nessa abordagem, cada validador é responsável por validar apenas um atributo de interesse e está associado a um detector de anomalias. Desse modo, passa-se a ter vários problemas de deteç̧ão de anomalias para validar um único lote. Entretanto, cada problema agora tem entradas com um número de dimensões relativamente pequeno, pois são constituídas apenas pelas proporções das categorias possíveis do atributo que está sendo validado. Com isso, ganha-se as seguintes características:

- Redução da dimensionalidade dos problemas de detecção de anomalias existentes, o que resulta na necessidade de uma menor quantidade de instâncias (lotes) de treinamento para o funcionamento apropriado dos detectores.

- No caso de um detector de anomalias indicar um lote anormal, sabe-se exatamente qual foi o atributo responsável (ou os atributos responsáveis) pelo comportamento anômalo, possibilitando a correção do sistema extrator de lotes. 
Nesse cenário apresentado, ao validador global que recebe como entrada um lote, e fornece como saída a validade do lote apresentado, damos o nome de processo de validação. Aos validadores que validam individualmente os atributos dos lotes, damos o nome de validadores individuais. No restante do texto, ao utilizarmos a palavra validador sem maiores explicações, estamos nos referindo a validadores individuais.

Os validadores individuais, diferentemente do processo de validação, não necessitam receber como entrada o lote original para fazer a validação de um único atributo de interesse. Para eles, é suficiente receber uma versão reduzida do lote, chamada de lote reduzido. Um lote reduzido está associado a um validador e é constituído somente dos elementos do lote original que são necessários e suficientes para o funcionamento do validador em questão. Por "elementos", entende-se atributos e tuplas. Nesse cenário apresentado, um lote reduzido associado a um validador conterá somente o atributo a ser validado e os atributos que constituem a chave da entidade ou relacionamento ao qual o atributo pertence. Todas as tuplas do lote original serão repassadas ao lote reduzido. Assim, se um validador se propõe a validar o tipo sanguíneo de doadores, seu lote reduzido associado será constituído apenas pelos atributos identificador do doador e tipo sanguíneo do doador. Além disso, no caso do atributo de interesse ter seus valores agrupados ou categorizados, o lote reduzido já deve conter a tradução para as novas categorias.

Um validador individual deve, portanto, receber como entrada um lote reduzido e produzir como saída se o lote reduzido é válido ou inválido. Para tanto, cada validador possui uma instância de um detector de anomalias, que pode ser utilizada quando necessário. Um validador, ao utilizar um detector de anomalias para classificar um lote reduzido, fornece a ele uma instância (vetor de características) composta pelas proporções das categorias do atributo que ele valida, em uma ordem predeterminada e recebe, como resposta, se a instância fornecida é normal ou anômala. Se a instância for normal, o validador conclui que o lote reduzido é válido. Caso contrário, conclui-se que é inválido. Existem casos em que o validador individual não necessita usar o detector de anomalias para classificar o lote reduzido, por exemplo, se o lote reduzido já existe no sistema e foi avaliado por um especialista. Em outros casos, o validador individual não pode usar o detector de anomalias, por ele não estar apto a fazer validações. Tais casos são tratados com mais detalhes na Seção 5.3.

Supondo que para validar $n$ atributos de interesse em um lote $l$ de dados sejam utilizados $n$ validadores individuais $v_{1}, v_{2}, \ldots, v_{n}$, com seus respectivos lotes reduzidos $l_{1}, l_{2}, \ldots, l_{n}$, sendo que $v_{i}\left(l_{i}\right)=1$ se $l_{i}$ for um lote reduzido válido e $v_{i}\left(l_{i}\right)=0$ se $l_{i}$ for um lote reduzido inválido, é possível definir o processo de validação $V$ como:

$$
V(l)=v_{1}\left(l_{1}\right) \wedge v_{2}\left(l_{2}\right) \wedge \ldots \wedge v_{n}\left(l_{n}\right)
$$

Dessa forma, o processo de validação de um lote de dados passa a ser o resultado da conjunção lógica de validadores individuais aplicados aos seus respectivos lotes reduzidos. Assim, $V$ será válido para a entrada $l$ se e somente se todos os lotes reduzidos $l_{i}$ forem válidos. $V$ será inválido se pelo menos um dos lotes reduzidos for inválido.

Foi visto anteriormente que cada validador individual possui um detector de anomalias associado. Se o validador $v$ se propõe a validar um atributo que pode assumir $n$ categorias distintas, as instâncias fornecidas ao detector terão sempre a forma de um vetor de caracterís- 
ticas $n$-dimensional. Por exemplo: seja $v$ um validador individual do atributo tipo sanguíneo. Esse atributo pode assumir as seguintes categorias: $A, B, A B, O$ e desconhecido. O detector de anomalias receberá, portanto, instâncias compostas de vetores 5-dimensionais, na forma $\langle p(A), p(B), p(A B), p(O), p($ desconhecido $)\rangle$, em que $p(x)$ corresponde à proporção da ocorrência da categoria $x$ dentro do lote reduzido.

A princípio, um detector de anomalias para classificar tais instâncias deveria considerar em seu funcionamento todas as características presentes nos vetores que recebe. Entretanto, analisando melhor a situação apresentada, percebe-se que não são necessárias todas as características para que a correta classificação seja efetuada pelo detector. Isso acontece pois, em se tratando de proporções de ocorrências de categorias, tem-se que uma das características pode ser deduzida em função das outras (pois a soma das proporções de todas as categorias deve ser igual a 1). Portanto, conclui-se que, se um detector de anomalias recebe instâncias $n$-dimensionais de um validador individual, internamente ele pode escolher apenas $n-1$ categorias para efetuar sua tarefa de classificar instâncias. Logo, no exemplo apresentado acima, apesar de receber instâncias 5-dimensionais, o detector pode trabalhar internamente com apenas 4 dessas características.

Um exemplo de funcionamento de uma validação de lote utilizando um processo de validação conforme descrito nos parágrafos anteriores é ilustrado de maneira simplificada na Figura 5.1.

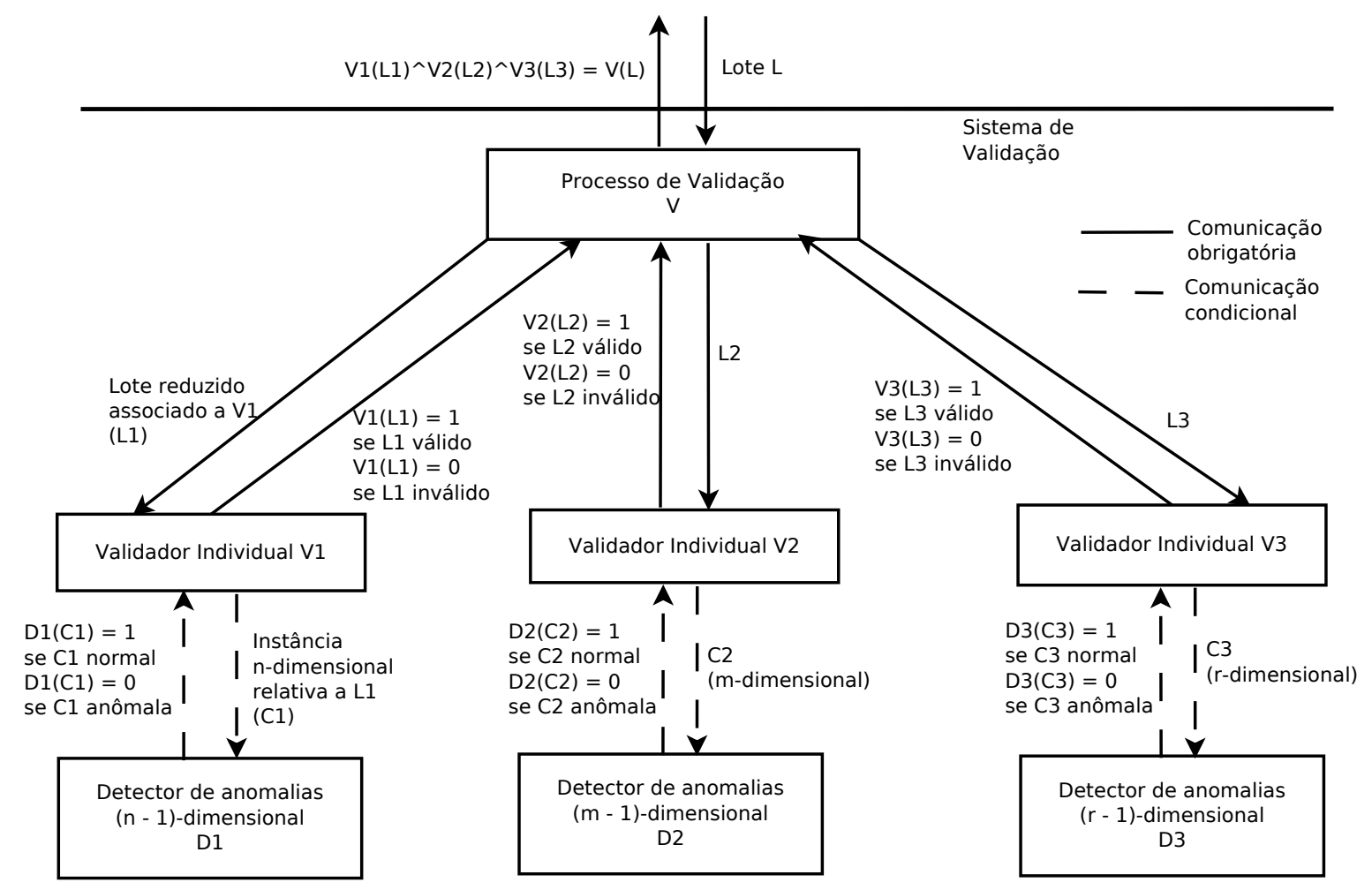

Figura 5.1: Exemplo de validação de lote utilizando detectores de anomalias (simplificado).

\section{Validações contextuais}

O método de validação estatística visto até aqui considera que, para validar um lote de dados, seus atributos são validados separadamente. Cada validador individual é responsável pela validação de um único atributo de interesse. Para cada atributo de interesse, existe um validador. 
Cada um dos validadores está associado a um detector de anomalias. Entretanto, nota-se que adotando esse método, possíveis dependências entre atributos que podem existir no interior dos lotes não são consideradas. Não considerá-las pode fazer com que o sistema de validação não seja capaz de reconhecer alguns tipos de inconsistências que podem surgir devido a sistemas extratores problemáticos.

Dado que este trabalho é uma primeira abordagem à validação estatística de dados, não está previsto em seu escopo fazer validação de dados considerando a dependência entre atributos dos lotes, visto que esse problema por si só é complexo e requer o estudo de outras técnicas sofisticadas. Entretanto, com algumas modificações no método proposto, é possível tratar casos simples de dependência entre atributos, em que a proporção das categorias de certo atributo a ser validado depende de um contexto ${ }^{1}$, e esse contexto é determinado pelo valor assumido por outros atributos. Seguem dois exemplos que ilustram casos de dependência envolvendo contexto.

1. Validação de sexo por hemocentro: um DW recebe lotes mensais de doadores de sangue de hemocentros distintos. Dependendo do hemocentro considerado, nota-se uma variação do perfil dos doadores com relação ao sexo. Por exemplo, em lotes provenientes de São Paulo, existe um equilíbrio da quantidade de homens e mulheres entre os doadores. Já em lotes de Pernambuco, percebe-se a predominância de homens (por volta de $80 \%$ dos doadores mensais) entre os doadores. É possível notar, portanto, que as proporções dos valores do atributo a ser validado (sexo) depende do valor de outro atributo (hemocentro).

2. Escolaridade por sexo: um DW recebe lotes mensais de doadores de sangue. É de conhecimento do especialista que o perfil do nível de escolaridade dos doadores do sexo masculino é significativamente diferente do nível de escolaridade dos doadores do sexo feminino. Nesse caso, as proporções dos valores do atributo escolaridade (que se quer validar) depende dos valores do atributo sexo.

Ao atributo alvo da validação, isto é, aquele que será validado, demos o nome de atributo comportamental. Aos atributos que fornecem o contexto para a validação, dá-se o nome de atributo contextual. Neste trabalho, os atributos contextuais devem, assim como os comportamentais, ser categóricos ou então categorizados por especialistas de domínio.

Para resolver os casos de dependência contextual, o método anteriormente apresentado foi alterado para incorporar esses comportamentos. Novamente, ao validador global que recebe como entrada um lote, e fornece como saída a validade do lote apresentado, damos o nome de processo de validação. Os validadores individuais do método anterior darão origem a dois tipos de validadores: validadores lógicos e validadores físicos ${ }^{2}$. Os validadores lógicos são aqueles responsáveis por validar um atributo de interesse levando em conta a possível existência de contextos. Para especificar um validador lógico, é necessário informar qual o seu atributo comportamental (com suas respectivas

\footnotetext{
${ }^{1}$ Neste trabalho, um contexto é determinado simplesmente observando-se os valores assumidos por alguns atributos predeterminados. Essa noção de contexto já é utilizada na teoria de deteç̧ão de anomalias [CBK09]. Considerar informações contextuais na resolução de problemas vem ganhando visibilidade não somente na área de deteç̧ão de anomalias [SWJR07, JWK09, AK12], como também na computação em geral [LH03, VBST08, $\left.\operatorname{VTS}_{11}, \mathrm{CLR}^{+} 14\right]$.

"Os nomes "lógico" e "físico" foram atribuídos aos validadores para fazer uma analogia com os modelos lógico e físico de BDs [EN10]. Da mesma maneira que um modelo físico é uma visão mais próxima da implementação de um modelo lógico, validadores físicos representam uma maneira de implementar validadores lógicos.
} 
categorias a serem consideradas) e quais são os atributos contextuais que influenciam na validação (também com as suas categorias a serem consideradas). Esses validadores não estão associados a detectores de anomalias como no método anteriormente apresentado. Eles existem para fornecer ao processo de validação uma camada de abstração. Cada atributo de interesse será validado por um único validador lógico.

Os validadores lógicos recebem lotes reduzidos. É importante notar que um lote reduzido associado a um validador lógico deve conter além do atributo comportamental e dos atributos que constituem a chave da entidade ou relacionamento ao qual o atributo comportamental pertence, os atributos contextuais caso eles existam. Assim, se um validador lógico se propõe a validar o sexo do doador dependendo do hemocentro, seu lote reduzido associado será constituído pelos atributos identificador do doador, sexo e hemocentro, e conterá todas as tuplas do lote original. No caso de algum de seus atributos ter seus valores agrupados ou categorizados, o lote reduzido já deve conter a tradução para as novas categorias em vez dos valores originais. Como saída, os validadores lógicos produzem a resposta se o lote reduzido associado a eles é válido ou inválido.

Supondo que para validar $n$ atributos de interesse em um lote $l$ de dados sejam utilizados $n$ validadores lógicos $v_{1}, v_{2}, \ldots, v_{n}$, com seus respectivos lotes reduzidos $l_{1}, l_{2}, \ldots, l_{n}$, sendo que $v_{i}\left(l_{i}\right)=1$ se $l_{i}$ for um lote reduzido válido e $v_{i}\left(l_{i}\right)=0$ se $l_{i}$ for um lote reduzido inválido, é possível definir o processo de validação $V$ como:

$$
V(l)=v_{1}\left(l_{1}\right) \wedge v_{2}\left(l_{2}\right) \wedge \ldots \wedge v_{n}\left(l_{n}\right)
$$

Dessa forma, o processo de validação de um lote de dados passa a ser o resultado da conjunção lógica de validadores lógicos aplicados aos seus respectivos lotes reduzidos. Assim, $V$ será válido para a entrada $l$ se e somente se todos os lotes reduzidos $l_{i}$ forem válidos. $V$ será inválido se pelo menos um dos lotes reduzidos for inválido.

Resta saber, agora, como um validador lógico decide se seu lote reduzido associado é válido ou inválido. Para isso, é necessário introduzir o conceito de validador físico. Validador físico é responsável por validar um atributo de interesse para um contexto determinado. Cada validador físico funciona exatamente da mesma maneira que os validadores individuais do método anterior, possuindo um detector de anomalias associado, que pode ser acionado caso seja necessário (mais detalhes na Seção 5.3.3). Um validador lógico cria um ou mais validadores físicos, dependendo da quantidade de contextos que precisa considerar. Seguem exemplos para facilitar o entendimento:

- Se, na especificação de um validador lógico foi informado que seu atributo comportamental é sexo e seu atributo contextual hemocentro, e o atributo hemocentro pode assumir três valores: 1 - São Paulo, 2 - Pernambuco e 3 - Minas Gerais, serão criados três validadores físicos, pois existem três contextos possíveis.

- Se, na especificação de um validador lógico foi informado que seu atributo comportamental é escolaridade do doador e seus atributos contextuais são sexo, que pode ser masculino ou feminino e hemocentro, com as mesmas categorias do exemplo anterior, serão criados seis validadores físicos, um para cada combinação possível de valores dos atributos contextuais. Cada combinação é um contexto.

Seja $v_{i}$ um validador lógico e $l_{i}$ seu lote reduzido associado. São criados $r$ validadores físicos 
$v_{i 1}, v_{i 2}, \ldots, v_{i r}$ associados a $v_{i}$, um para cada contexto (um para cada combinação possível de categorias dos atributos contextuais de $v_{i}$ ). Para alimentá-los, $r$ lotes reduzidos serão produzidos pelo validador lógico, um para cada validador físico criado. Para cada $j$, tal que $1 \leq j \leq r$, o lote reduzido $l_{i j}$ será produzido retirando-se os atributos contextuais presentes em $l_{i}$ e trazendo para $l_{i j}$ somente as tuplas de $l_{i}$ cujo contexto é aquele validado por $v_{i j}$. Caso não existam tuplas de determinado contexto dentro de $l_{i}$, é esperado que um lote vazio seja gerado para esse contexto. Então, tem-se que $v_{i}\left(l_{i}\right)=v_{i 1}\left(l_{i 1}\right) \wedge v_{i 2}\left(l_{i 2}\right) \wedge \ldots \wedge v_{i r}\left(l_{i r}\right)$. Se $l_{i j}$ for vazio para algum $j$, então $v_{i j}\left(l_{i j}\right)=1$, pois não há o que ser validado para o determinado contexto.

A validação não contextual pode ser tratada da mesma maneira, pois pode ser considerada como um subcaso do que foi apresentado acima quando existe somente um contexto. Dessa maneira, na implementação do sistema de validação, a validação contextual é utilizada.

Um exemplo de funcionamento de uma validação de lote utilizando um processo de validação considerando a existência de contextos, conforme descrito nos parágrafos anteriores, é ilustrado de maneira simplificada na Figura 5.2.

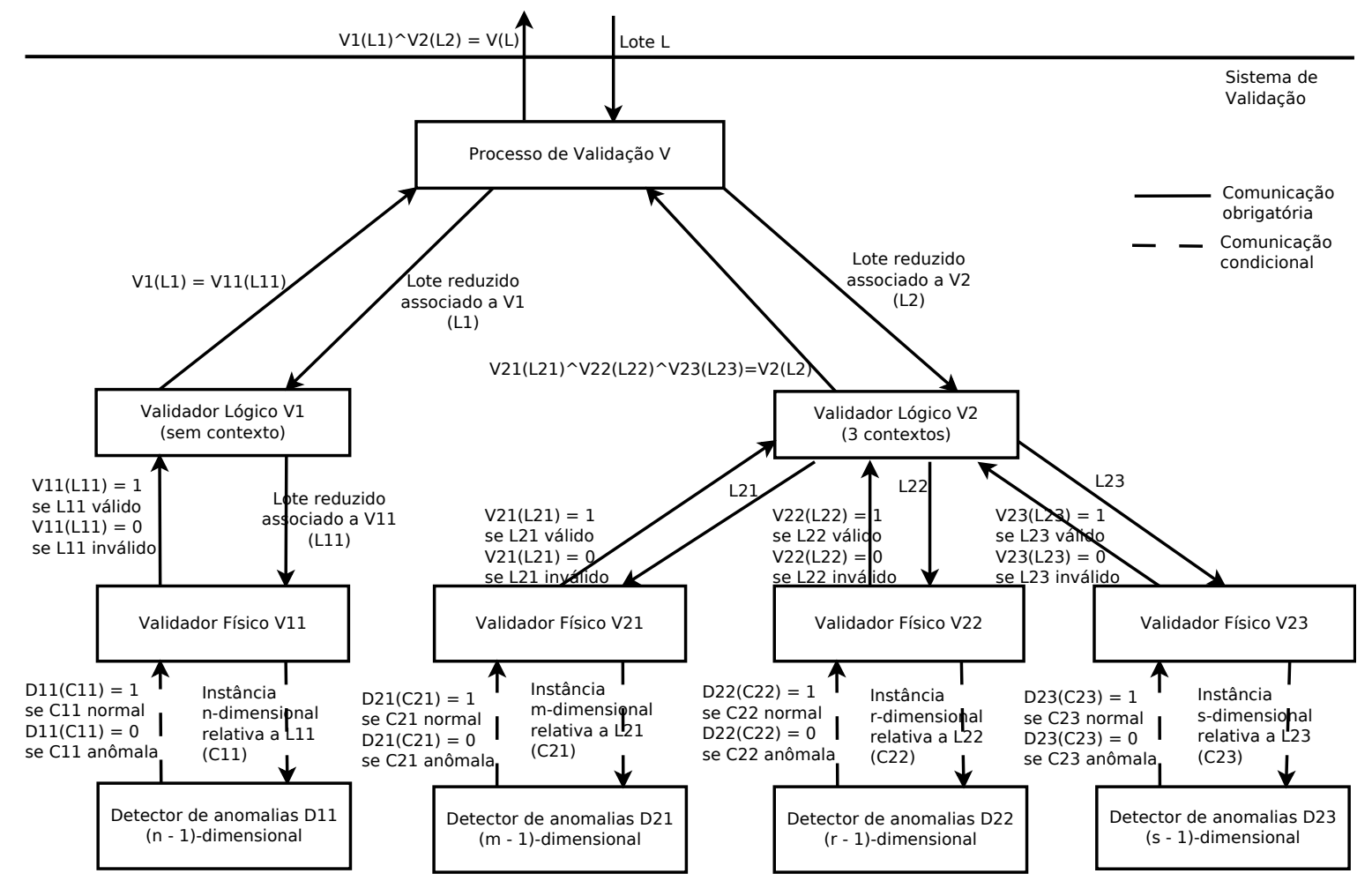

Figura 5.2: Exemplo de validação de lote utilizando detectores de anomalias considerando contextos (simplificado).

É possível perceber, pelo tipo de solução empregada, que esse método só é factível quando existem poucos atributos contextuais por validador lógico e quando esses atributos possuem poucas categorias possíveis. Caso contrário, ocorrerá uma explosão do número de validadores físicos necessários para implementar os diferentes contextos possíveis e o problema se torna impraticável devido ao custo computacional extremamente alto envolvido para treinar um número muito grande de detectores de anomalias. 


\subsection{Implementação do sistema de validação}

Na seção anterior foi descrito como é possível abordar o problema de validação estatística de lotes de dados utilizando detectores de anomalias. Nesta seção apresentamos os principais pontos para o entendimento de como implementar um sistema que utiliza os conceitos e o método anteriormente descrito (considerando contextos) para validar lotes de dados. Tal sistema viabiliza a concretização das ideias apresentadas anteriormente em uma solução de validação que pode se integrar a sistemas de DW preexistentes e em plena execução ou participar da implantação de novos.

Existem duas maneiras de interagir com o sistema de validação: por meio de uma interface web, pela qual é possível criar, configurar e manter os processos de validação, treiná-los com lotes preexistentes e fazer validações pontuais de lotes; e por meio de uma API (Interface de Programação de Aplicações), cuja finalidade é a integração com sistemas de DW, que, após a criação e treinamento dos processos de validação, utilizarão o validador de maneira automática, sem a necessidade de intervenções humanas constantes para realizar a validação dos dados. O núcleo do sistema é responsável por conter os algoritmos de detecção de anomalias, permitindo a adição de novos detectores, em forma de módulos, à medida que for necessário implementá-los.

\subsubsection{Criação e configuração dos processos de validação}

Para utilizar o sistema de validação, existem alguns passos que precisam ser seguidos para adequá-lo à realidade dos sistemas de DW que o utilizarão e aos lotes de dados já existentes. O primeiro desses passos é criar e configurar processos de validação pelos quais os lotes passarão para determinar se os seus dados estão aptos a serem integrados no DW. A criação e a configuração dos processos de validação podem ser feitos por meio das telas encontradas na aba Configuração (Setup), presente na interface web. Pela tela de gerenciamento de processos de validação (Figura 5.3), é possível criar novos processos, editá-los e apagá-los conforme necessário.

Para especificar um processo de validação (Figura 5.4), é necessário dar-lhe um nome, pelo qual será identificado no restante do sistema, descrever qual é a estrutura dos lotes que serão validados por ele e adicionar, um a um, os validadores lógicos que o compõem.

Um lote de dados é fornecido ao sistema por meio de um arquivo compactado, em formato zip [zip], cujo nome (sem a terminação) poderá ser usado para identificar o lote na fase de treinamento ou validação. Esse arquivo não pode conter diretórios na sua estrutura. A especificação de uma estrutura de lotes pode ser feita por meio da sua tela de criação e edição (Figura 5.5), e basicamente tem a finalidade de dizer ao sistema quais são os arquivos que o lote conterá, quais são as particularidades desses arquivos com relação à forma e que tipos de dados eles contêm. Uma estrutura de lotes deve ser criada anteriormente à criação de algum processo de validação que a utilizará e pode ser usada, inclusive, por mais de um processo. O gerenciamento das estruturas é realizado por meio do gerenciador de estruturas de lotes (Figura 5.6).

Para criar uma estrutura de lotes, é necessário nomeá-la e adicionar quais serão os arquivos que conterão os dados. Cada arquivo que compõe o lote será nomeado e esse nome será fixo em todos os lotes. Como cada arquivo representa uma tabela no modelo relacional, o nome dessa tabela deve ser informado. Seus campos constituintes devem ser então fornecidos (nomes e 


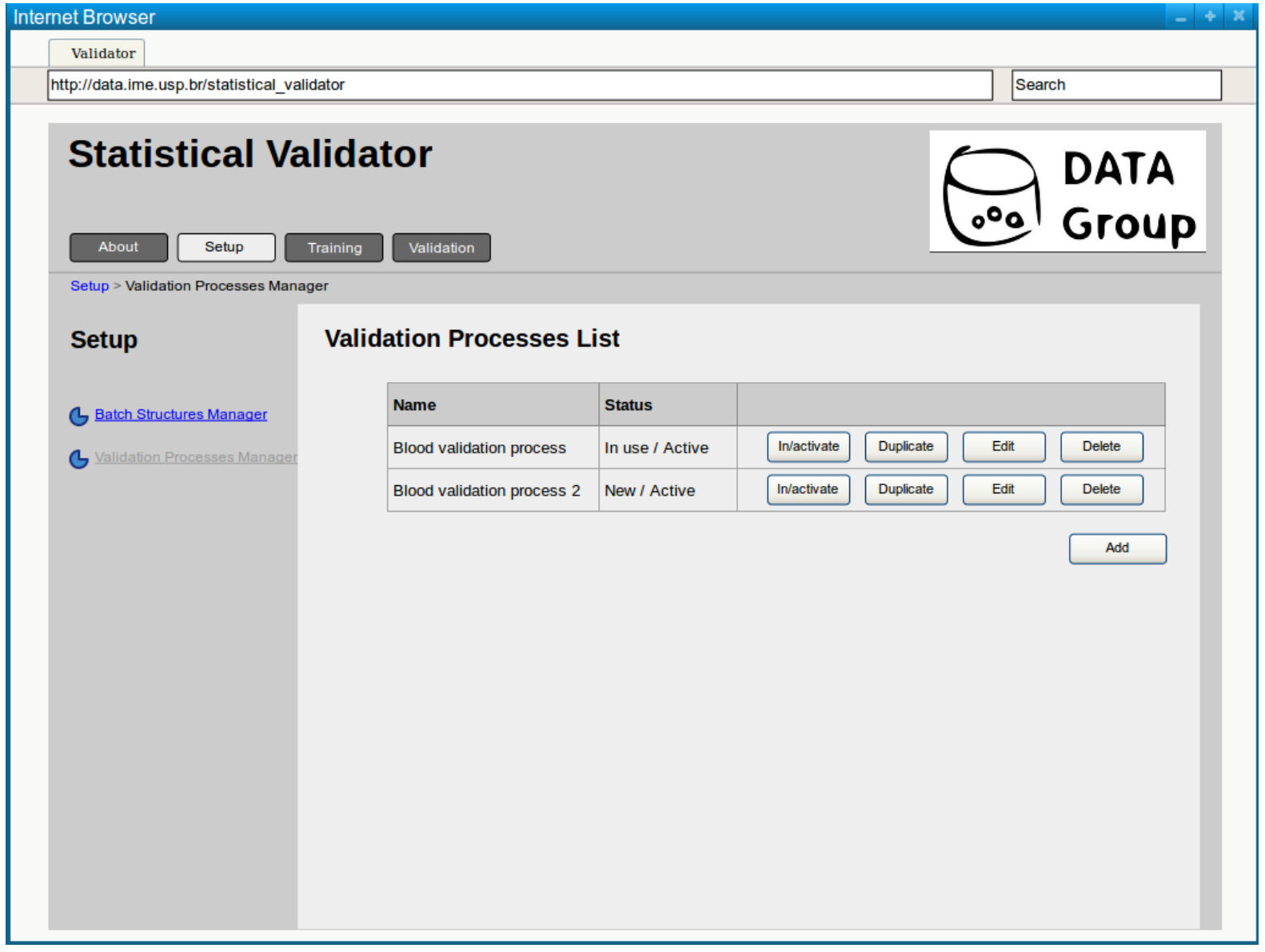

Figura 5.3: Sistema de validação: protótipo da tela de gerenciamento de processos de validação.

tipos) na ordem correta em que aparecem no arquivo. Devem ser informados também qual será o caractere utilizado para separar os campos no interior do arquivo, a codificação de caracteres utilizada dentro dele, o caractere delimitador de campo, quando houver, e se a primeira linha do arquivo corresponde a um cabeçalho com os nomes dos campos. A configuração da estrutura de cada arquivo do lote pode ser feita por meio da tela de criação e edição de estrutura de arquivo (Figura 5.7).

Uma vez que uma estrutura de lotes é criada, ela só poderá ser editada ou apagada se não estiver em uso, isto é, se não estiver sendo utilizada em algum processo de validação. Sempre é possível duplicar uma estrutura de lotes. Sua duplicata, enquanto não estiver sendo usada, poderá ser editada e apagada livremente.

Depois de criada a estrutura de lotes, resta criar os diversos validadores lógicos que comporão o processo. Para criar um validador lógico, utiliza-se a tela de criação de validadores (Figura 5.8), fornecendo as seguintes informações necessárias:

- Consulta SQL do lote reduzido: o lote reduzido associado ao validador lógico é definido por meio de uma consulta SQL que será executada sobre o lote original. Dessa maneira, a consulta deve respeitar a estrutura do lote original, conforme foi especificada em fase anterior da criação do processo de validação. Essa consulta deve resultar em uma tabela que contém todos os atributos necessários e suficientes para a validação pretendida. Deve conter, portanto, a chave da entidade (ou relacionamento) que identifica o atributo comportamental, 


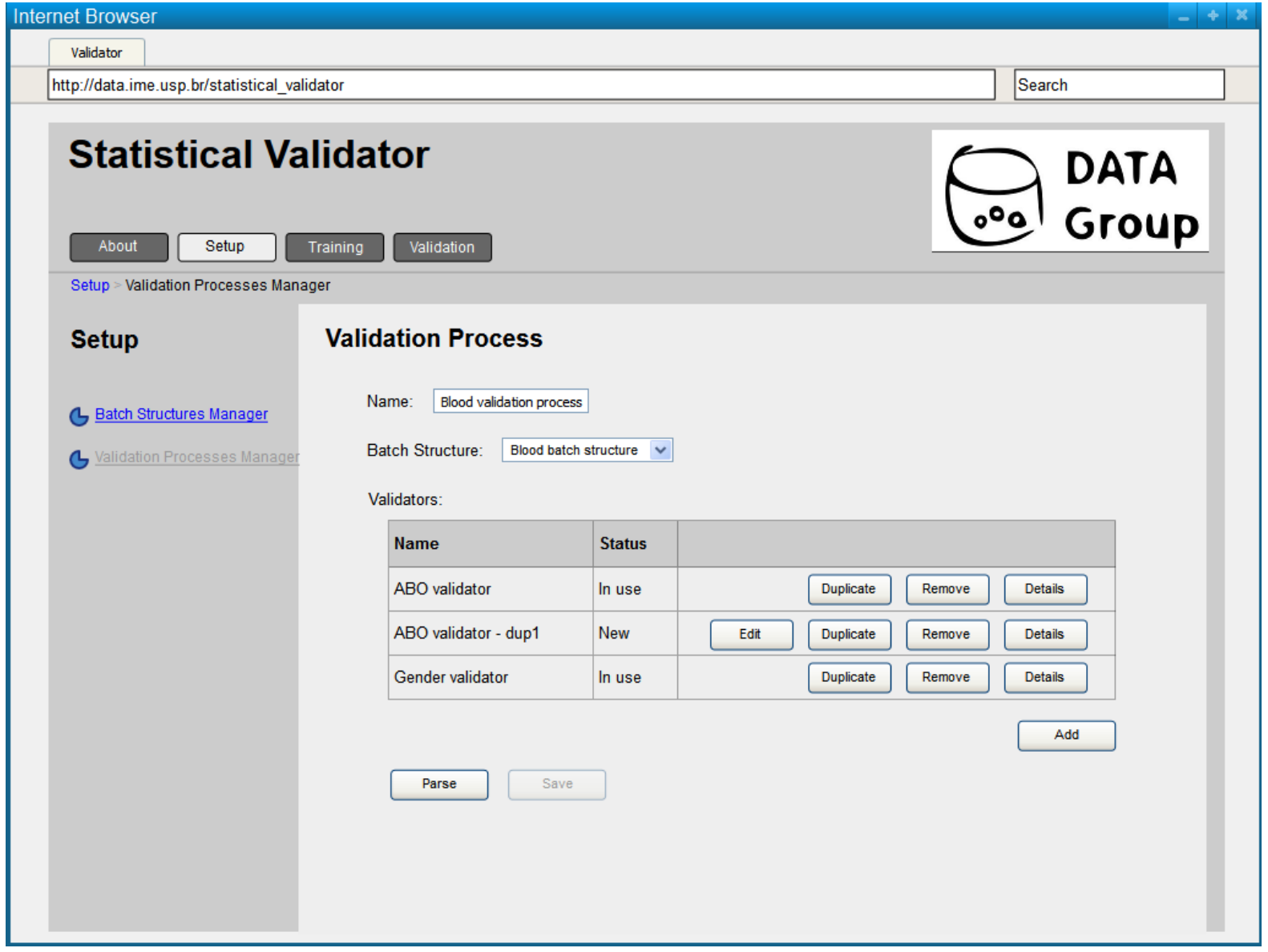

Figura 5.4: Sistema de validação: protótipo da tela de criação e edição de processos de validação.

o atributo comportamental, e atributos contextuais necessários. Vale lembrar que os atributos resultantes dessa consulta devem ser subconjunto dos atributos do lote original, cujos tipos de dados já foram informados na fase de definição da estrutura do lote.

- Chave primária: depois que o lote reduzido foi definido, é necessário informar ao sistema quais dos seus campos constituem a chave primária que identifica o atributo comportamental.

- Atributo comportamental: informa ao sistema qual dos atributos do lote reduzido é o atributo que será validado.

- Valores, intervalos e grupos: para o correto funcionamento do validador, é necessário informar a ele quais são os valores possíveis (intervalos, no caso de variáveis não categóricas) que o atributo comportamental pode apresentar. Esses valores não podem ser inferidos por meio dos lotes, pois nem sempre os lotes contêm todos os valores que precisam ser considerados. As categorias poderão também ser reunidas por meio da definição de grupos.

- Atributos contextuais: informa ao sistema quais são os atributos do lote reduzido que indicam os contextos da validação. Assim como no atributo comportamental, seus valores ou intervalos precisam ser informados e grupos podem ser definidos. Isso pode ser feito por meio da tela de criação de atributos contextuais (Figura 5.9).

- Algoritmos de detecção de anomalias: É possível informar ao sistema quais algoritmos de 


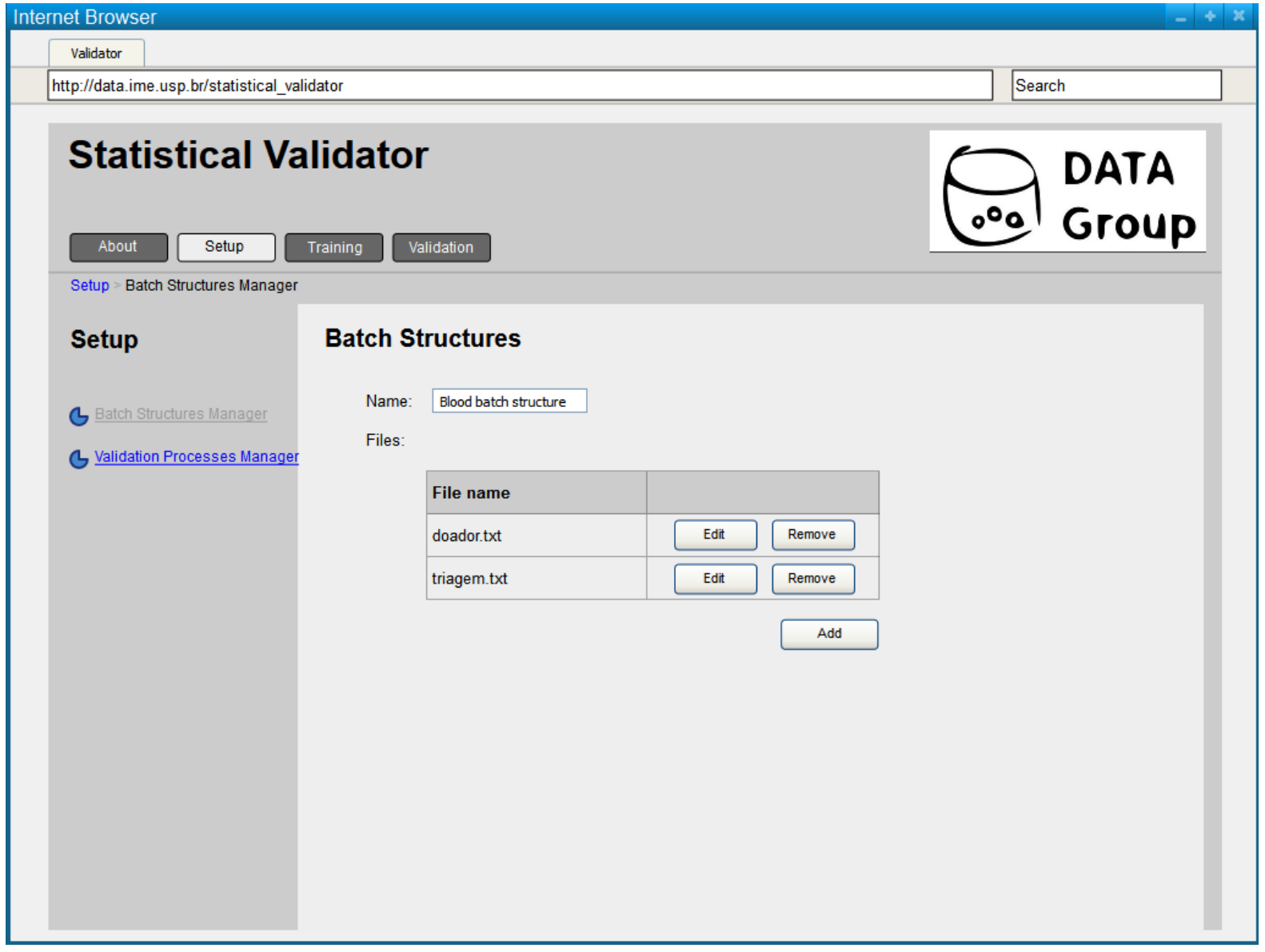

Figura 5.5: Sistema de validação: protótipo da tela de criação e edição de estrutura de lotes.

deteç̧ão de anomalias serão utilizados nos validadores físicos criados a partir da especificação do validador lógico. Para tanto, especifica-se um algoritmo de detecção padrão e, caso haja atributos contextuais, é possível também especificar casos excepcionais, adicionando algoritmos diferentes para contextos específicos se for necessário. Se não houver atributos contextuais, o algoritmo padrão será usado para criar o único validador físico associado a ele. Além de especificar os algoritmos, é possível também, para cada um deles, informar sua periodicidade de treinamento e parâmetros adicionais necessário (maiores detalhes na Seção 5.3.4).

Antes de finalizar a criação de um processo de validação, é necessário, pela tela de criação do processo de validação, verificar se existe alguma inconsistência entre a estrutura do lote associada ao processo e os validadores criados. A opção de salvar as alterações feitas no processo de validação somente será habilitada se não houver qualquer tipo de inconsistência detectada.

Criado um processo de validação já é possível utilizá-lo, treinando-o e, posteriormente, usandoo para validar novos lotes. Enquanto um processo não for utilizado, isto é, não receber nenhum lote de dados, quer seja para treinamento ou validação, ele é considerado como um processo novo. Enquanto ele permanecer nesse estado, é possível modificá-lo com bastante liberdade. Seu nome pode ser modificado, a estrutura de lotes associada a ele pode ser trocada por outra e seus validadores lógicos podem ser criados, apagados ou até mesmo alterados. Para salvar as alterações realizadas, basta que não haja inconsistências entre os validadores e a estrutura do lote. 


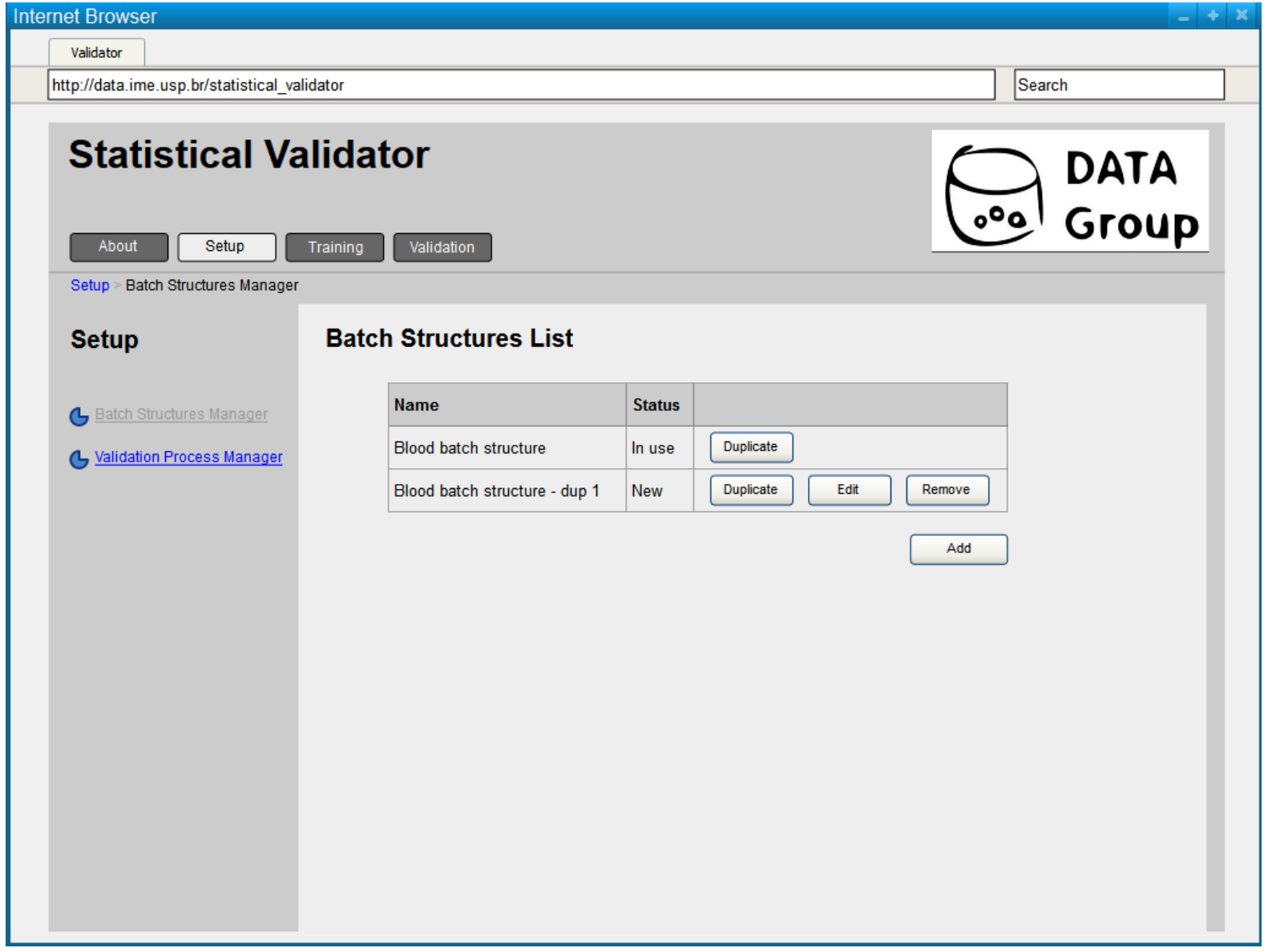

Figura 5.6: Sistema de validação: protótipo da tela de gerenciamento de estruturas de lotes.

Entretanto, ao utilizar um processo de validação, ele deve seguir algumas restrições com relação às modificações que pode sofrer. Seus validadores já não podem ser alterados. Entretanto, novos validadores podem ser criados e os já existentes, apagados. Ao apagar um validador existente, perde-se todas as informações de treinamento que possivelmente estejam associadas aos seus validadores físicos. Essa informação não poderá ser mais recuperada, mesmo que seja criado um novo validador idêntico ao original. Ao criar um novo validador, não haverá associado aos seus validadores físicos qualquer lote reduzido, pois os lotes já inseridos no sistema não serão utilizados para treinamento de novos validadores. Enquanto um validador lógico não for utilizado, poderá ser modificado. Ao receber seu primeiro lote reduzido, ele perde a sua capacidade de ser editado. Com relação à estrutura de lotes associada, é possível efetuar a troca de estrutura desde que ela não altere as validações existentes no processo. Essa verificação é feita antes que seja possível salvar qualquer alteração no processo.

Apesar de ser possível simplesmente alterar um processo de validação que esteja em uso, em sistemas de DW essa prática não é recomendada. Como sistemas de DW estão em constante evolução, é comum trabalhar ao mesmo tempo com mais de uma estrutura de lotes. Além disso, costuma-se manter também, para uma mesma estrutura de lotes, mais de um processo de validação (muitas vezes observa-se um aumento do número de validações com o passar do tempo, para que haja um aumento progressivo da qualidade dos dados presentes no DW). Por esses motivos, o sistema permite a criação de novas versões de processos de validação a partir de processos já 


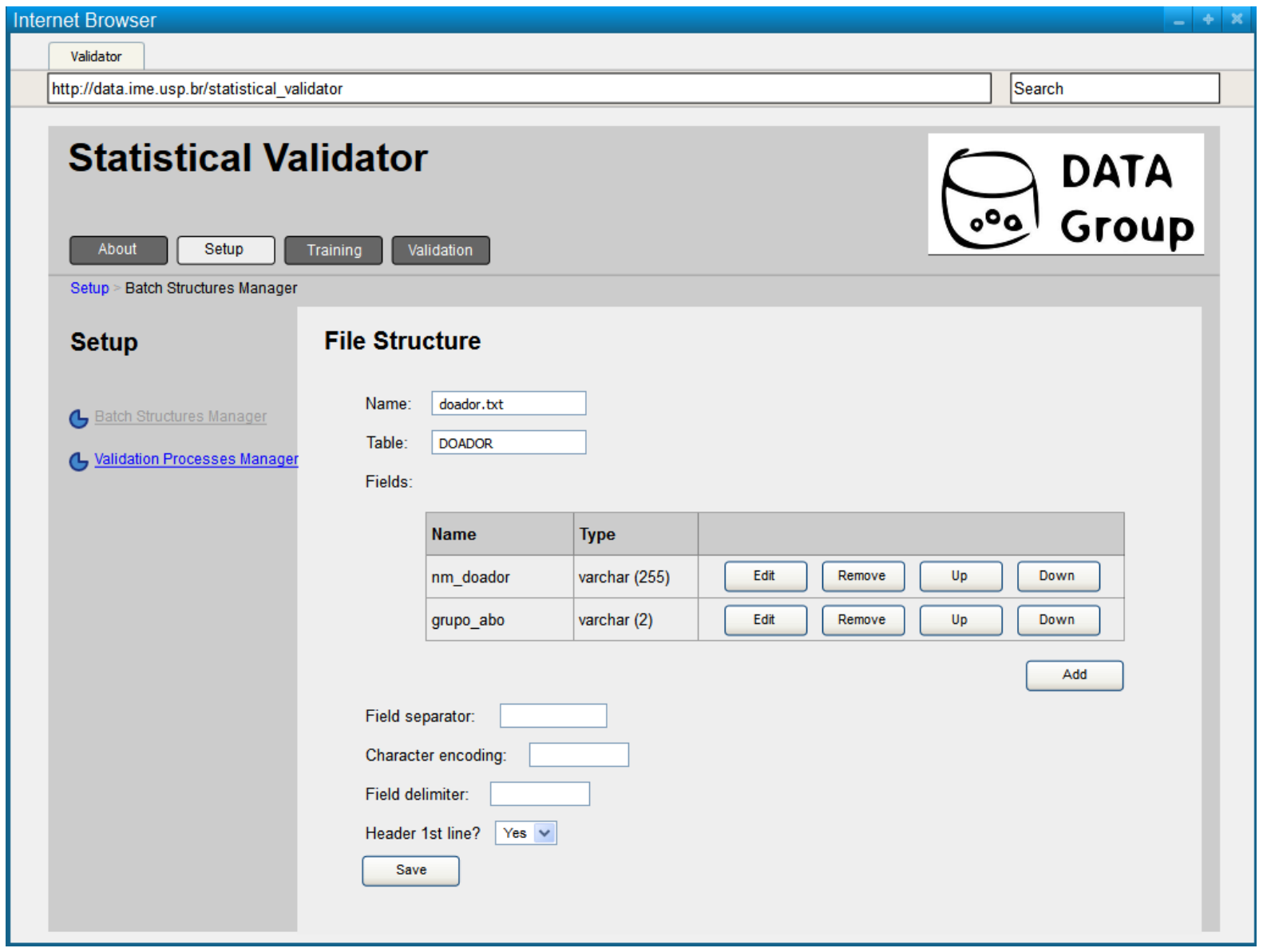

Figura 5.7: Sistema de validação: protótipo da tela de criação e edição de estrutura de arquivo presente no lote.

existentes. Ao criar uma nova versão, obtém-se um novo processo de validação que utiliza a mesma estrutura de lotes e os mesmos validadores do anterior, herdando também os dados de treinamento do processo original. Apesar disso, não há qualquer tipo de vínculo entre o processo original e a sua cópia, pois internamente seus dados e as estruturas que os armazenam são completamente separados após a duplicação. Dessa maneira, é possível fazer alterações na nova versão do processo sem perder a possibilidade de continuar submetendo lotes que obedecem ao processo anterior. É bom lembrar que, se o processo a ser duplicado estiver em uso, o processo gerado a partir dele sofrerá as mesmas restrições do primeiro, pois ambos os processos já estão populados com dados de treinamento.

\subsubsection{Treinamento dos validadores}

Após a criação dos processos de validação necessários, a próxima etapa a ser cumprida é o treinamento dos detectores de anomalias associados aos seus validadores físicos. Esse treinamento, em geral, é constituído de duas fases distintas: uma fase inicial e uma fase de aperfeiçoamento. A fase inicial se baseia na inserção de lotes de treinamento no sistema. Dá-se o nome de lote de treinamento ao lote inserido somente com a finalidade de treinar os detectores de anomalias. Esse tipo de lote não será validado. Essa fase é necessária para habilitar os detectores de anomalias a classificar novos lotes. A fase de aperfeiçoamento se dá ao longo da utilização do sistema, 


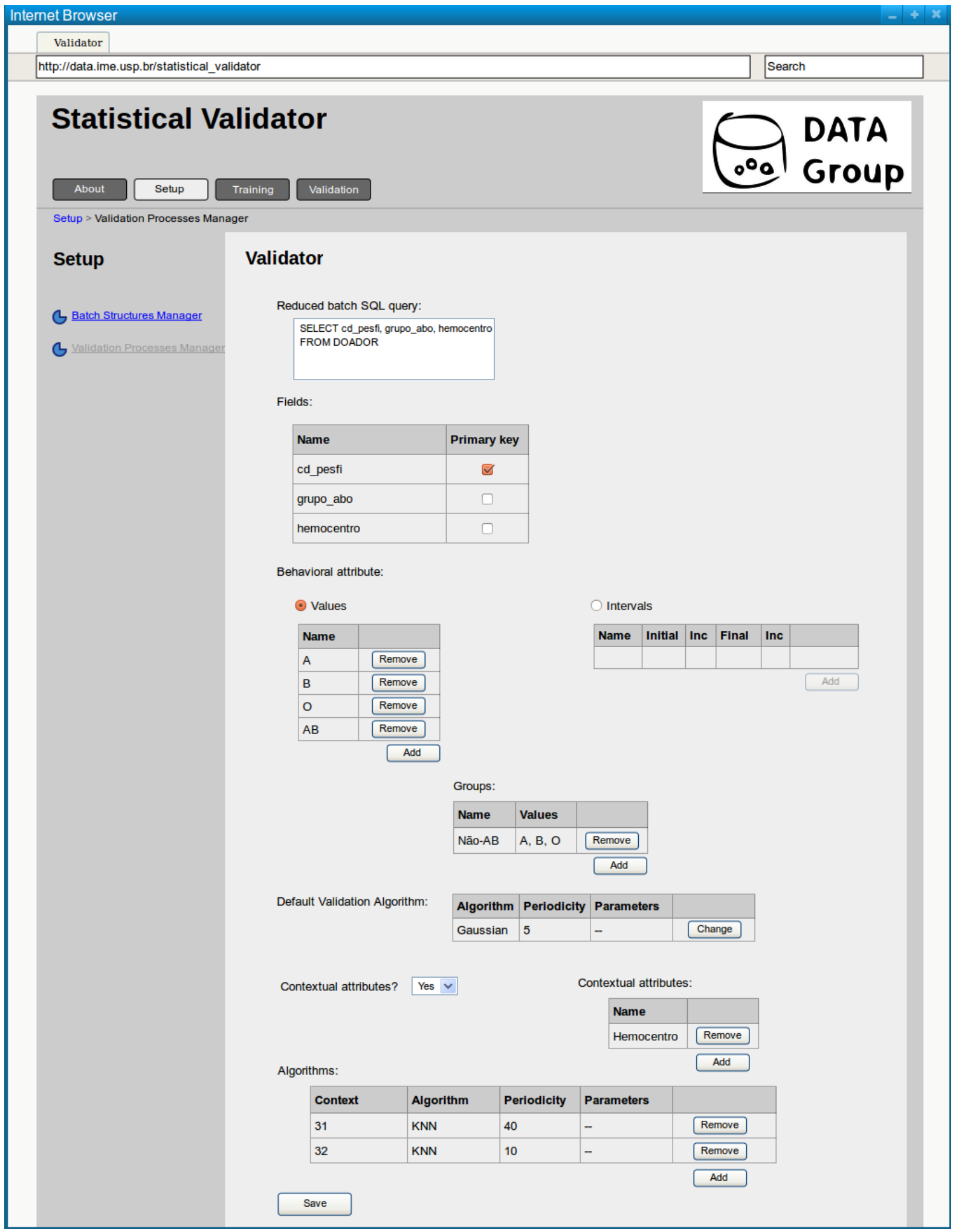

Figura 5.8: Sistema de validação: protótipo da tela de criação e edição de validadores lógicos. 


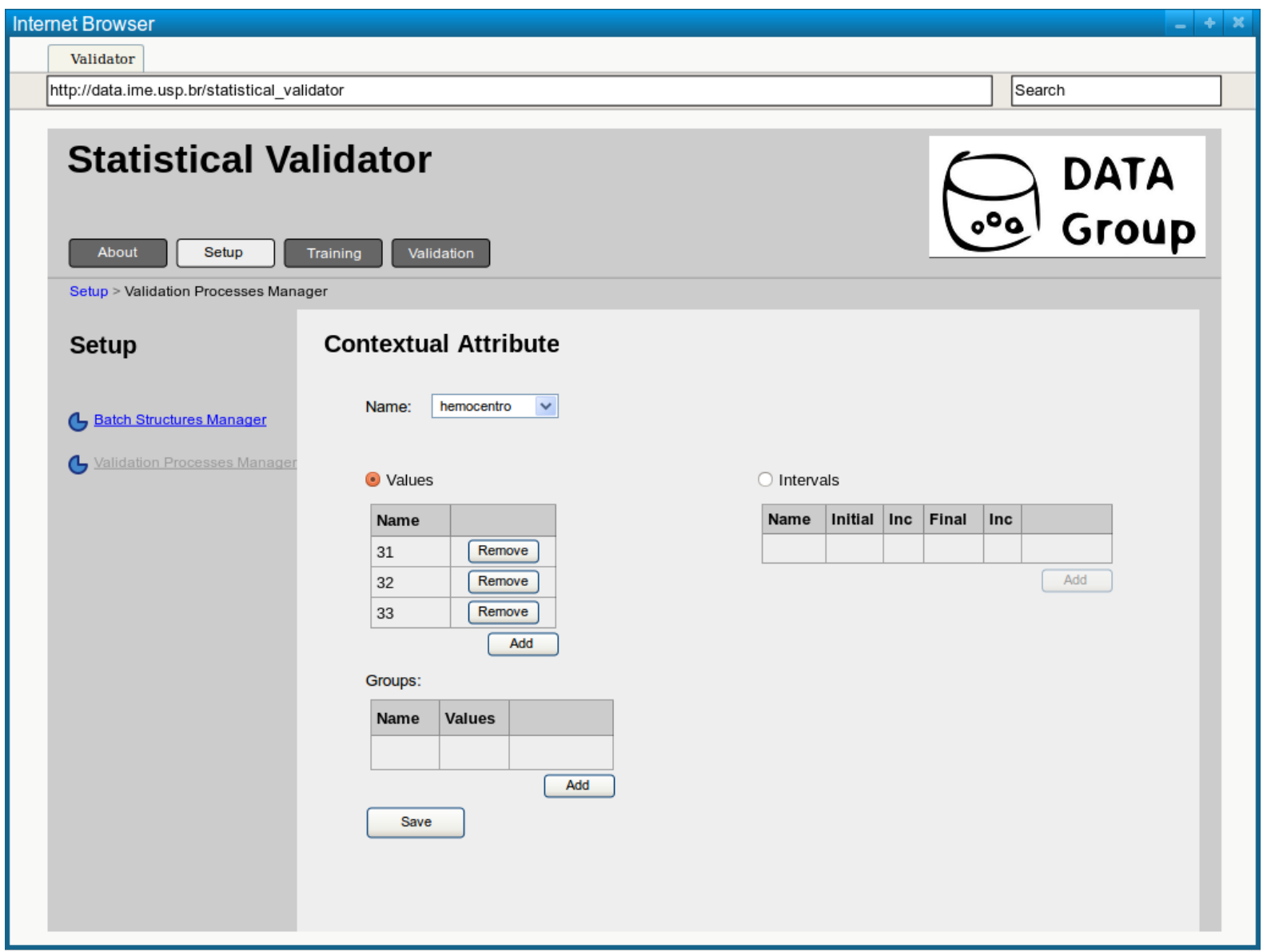

Figura 5.9: Sistema de validação: protótipo da tela de criação de atributo contextual.

que incorpora novos dados aos detectores à medida que novos lotes são submetidos à validação (detalhes serão fornecidos na Seção 5.3.3). No restante desta seção, nos concentramos na fase inicial de treinamento.

O treinamento dos detectores é realizado em duas etapas distintas. A primeira etapa refere-se à entrada de dados, sob forma de lotes de treinamento, até a transformação desses lotes em instâncias de treinamento para os detectores de anomalias. Isso será visto sob a perspectiva do gerenciamento de lotes. A segunda etapa trata da incorporação do conhecimento do especialista às instâncias de treinamento, por meio da perspectiva do gerenciamento de lotes reduzidos nos validadores físicos.

\section{Gerenciamento de lotes}

Um processo de validação pode receber lotes de dados com dois objetivos distintos. Para validá-lo e para treinar seus detectores de anomalias. A validação de lotes é vista com mais detalhes na Seção 5.3.3.

Ao receber um lote de treinamento, um processo de validação produz, para cada um dos seus validadores lógicos, um lote reduzido. Um validador lógico, por sua vez, ao receber um lote reduzido, gera os lotes reduzidos para os seus validadores físicos. Cada validador físico possui uma lista de lotes reduzidos recebidos por ele. Ao receber um lote reduzido, esse lote poderá ser vazio (não conter tuplas). Se for esse o caso, o lote será descartado. Caso contrário, ele entra para 
a lista. É importante notar que um lote reduzido proveniente de um lote de treinamento não é validado pelo detector de anomalias. O validador físico tem a responsabilidade de garantir que todos os lotes reduzidos existentes em sua lista e que estejam ativos (o conceito de inativação de lotes reduzidos será visto posteriormente) correspondam a instâncias de treinamento em seu detector associado. Esse controle é desempenhado pelos validadores físicos via interface fornecida pelo detector, que inclui métodos de inserção, atualização e remoção de instâncias de treinamento nos detectores (detalhes na Seção 5.3.4). Esse fluxo de dados desde a inserção de um lote de treinamento até a geração de instâncias de treinamento nos detectores é ilustrado na Figura 5.10.

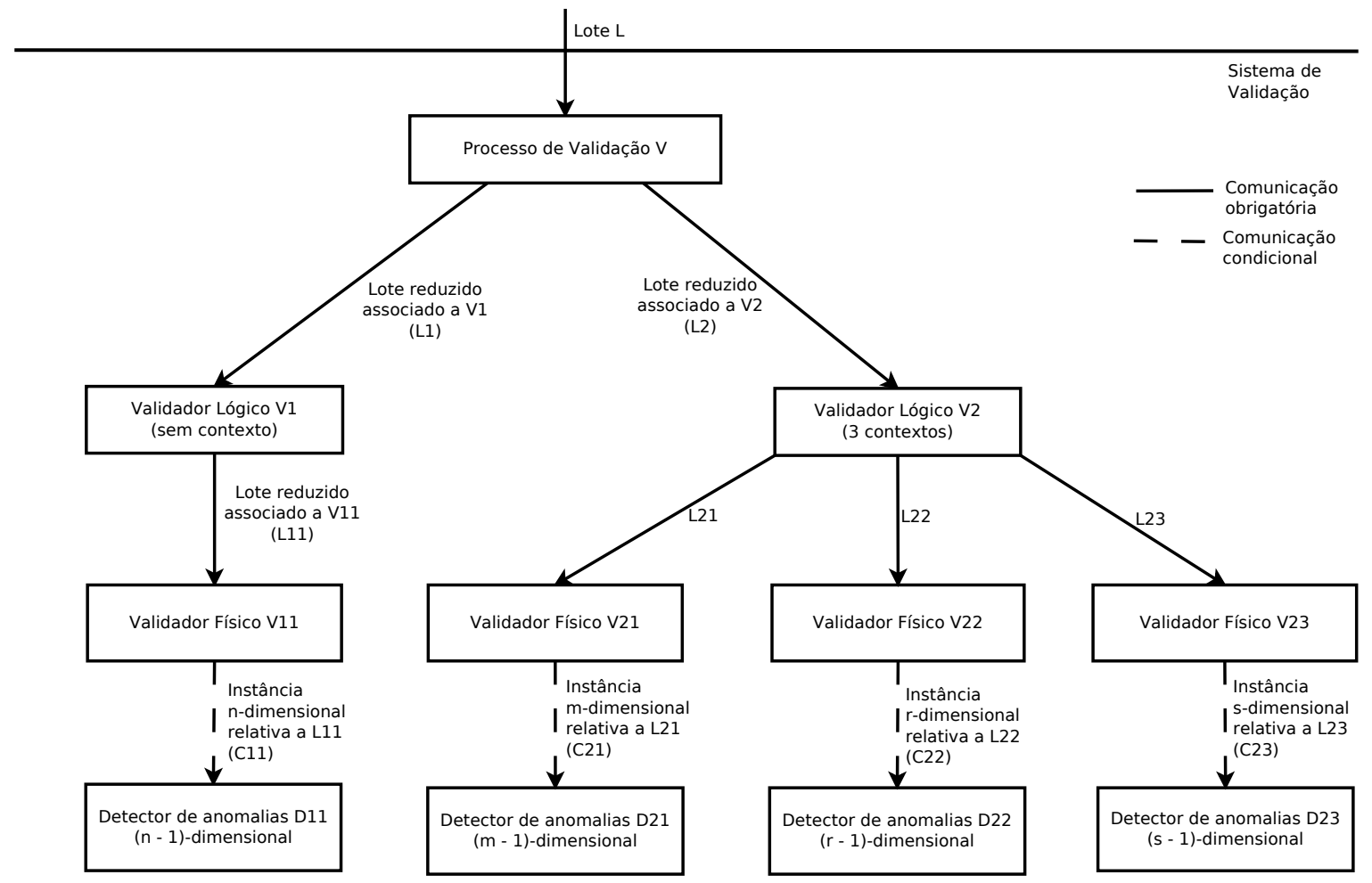

Figura 5.10: Fluxo de dados no treinamento dos detectores de anomalias considerando contextos (simplificado).

Por meio de sua interface web, pela aba Treinamento (Training), o sistema provê os meios necessários para realizar o treinamento dos detectores. A inserção de um novo lote de treinamento pode ser feita por meio da tela de inserção de lote (Figura 5.11). Em linhas gerais, escolhido um processo de validação, é possível submeter um lote de treinamento a ele fornecendo um arquivo de lote (conforme descrito na Seção 5.3.1) e um nome para identificá-lo no sistema. O conceito de lote corretivo, que aparece na tela, será explicado na Seção 5.3.3. O sistema também possibilita a inserção de múltiplos lotes, permitindo selecionar diversos arquivos de lotes. Nesse caso, os nomes dos lotes serão determinados pelos nomes dos arquivos zip (sem as extensões), e a ordem das inserções será determinada por ordem alfabética dos nomes dos lotes que se quer inserir.

Assim como os validadores físicos mantêm uma lista de seus lotes reduzidos, os processos de validação também mantêm uma lista dos lotes que foram submetidos a ele. Dessa maneira é possível gerenciá-los. O vínculo entre um lote e seus lotes reduzidos gerados a partir dele é mantido pelo sistema, de tal forma que possibilita, por meio do gerenciamento dos lotes, a manipulação indireta de lotes reduzidos. Dado um processo de validação, o gerenciamento de seus lotes de 


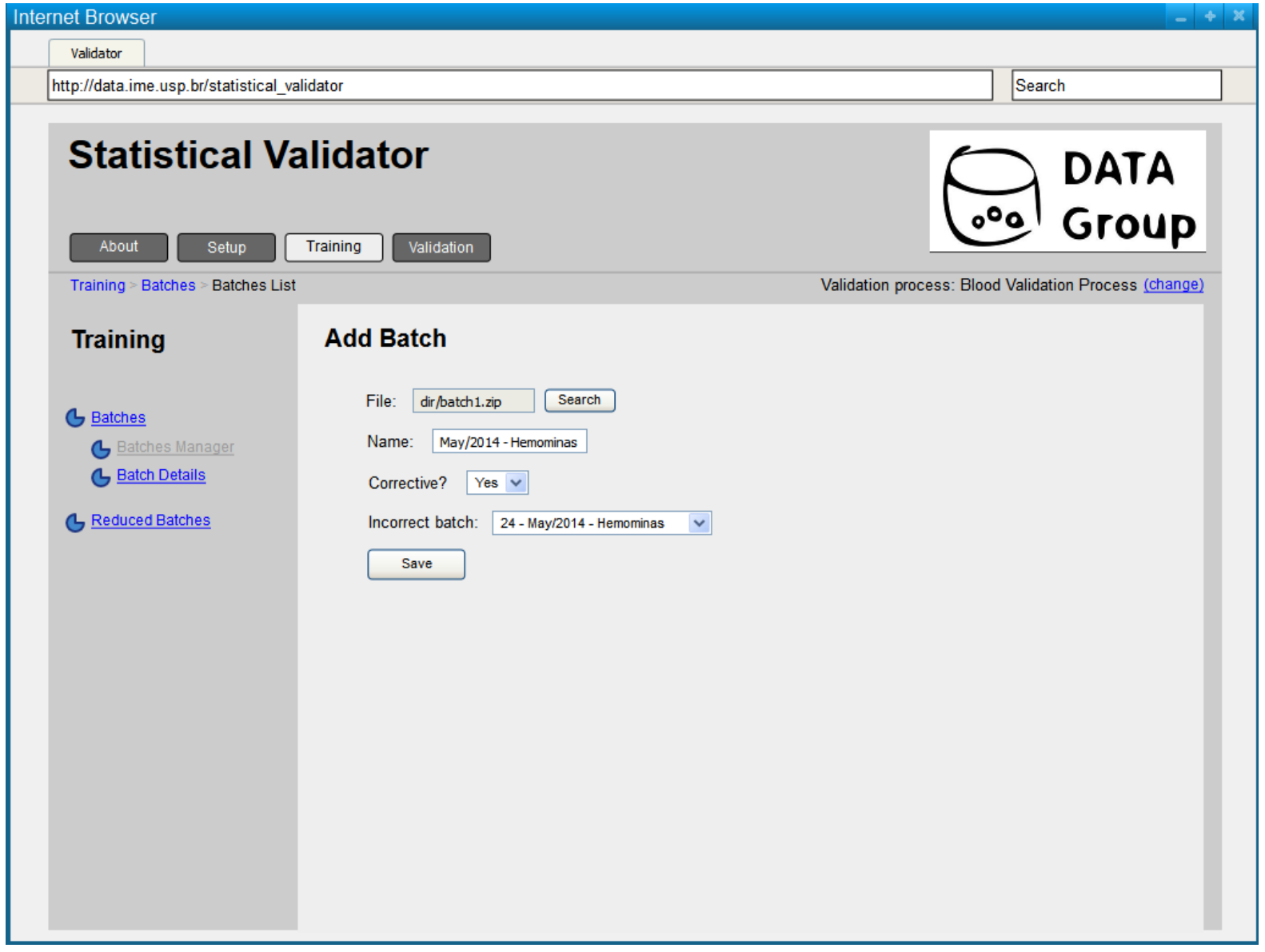

Figura 5.11: Sistema de validação: protótipo da tela de inserção de lote.

treinamento pode ser realizado por meio da tela de gerenciamento de lotes (Figura 5.12). Por meio dessa tela, é possível ver os lotes de treinamento na ordem decrescente em que foram inseridos e editar as sua propriedades, adicionar um lote, adicionar múltiplos lotes, apagar lotes existentes ou ainda inativar (ou ativar) lotes inseridos.

Inativar um lote significa não utilizá-lo no treinamento dos detectores. Essa é uma maneira de fazer com que um lote que foi inserido no sistema de validação seja desconsiderado no momento do treinamento dos detectores de anomalias, sem que para isso seja necessário remover o lote do sistema, mantendo o registro da sua submissão. No sistema de validação, existem duas formas de inativação de lotes: aquela realizada a critério do próprio sistema de validação, chamada de inativação sistêmica e aquela realizada a critério do usuário, chamada de inativação manual. Uma inativação sistêmica só pode ser desfeita pelo sistema. Uma inativação manual só pode ser desfeita pelo usuário. Lotes reduzidos também podem ser ativados e inativados da mesma forma. A inativação de lotes e seus lotes reduzidos associados estão relacionadas. Um lote inativo resulta na inativação de todos os seus lotes reduzidos. Ao ativá-lo, ativa-se todos os lotes reduzidos. Se nos validadores físicos, todos os lotes reduzidos forem inativados, o lote será considerado inativo. Ao ativar um ou mais dos seus lotes reduzidos, o lote volta a ser considerado ativo. Todo lote de treinamento entra no sistema inativo por padrão, para que não interfira no treinamento até que o usuário possa incorporar o conhecimento que possui ao lote reduzido (essa fase será vista no gerenciamento de lotes reduzidos), momento em que o usuário pode retirar a inativação. 


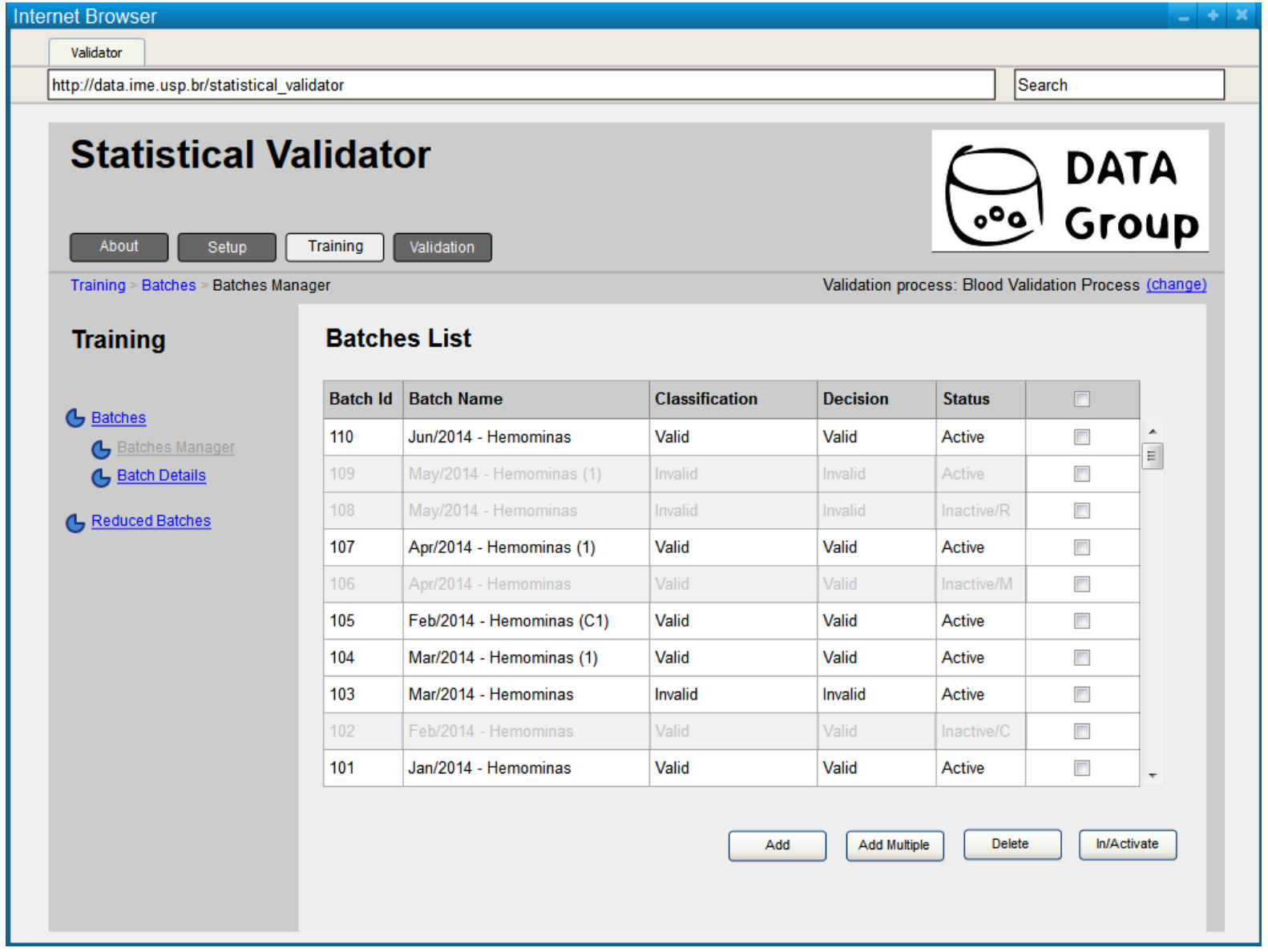

Figura 5.12: Sistema de validação: protótipo da tela de gerenciamento de lotes.

Apesar de um lote de treinamento não ser validado, ele possui uma classificação em válido ou inválido. Tal classificação é baseada no conhecimento que se incorpora aos lotes reduzidos, e não da sua validação. Basicamente, um lote é considerado inválido se pelo menos um dos seus lotes reduzidos é considerado inválido pelos validadores físicos. Caso contrário, o lote é considerado válido. A classificação de um lote pode mudar com o decorrer do funcionamento do sistema e com intervenções de especialistas.

O campo de decisão, presente no gerenciamento de lotes, só é utilizado para lotes a serem validados. Logo, sua utilização será vista na Seção 5.3.3.

\section{Gerenciamento de lotes reduzidos}

Até o momento, foi descrito como incluir lotes e, por consequência, instâncias de treinamento dos detectores de anomalias no sistema de validação. Entretanto, somente com as interfaces apresentadas, não é possível associar o conhecimento do especialista aos dados de treinamento. Para incluir tal conhecimento, é necessário manipular os dados de entrada sob outra perspectiva, olhando para os validadores físicos e suas listas de lotes reduzidos resultantes da inclusão de lotes no sistema.

Conforme explicado anteriormente, cada validador físico possui uma lista de lotes reduzidos recebidos por ele. Quando um lote reduzido é inserido na lista de um validador físico, uma função de espalhamento [Sch96] é aplicada sobre ele gerando um código de tal forma que, se dois lotes 
reduzidos contiverem os mesmos dados, independentemente da ordem com que esses dados se apresentam, eles gerarão códigos idênticos. Dessa maneira é possível ao sistema impedir que lotes reduzidos repetidos contem como instâncias distintas no treinamento dos detectores de anomalias. Para isso, o sistema possui o conceito de inativação sistêmica de lotes reduzidos por repetição. Ao ser inserido um lote reduzido em um validador físico, automaticamente são inativados outros lotes reduzidos da sua lista que possuírem o mesmo código de espalhamento, evitando problemas de dados replicados. É importante notar que, conforme lotes reduzidos são inseridos, ativados, excluídos, inativados ou modificados, o validador físico é responsável por transformar essas ações em ações de inclusão, alteração e remoção de instâncias ao seu detector de anomalias, que as considerará para atualizar as suas instâncias de treinamento.

Por meio da tela do gerenciador de lotes reduzidos (Figura 5.13), ao selecionar o nome de um validador lógico e um contexto, seleciona-se univocamente um validador físico, e é possível visualizar sua lista de lotes reduzidos. Um lote reduzido herda seu nome e identificador (campos Batch Name e Batch Id) do lote original. Seu estado (Status) de atividade/inatividade também é apresentado, da mesma maneira como ocorre no gerenciamento de lotes.

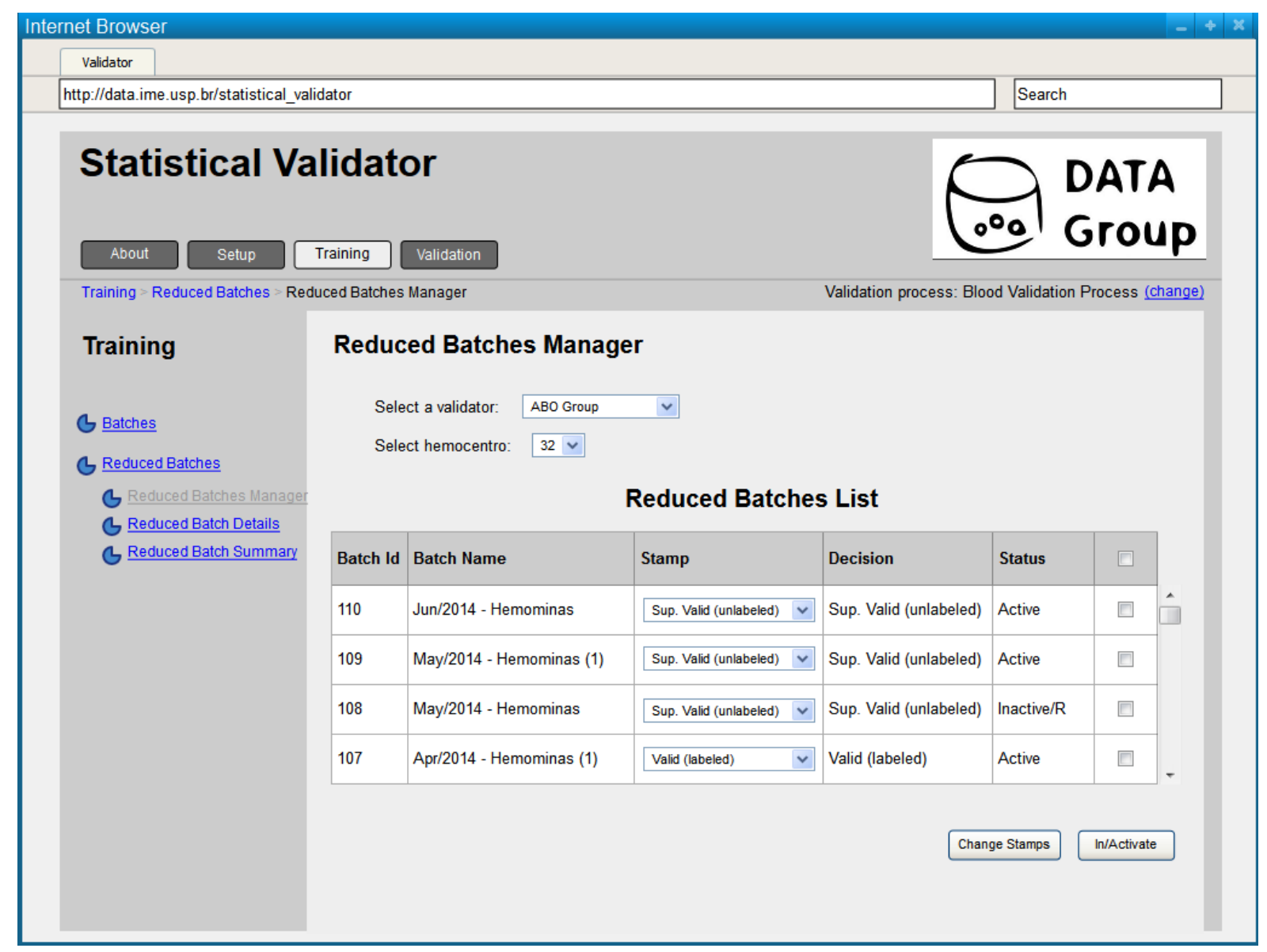

Figura 5.13: Sistema de validação: protótipo da tela de gerenciamento de lotes reduzidos.

Todo lote reduzido associado a um validador físico possui uma marca (campo Stamp), que associa a ele o conhecimento que se tem a respeito da sua validade. No treinamento dos detectores de anomalias, é esperado que, após a inserção dos lotes de treinamento, as marcas dos lotes reduzidos gerados sejam alteradas por especialistas no domínio. Um lote reduzido pode ter uma 
de cinco marcas diferentes:

- Válido (rotulado) - valid (labeled): lote reduzido cuja validade foi comprovada por um especialista.

- Inválido (rotulado) - invalid (labeled): lote reduzido cuja invalidade foi comprovada por um especialista.

- Supostamente válido (não rotulado) - supposedly valid (unlabeled): apesar de não ter sido comprovada a sua validade como no caso rotulado, existem indícios de que o lote reduzido seja válido. Sua validade, apesar de provável, não é garantida.

- Supostamente inválido (não rotulado) - supposedly invalid (unlabeled): apesar de não ter sido comprovada a sua invalidade como no caso rotulado, existem indícios de que o lote reduzido seja inválido. Sua invalidade, apesar de provável, não é garantida.

- Desconhecido (não rotulado) - unknown (unlabeled): nada se sabe a respeito da validade do lote reduzido.

Logo que um lote é introduzido no sistema por meio da interface de treinamento e seus lotes reduzidos são introduzidos na lista dos validadores físicos, se um lote reduzido é inédito, isto é, não possui repetição, a ele é dada a marca inicial desconhecido (não rotulado), por não se saber nada a seu respeito. Se um lote reduzido é a repetição de outros já inseridos, sua marca inicial passa a ser aquela dos lotes reduzidos previamente existentes. As marcas dos lotes reduzidos podem ser visualizadas e modificadas livremente. Mesmo lotes reduzidos inativados podem ter as suas marcas modificadas. Lotes reduzidos repetidos possuem somente uma marca internamente no sistema. Assim, ao modificar a marca de um lote reduzido repetido, modifica-se a marca de todas as réplicas. As modificações em marcas de lotes reduzidos ativos são repassadas imediatamente aos detectores de anomalias. Em lotes reduzidos inativos, as novas marcas são repassadas no momento da ativação dos lotes reduzidos.

Por meio da tela de sumário de lotes reduzidos (Figura 5.14), é possível visualizar rapidamente a distribuição dos lotes reduzidos com relação à marca que apresentam. É importante notar que pode existir uma divergência entre os lotes reduzidos de um validador físico com suas respectivas marcas apresentadas na lista de lotes e as instâncias de treinamento geradas com as marcas presentes no detector de anomalias. Isso acontece pois as instâncias do validador só são atualizadas na ocorrência de um novo treinamento. A periodicidade com que novos treinamentos ocorrem são parâmetros ajustados pelo usuário do sistema (maiores detalhes na Seção 5.3.4).

Uma última observação se faz necessária a respeito da influência das marcas dos lotes reduzidos para a classificação de lotes de treinamento. Se um lote reduzido possuir a marca válido, supostamente válido ou desconhecido, o validador individual considerará esse lote como válido (valor 1). Lotes reduzidos marcados como inválido ou supostamente inválido serão considerados inválidos (valor 0). Essa classificação é usada para calcular a classificação do lote de treinamento, conforme já discutido. 


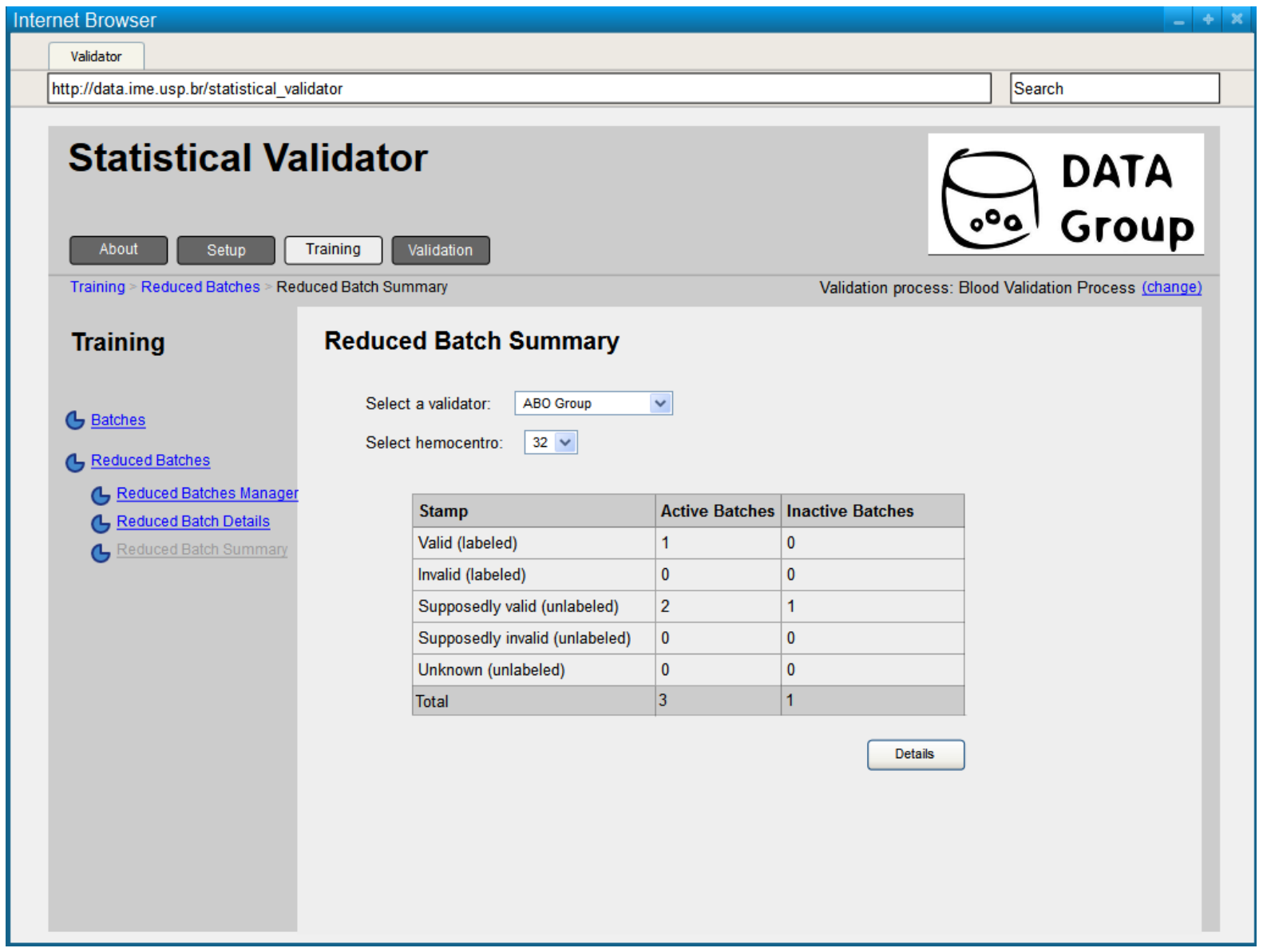

Figura 5.14: Sistema de validação: protótipo da tela de sumário de lotes reduzidos.

\subsubsection{Validação de lotes}

Após a realização do treinamento inicial por meio da interface apresentada na sessão anterior, os detectores de anomalias estarão treinados e o sistema pode começar a receber lotes para serem validados. Quando submete-se um lote para validação, a principal finalidade da submissão é obter uma resposta acerca da validade do lote. Mas, além disso, cada lote submetido ajuda a aperfeiçoar o próprio sistema.

$\mathrm{Na}$ Seção 5.2.1, foi explicado como funciona o mecanismo de validação de dados considerando contextos. Entretanto, deixamos para esta seção a explicação sobre em quais situações os detectores de anomalias precisam ser utilizados pelos validadores físicos para validar os lotes reduzidos. Além disso, tratamos de alguns outros detalhes de implementação que consideramos importantes para o entendimento geral do sistema e damos uma visão sobre como o lote validado entra no treinamento dos validadores. Para facilitar o entendimento, retomamos algumas ideias já vistas anteriormente.

Ao receber um lote com a finalidade de ser validado, um processo de validação produz, para cada um dos seus validadores lógicos, um lote reduzido. Um validador lógico, por sua vez, ao receber um lote reduzido, gera os lotes reduzidos para os seus validadores físicos. Cada validador físico possui uma lista de lotes reduzidos recebidos por ele. Ao receber um lote reduzido, esse lote poderá ser vazio (não conter tuplas). Se for esse o caso, o lote será descartado. Caso contrário, ele entra para a lista e seu código de espalhamento é calculado. Diferentemente do que ocorre quando 
um lote de treinamento é recebido, esse lote reduzido precisa ser validado. Para isso, compara-se o seu código de espalhamento com o código de outros lotes reduzidos. Assim, é possível saber se o lote reduzido é inédito ou se é repetido. Cada situação é tratada de maneira diferente pelo validador físico, conforme se segue:

- Lote reduzido inédito: Caso seja um lote reduzido inédito, um vetor de características é gerado a partir dele (como visto na Seção 5.2.1) e submetido ao detector de anomalias associado ao validador físico para ser avaliado. O detector, então, responde se o vetor corresponde a uma instância normal ou anômala. Essa resposta, então, é utilizada pelo validador físico para estabeler uma marca para o lote reduzido. Se o vetor de características for considerado normal pelo detector, o validador físico atribui a marca supostamente válido ( não rotulado) ao lote reduzido. Se o vetor de características for considerado anômalo, a marca supostamente inválido (não rotulado) é atribuída.

- Lote reduzido repetido: Caso seja um lote reduzido repetido, o comportamento do validador dependerá do valor da marca já existente nas repetições do lote reduzido. Se a marca anterior for rotulada, isto é, o lote reduzido já foi submetido a uma análise de um especialista, essa marca será herdada pelo lote reduzido sendo validado, e o lote reduzido não passará pelo crivo do detector de anomalias. Se a marca anterior for não rotulada, seja o valor supostamente válido, supostamente inválido ou desconhecido, o lote reduzido será classificado pelo detector de anomalias da mesma maneira que um lote reduzido inédito. Sua marca será então atualizada para supostamente válido ou supostamente inválido (dependendo da resposta do detector). Atualizando a marca do lote reduzido, todas as suas repetições terão a sua marca atualizada automaticamente (pois existe uma só marca para todos os lotes reduzidos com o mesmo código de espalhamento).

Existe ainda um outro caso a ser considerado. Às vezes, mesmo após a fase de treinamento inicial, certos detectores de anomalias não possuem instâncias suficientes para funcionar. Isso pode acontecer por diversos motivos, por exemplo: 1) os algoritmos associados aos detectores desses validadores físicos precisam de um número de instâncias de treinamento superior ao número de instâncias necessário aos algoritmos dos outros detectores; assim, as instâncias fornecidas pelo treinamento inicial não foram suficientes para permitir o funcionamento desses detectores, e 2) esses validadores foram inseridos a posteriori, por alteração no processo de validação, e os lotes reduzidos inseridos na fase de validação inicial não foram utilizados nesses validadores para gerar instâncias de treinamento aos detectores. Nos casos de instâncias insuficientes, a validação dos lotes reduzidos tem o seguinte comportamento: se o lote reduzido for inédito, à sua marca é atribuído o valor desconhecido. Se o lote reduzido for repetido, a marca dos lotes repetidos é herdada, independentemente de qual seja ela. Repetir a marca é o melhor que pode ser feito, pois é o que se sabe sobre o lote reduzido até o momento, já que não é possível utilizar o detector de anomalias nele. Uma medida que pode ser tomada para minimizar a ocorrência desse tipo de situação é conduzir o treinamento inicial até que todos os detectores de anomalias utilizados tenham as suas necessidades de volume de instâncias para funcionamento satisfeitas.

Após a atribuição das marcas aos lotes reduzidos pelos validadores físicos, os campos decisão desses lotes são preenchidos pelos validadores, recebendo o mesmo valor atribuído à marca imedia- 
tamente depois que a validação ocorreu. Para o sistema, o campo decisão é utilizado para calcular o resultado da validação. Lotes reduzidos cujo campo decisão tenha valor válido, supostamente válido ou desconhecido serão considerados como lotes reduzidos válidos (valor 1). Lotes reduzidos cujo campo decisão tenha valor inválido ou supostamente inválido serão considerados como lotes reduzidos inválidos (valor 0). A partir dessa validação feita pelos validadores físicos, de acordo com o método explicado na Seção 5.2.1, a classificação de cada um dos validadores lógicos é calculada e, a partir daí, calcula-se a classificação do lote. O campo de decisão do lote será atualizado com o mesmo valor da sua classificação no momento imediatamente depois que a classificação ocorreu.

O campo decisão de um lote representa o veredicto do processo de validação com relação à validade daquele lote. Assim, se um lote tiver o valor válido em seu campo de decisão, o sistema de DW o aceitará, incluindo seus dados no seu BD. Se contiver o valor inválido, o sistema de DW rejeitará o lote. Em casos excepcionais, entretanto, é possível querer incluir no sistema de DW um lote que foi rejeitado pelo processo de validação. A um lote aceito pelo DW independentemente do resultado do processo de validação, daremos o nome de lote excepcional. Para adequar o sistema de validação também aos casos de lotes excepcionais, a resposta do sistema de validação, nos casos em que recebe um lote assinalado como excepcional, independentemente do valor do campo decisão, será sempre válido (valor 1).

Após o processamento do lote produzindo uma resposta sobre a sua validade, o sistema o usará para treinamento, isto é, o acesso a ele, bem como aos lotes reduzidos associados a ele poderá ser feito por meio da interface de treinamento, permitindo a aplicação de modificações como qualquer outro lote de treinamento. Dessa maneira, o funcionamento dos detectores tende a se aperfeiçoar ao longo do tempo, contando com um número crescente de instâncias para fazer suas classificações.

Existem duas formas de submeter lotes a processos de validação. A primeira delas é por meio do sistema web, e a segunda, por meio de uma API. A interface web é adequada para a interação entre um humano e o sistema de validação, permitindo que usuários possam submeter lotes diretamente ao sistema ou até mesmo realizar simulações e testes. Já a existência de uma API é adequada às interações entre sistemas, sendo esse o modo indicado para a comunicação entre sistemas de DW e o sistema validador.

No sistema web, por meio da aba Validação (Validation), é possível submeter um lote para validação (Figura 5.15). Para isso, é necessário fornecer ao sistema as seguintes informações:

- Processo de validação (Validation process): processo de validação ao qual o lote será submetido.

- Arquivo (File): arquivo zip com o lote a ser validado.

- Lote excepcional? (Exceptional?): deve ser marcado se o lote for considerado excepcional.

- Usar no treinamento? (Use in training?): se essa opção estiver desmarcada, o sistema permite o uso do validador em modo simulação, sendo possível saber qual seria a resposta do sistema a respeito do lote sem que, para isso, seja necessário alterar o estado do sistema incluindo os lotes reduzidos nas listas dos validadores físicos e o lote na lista do gerenciador de lotes. 


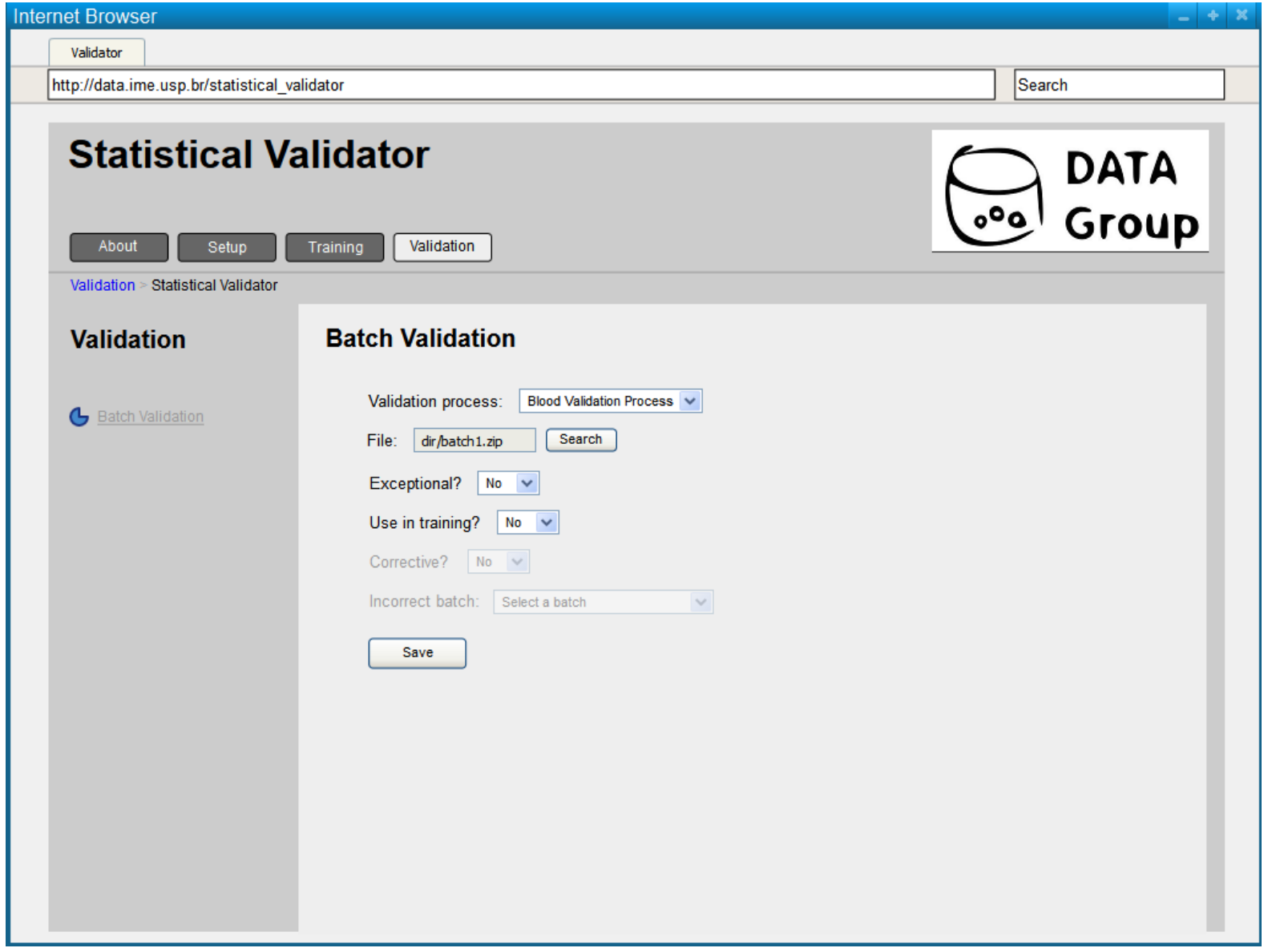

Figura 5.15: Sistema de validação: protótipo da tela de submissão de lote para validação.

- Lote corretivo? (Corrective?): opção somente habilitada se o lote for utilizado para treinamento. Informa ao sistema que o lote é corretivo. Um lote corretivo é um tipo especial de lote que visa substituir algum lote previamente aceito pelo sistema de DW. Assim, a inserção de um lote corretivo precisa inativar no sistema de validação o lote substituído por ele. Sua validação ocorre da mesma forma que outros lotes convencionais.

- Lote incorreto (Incorrect batch): opção habilitada somente se o lote for utilizado para treinamento e se o lote for corretivo. Informa ao sistema qual o lote que deverá ser desabilitado por ocasião da entrada do lote corretivo, isto é, qual é o lote a ser substituído.

Como resposta à submissão de um lote de dados para validação, o usuário recebe:

- O resultado da validação do lote: lote válido ou inválido.

- No caso de um lote inválido, quais foram os validadores físicos que invalidaram o lote. Dessa maneira é possível saber exatamente qual é o atributo problemático e em qual contexto o problema ocorreu, quando houver.

- No caso de validadores cujos detectores não estavam operantes durante a validação por falta de instâncias de treinamento, esses validadores serão listados para que o usuário fique ciente de que a validação foi incompleta. 
A API do sistema tem por objetivo oferecer, via chamada de função, a mesma funcionalidade apresentada no sistema web, recebendo as mesmas entradas e produzindo as mesmas saídas. Dessa maneira possibilita que um sistema de DW consiga validar os seus lotes de maneira automatizada, podendo incluir no DW os lotes válidos e, em caso de lotes inválidos, utilizar os erros apontados para a correção do sistema extrator de lotes.

\subsubsection{Núcleo: detectores de anomalias}

Nas seções anteriores, foi visto que cada validador físico está associado a um detector de anomalias. Na Seção 2.3.1 foram descritos dois métodos de detecção de anomalias, que são o método da distribuição gaussiana e a sua versão multivariada. Esses métodos se mostram bastante eficazes quando utilizados em casos práticos de validação de dados, pois muitos desses casos são caracterizados por uma concentração de instâncias ditas normais em uma única região do espaço e, quanto mais afastado uma instância esteja dessa região, maiores as chances de que ela represente uma anomalia. Mesmo que as instâncias existentes em um detector de anomalias não obedeçam exatamente a uma distribuição gaussiana, esses métodos ainda se mostram eficazes em seu propósito $[\mathrm{Ng}]$.

Apesar de o método ilustrado servir apropriadamente para muitas situações, algumas vezes será necessária a utilização de outro método de deteç̧ão. Isso pode ocorrer em casos nos quais se sabe que algum outro método de deteç̧ão modela melhor o problema em questão ou quando a própria natureza do problema impede o uso de uma gaussiana para representar as instâncias utilizadas em um validador. A Figura 5.16 ilustra um caso em que o uso de outro método torna-se necessário. Nela, é possível notar a representação de instâncias bidimensionais agrupadas em dois núcleos distintos, sendo que o contexto que causa a separação dos núcleos é desconhecido ou não é fornecido ao sistema de DW. Nesse caso, mostra-se mais apropriado utilizar algum método baseado na distância entre pontos ou em densidade.

Devido à possibilidade de ser necessário o uso de outros detectores de anomalias, o sistema deve possibilitar a inclusão de implementações de novos algoritmos de maneira facilitada. O núcleo é responsável por conter as implementações dos detectores de anomalias. Nele, novos algoritmos de detecção de anomalias podem ser depositados como módulos, desde que implementem uma certa interface, obedecendo certas regras.

A interface apresentada a seguir visa a integração do detector de anomalias com o restante do sistema. Ela apresenta quais são os métodos necessários que o detector de anomalias deve fornecer ao sistema de validação.

\section{- módulo.criaDetector}

- Parâmetros:

* número_dimensões (Inteiro)

* valor_treinamento(Inteiro)

* absoluto (Booleano)

* parâmetros_adicionais (Dicionário)

- Devolve: 


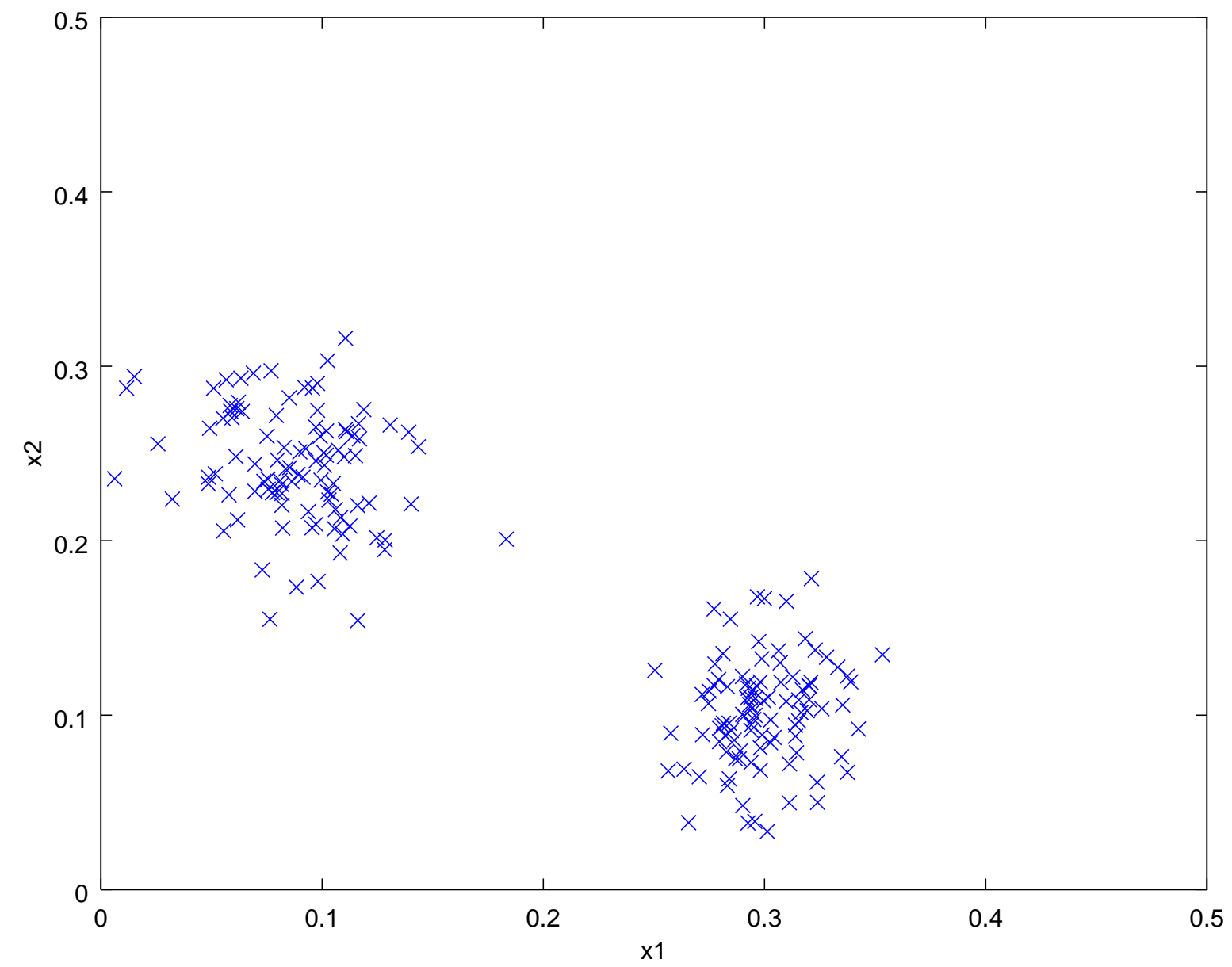

Figura 5.16: Exemplo de instâncias que excluem o uso de métodos gaussianos para detecção de anomalias.

* Detector

- Descrição:

* Método que deve ser fornecido pelo módulo para gerar novas instâncias de detectores de anomalias. Cada um dos validadores físicos deve criar e se associar a uma dessas instâncias de detectores.

* O primeiro parâmetro a ser fornecido ao método é a quantidade de categorias, intervalos ou grupos do atributo a ser validado. Se a quantidade de dimensões fornecidas for $n$, o detector de anomalias estabelecerá um critério para escolher $n-1$ dimensões para usar no seu algoritmo de deteç̧ão.

* O treinamento de detectores de anomalias costuma ser a fase com maior custo computacional no uso de detectores. O sistema deve permitir, portanto, o ajuste da periodicidade com que o treinamento será executado em um detector. Tal periodicidade será medida em número de operações de adições e remoções de instâncias no detector. Fornecer, em valor_treinamento um valor 10 e em absoluto o valor Verdadeiro diz ao detector que ele deve realizar o seu treinamento somente quando houver o acúmulo de 10 novas operações de adição, alteração ou remoção de instâncias no detector. É possível também, utilizando uma porcentagem em valor_treinamento e absoluto como Falso, informar ao validador um número relativo de operações necessárias acumuladas para um novo treinamento, significando 
um percentual da quantidade de instâncias que o detector já possui.

* Alguns algoritmos de detecção de anomalias podem exigir alguns parâmetros para ajustar o seu funcionamento. O dicionário parâmetros_adicionais permite informar tais parâmetros ao método, na forma de pares (chave, valor), quando assim for necessário.

* Dados esses parâmetros, esse método gera um detector de anomalias que deve ser associado a um validador físico.

\section{- detector.adiciona}

- Parâmetros:

* instância (Instância de entrada)

* marca (Marca)

- Descrição:

* Método fornecido pelo detector de anomalias para permitir a inclusão de novas instâncias de entrada com suas respectivas marcas no detector. Cada instância de entrada conterá um identificador da instância e um vetor n-dimensional com as proporções das categorias extraídas dos lotes reduzidos. Associada a uma instância, sua marca deve ser fornecida. Se a instância de entrada já foi inserida previamente no detector, o método deve somente atualizar a sua marca.

* Esse método será chamado pelo validador físico nas ocasiões de inserções, mudanças de marca e ativações de lotes reduzidos.

* A chamada desse método não garante a imediata inclusão ou alteração da instância de entrada e sua marca. É garantido apenas que a operação de adição de uma nova instância ou a sua atualização será agendada para ocorrer no próximo treinamento realizado. A ordem com que as chamadas ocorrem também deve ser respeitada na ocasião do treinamento.

\section{- detector.remove}

- Parâmetros:

* id_instância (Campo textual)

\section{- Descrição:}

* Método fornecido pelo detector de anomalias para permitir a remoção de instâncias previamente inseridas (ou agendadas para inserção) no detector. Remove a instância cujo id é representado por id_instância, bem como a sua marca associada.

* Esse método será chamado pelo validador físico nas ocasiões de remoções e inativações de lotes reduzidos.

* A chamada desse método não garante a imediata remoção da instância referida. É garantido apenas que a sua remoção será agendada para ocorrer no próximo treinamento realizado. A ordem com que as chamadas ocorrem também deve ser respeitada na ocasião do treinamento. 


\section{- detector.classifica}

- Parâmetros:

* instância (Instância de entrada)

- Devolve:

* Booleano

- Descrição:

* Método fornecido pelo detector de anomalias para permitir a classificação de instâncias pelo detector.

* Esse método será chamado pelo validador físico quando for necessário validar o lote reduzido utilizando o detector de anomalias.

* A utilização desse método não leva em consideração as operações de inserção, remoção e atualização de entradas que estão aguardando para serem consumidas pelo próximo treinamento do detector de anomalias. Dessa forma, somente as instâncias que o detector já possuia durante o último treinamento realizado serão usados para classificar a instância em questão. A validação de uma instância não garante a sua inclusão nas instâncias de treinamento do detector. Para isso, é preciso utilizar o método detector.adiciona.

* Esse método deve devolver os valores Verdadeiro ou 1 se a instância de entrada é normal. Deve devolver Falso ou 0 se a instância de entrada é anômala. Cabe aos validadores físicos a tradução da resposta 1 do detector para a marca Supostamente válido (não rotulado) e 0 para a marca Supostamente inválido (não rotulado).

\section{- detector.estaAtivo}

- Devolve:

* Booleano

- Descrição:

* Método fornecido pelo detector de anomalias para permitir que o sistema de validação saiba quando um detector de anomalias está ativo, isto é, quando ele está apto a receber pedidos de validação de entradas.

* Esse método será chamado pelo validador físico antes de validar lotes reduzidos utilizando o detector de anomalias. O detector só poderá ser usado se o método devolver Verdadeiro. Caso contrário, o detector não poderá ser usado para validar instâncias.

* A utilização desse método não leva em consideração as operações de inserção, remoção e atualização de entradas que estão aguardando para serem consumidas pelo próximo treinamento do detector de anomalias. Dessa forma, somente as instâncias que o detector já possuia durante o último treinamento realizado serão usados para determinar se o detector está apto para validar novas instâncias. 
Existem diversas formas de implementar um módulo de detecção de anomalias de maneira a garantir a interface aqui descrita. Uma sugestão de implementação é a manutenção das seguintes estruturas dentro de um detector:

- Conjunto de instâncias: contém as instâncias que estão ativas dentro de um detector juntamente com as suas marcas. Tais instâncias participaram do último treinamento realizado. Um conjunto de instâncias é uma estrutura de dados indicada pois não pode haver replicação de uma instância dentro de um detector. O número de instâncias presentes deve ser monitorado para que o detector saiba quando está apto a operar e também para saber, em determinados casos, quando um novo treinamento deve ser disparado. Dependendo do algoritmo, pode ser interessante ter diversos conjuntos de instâncias em vez de um só. Cada conjunto seria responsável por armazenar instâncias associadas a uma determinada marca. É importante notar que nem todo algoritmo utilizará instâncias de todas as marcas possíveis. Por exemplo, se um detector utilizar somente instâncias rotuladas em seu treinamento, cabe a ele saber o que fazer com as instâncias não rotuladas, como desprezá-las ou, dependendo do caso, utilizá-las como se tivessem outro tipo de marca.

- Fila de operações: os pedidos de inserções, atualizações e remoções de pontos que ainda não foram contabilizados podem ser armazenados em uma fila. Dessa maneira, a ordem com que as operações foram chamadas é garantida. Essa fila deve ser monitorada e suas entradas contabilizadas para ser possível disparar um novo treinamento de acordo com o que foi especificado pelo usuário ao instanciar o detector. Na ocasião de um novo treinamento, todos os elementos da fila serão consumidos, resultando em modificações no(s) conjunto(s) de instâncias ativas. Em seguida o treinamento é realizado já com o conjunto de instâncias atualizado.

É interessante perceber que, em máquinas com múltiplos processadores ou múltiplos núcleos, as execuções dos validadores físicos e seus respectivos detectores de anomalias podem ser facilmente paralelizadas, devido à natureza do problema. Não há qualquer tipo de comunicação entre os processos durante o treinamento ou validação utilizando os detectores. A única comunicação que existe é uma sincronização, ao final de todas as validações de cada um dos detectores físicos, para produzir uma classificação para os validadores lógicos por meio da conjunção de respostas e, a partir daí, produzir um veredicto sobre a validade de um lote.

\subsection{Conclusão}

Neste capítulo, apresentamos um método de validação de lotes de dados que utiliza o perfil estatístico de lotes previamente analisados para tomar decisões a respeito da validade de novos lotes. Tal método é baseado na utilização conjunta de diversos detectores de anomalias, que melhoram o seu desempenho à medida que são utilizados. Além disso, apresentamos um projeto de sistema que viabiliza o uso do método apresentado no contexto de sistemas integradores, constituindo uma solução de validação que buscávamos desenvolver. No próximo capítulo serão apresentadas as principais conclusões deste trabalho de doutorado, bem como algumas sugestões para pesquisas futuras. 


\section{Capítulo 6}

\section{Conclusões}

O desenvolvimento de sistemas de integração que utilizam DW e cujos dados vêm de fontes heterogêneas traz diversos desafios aos desenvolvedores. Dentre esses desafios, a entrega de versões funcionais de sistemas de DW dentro de um prazo plausível tem se mostrado uma grande barreira a ser ultrapassada. Assim, para superar essa barreira, este trabalho apresenta duas importantes contribuições para facilitar o desenvolvimento desses sistemas integradores: 1) diretrizes metodológicas para guiar a sua construção; 2) um validador estatístico de lotes de dados para auxiliar na implementação das validações de seus dados.

Nas diretrizes metodológicas, mostramos que o uso combinado de três boas práticas é muito conveniente para desenvolver um DW. Essas práticas são as seguintes: a estruturação do código de acordo com uma arquitetura modular; a criação e a manutenção de um modelo conceitual para conduzir a construção do DW; e análise de dados como um caminho para detectar possíveis erros no sistema. Essas práticas devem ser aplicadas de maneira conjunta com correções e devem ter as principais entidades como foco principal. As entidades menos importantes devem ser incorporadas somente quando uma versão funcional do sistema já existir. Essas diretrizes foram aplicadas com sucesso na construção do projeto REDS-II, cujo DW está em franca expansão, abrangendo cada vez mais hemocentros brasileiros.

No validador estatístico, apresentamos um método que se propõe a utilizar o perfil estatístico de lotes previamente analisados para tomar decisões a respeito da validade de novos lotes. Mais concretamente, dividimos o problema de validação de lotes em diversos problemas de validação. Em nossa abordagem, cada validador é responsável por validar apenas um atributo de interesse e está associado a um método específico de deteç̧ão de anomalias. Desse modo, passa-se a ter vários detectores de anomalias trabalhando conjuntamente com a finalidade de validar os lotes. O validador estatístico foi projetado como um sistema de software que utiliza os conceitos e o método de validação descrito no Capítulo 5 . Tal sistema viabiliza a concretização das ideias apresentadas numa solução de validação que pode se integrar a sistemas de DW preexistentes ou em fase de implantação.

\subsection{Detalhes das principais contribuições}

Como principais contribuições deste trabalho, pode-se citar: 
- Especificação e descrição de diretrizes metodológicas para a construção de um sistema integrador de dados utilizando DW, tendo como base os aprendizados adquiridos durante a construção do sistema integrador do projeto REDS-II. Essa contribuição foi publicada em sua íntegra no periódico Decision Support Systems (DSS), com o título: "Methodological guidelines for reducing the complexity of data warehouse development for transactional blood bank systems" [TOB $\left.{ }^{+} 13\right]$. Esse periódico é classificado como Qualis CAPES A1 na área de Ciência da Computação. Um resultado parcial dessa contribuição foi publicado no Workshop de Teses e Dissertações do Simpósio Brasileiro de Bancos de Dados, 2012 com o título: "Methodological Guidelines and Adaptive Statistical Data Validation to Build Effective DataWarehouses" [TF12].

- Desenvolvimento de um método de validação estatística de lotes de dados, que utiliza técnicas de detecção de anomalias para classificar os lotes de dados. Além do método apresentado, foi também projetado um sistema de software que utiliza esse método. $\mathrm{O}$ método e o sistema projetado estão sendo descritos em um trabalho a ser submetido para um periódico de grande impacto.

Além dessas duas principais contribuições diretas, este trabalho foi a base para mais três outras publicações em periódicos com Qualis CAPES A1/A2 para a área de Medicina e Qualis CAPES B2 para Ciência da Computação. São elas:

- "Demographic characteristics and prevalence of serologic markers among blood donors who use confidential unit exclusion (CUE) in São Paulo, Brazil: implications for modification of CUE polices in Brazil." [dANLW $\left.{ }^{+} 11\right]$.

- "Vasovagal reactions in whole blood donors at three REDS-II blood centers in Brazil." [GSS $\left.{ }^{+} 12\right]$.

- "Accuracy of a probabilistic record-linkage methodology used to track blood donors in the Mortality Information System database" [CBA $\left.{ }^{+} 14\right]$.

\subsection{Sugestões para pesquisas futuras}

Os próximos passos deste trabalho podem ser divididos em duas classes. No caso das diretrizes metodológicas, planeja-se:

- Expandir as análises estatísticas realizadas sobre os dados, utilizando técnicas mais avançadas. Com essas técnicas, pretendemos proporcionar ao usuário final o acesso a diferentes visões e perspectivas sobre os dados, o que facilitará a correção de erros sistêmicos e a busca por novos requisitos.

- Consolidar essas diretrizes aplicando-a em diferentes domínios de modo a contribuir para uma metodologia plausível para desenvolvimento de sistemas de data warehouse.

No caso do método de validação estatística, planeja-se estudar novas maneiras de adaptar a solução desenvolvida para conseguir detectar novos tipos de erros. Para isso, buscaremos: 
- Novos métodos para trabalhar com validações que envolvem casos mais complexos de dependências entre atributos;

- Validar variáveis numéricas sem categorizá-las, considerando as suas distribuições de frequência nos diversos lotes como perfil estatístico a ser considerado;

- Ampliar o perfil estatístico dos lotes, incluindo mais medições que capturem outras características dos dados sendo analisados;

- Analisar outros métodos de detecção de anomalias que possam ser usados para tratar casos de atributos que não podem ser validados por detectores gaussianos. 



\section{Referências Bibliográficas}

[ABA06] Malik Agyemang, Ken Barker e Rada Alhajj. A comprehensive survey of numeric and symbolic outlier mining techniques. Intell. Data Anal., 10(6):521-538, Dezembro 2006. 22

[AK12] Ahmed AlEroud e George Karabatis. A contextual anomaly detection approach to discover zero-day attacks. Em CyberSecurity, páginas 40-45. IEEE Computer Society, 2012. 56

[Amb03] Scott W. Ambler. Agile Database Techniques: Effective Strategies for the Agile Software Developer. Wiley, 2003. 8

[AS06] Scott W. Ambler e Pramodkumar J. Sadalage. Refactoring Databases: Evolutionary Database Design. Addison-Wesley Professional, 2006. 8, 44

[AT00] James Ang e Thompson S. H. Teo. Management issues in data warehousing: insights from the Housing and Development Board. Decision Support Systems, $29: 11-20,2000.8$

[BCFM09] Carlo Batini, Cinzia Cappiello, Chiara Francalanci e Andrea Maurino. Methodologies for data quality assessment and improvement. ACM Computing Surveys, 41(3):16:1-16:52, Julho 2009. 14

[BG10] Irad Ben-Gal. Outlier detection. Em Oded Maimon e Lior Rockach, editors, Data Mining and Knowledge Discovery Handbook: A Complete Guide for Practitioners and Researchers. Springer, segunda edição, 2010. 22

[bio12] BIOLAP. http://biolap.sourceforge.net/, 2012. Acessado em 14/Fev/2013. 8

[BL94] Vic Barnett e Toby Lewis. Outliers in Statistical Data. Wiley Series in Probability \& Mathematical Statistics. Wiley, terceira edição, 1994. 20

$\left[\mathrm{BMP}^{+}\right.$08a] Angela Bonifati, Giansalvatore Mecca, Alessandro Pappalardo, Salvatore Raunich e Gianvito Summa. Schema mapping verification: the Spicy way. Em Proceedings of the 11th International Conference on Extending Database Technology, EDBT'08, páginas 85-96, Nantes, França, Março 2008. 2, 12, 13

$\left[\mathrm{BMP}^{+} 08 \mathrm{~b}\right]$ Angela Bonifati, Giansalvatore Mecca, Alessandro Pappalardo, Salvatore Raunich e Gianvito Summa. The Spicy system: towards a notion of mapping quality. Em Proceedings of the 28th ACM SIGMOD International Conference on Management of Data, SIGMOD’08, páginas 1289-1294, Vancouver, Canadá, Junho 2008. 2, 13

$\left[\mathrm{CBA}^{+}{ }^{14}\right]$ Ligia Capuani, Ana Luiza Bierrenbach, Fatima Abreu, Pedro Losco Takecian, João Eduardo Ferreira e Ester Cerdeira Sabino. Accuracy of a probabilistic recordlinkage methodology used to track blood donors in the mortality information system database. Cadernos de Saúde Pública - Reports in Public Health, 30(8):1623 - 1632, Agosto 2014. 82 
[CBK09] Varun Chandola, Arindam Banerjee e Vipin Kumar. Anomaly detection: A survey. ACM Computing Surveys (CSUR), 41(3):15:1-15:58, Julho 2009. 19, 21, 22, 56

[CD97] Surajit Chaudhuri e Umeshwar Dayal. An overview of data warehousing and OLAP technology. SIGMOD Rec, 26:65-74, Março 1997. 9, 33

$\left[\mathrm{CLR}^{+} 14\right]$ Gregory Chu, Pechin Lo, Bharath Ramakrishna, Hyun Kim, Darren Morris, Jonathan Goldin e Matthew Brown. Bone tumor segmentation on bone scans using context information and random forests. Em Medical Image Computing and Computer-Assisted Intervention - MICCAI 2014, volume 8673 de Lecture Notes in Computer Science, páginas 601-608. Springer, 2014. 56

[cou] Coursera: Aprendizagem automática. https://www.coursera.org/course/ml. Acessado em 09/02/2014. 23

$\left[\mathrm{CPSS}^{+} 10\right]$ Anna B. F. Carneiro-Proietti, Ester C. Sabino, Divaldo Sampaio, Fernando A. Proietti, Thelma T. Gonçalez, Claudia D. L. Oliveira, João E. Ferreira, Jing Liu, Brian Custer, George B. Schreiber, Edward L. Murphy e Michael P. Busch. Demographic profile of blood donors at three major Brazilian blood centers: results from the International REDS-II study, 2007 to 2008. Transfusion, 50(4):918-925, 2010. 30

[dANLW $\left.{ }^{+} 11\right]$ Cesar de Almeida-Neto, Jing Liu, David J. Wright, Alfredo Mendrone-Junior, Pedro L. Takecian, Yu Sun, João E. Ferreira, Dalton de A. F. Chamone, Michael P. Busch e Ester C. Sabino. Demographic characteristics and prevalence of serologic markers among blood donors who use confidential unit exclusion (CUE) in São Paulo, Brazil: implications for modification of CUE polices in brazil. Transfusion, 51(1):191-197, 2011. 30, 82

[DD97] Christopher J. Date e Hugh Darwen. A guide to the SQL standard : a users guide to the standard database language SQL. Addison Wesley, quarta edição, 1997. 2

[DEE $\left.{ }^{+} 13\right]$ Michele Dallachiesa, Amr Ebaid, Ahmed Eldawy, Ahmed Elmagarmid, Ihab F. Ilyas, Mourad Ouzzani e Nan Tang. NADEEF: A commodity data cleaning system. Em Proceedings of the 2013 ACM SIGMOD International Conference on Management of Data, SIGMOD '13, páginas 541-552, Nova Iorque, NY, EUA, 2013. ACM. 17

[DiM08] Len DiMaggio. What is middleware? in plain english, please. http://magazine. redhat.com/2008/03/11/what-is-middleware-in-plain-english-please/, 2008. Acessado em $12 / 10 / 2013.10$

[EEI $\left.{ }^{+} 13\right]$ Amr Ebaid, Ahmed Elmagarmid, Ihab F. Ilyas, Mourad Ouzzani, Jorge-Arnulfo Quiane-Ruiz, Nan Tang e Si Yin. NADEEF: A generalized data cleaning system. Proceedings of the VLDB Endowment, 6(12):1218-1221, 2013. 17

[EN10] Ramez Elmasri e Shamkant Navathe. Fundamentals of Database Systems. AddisonWesley Publishing Company, EUA, sexta edição, 2010. 6, 7, 9, 30, 48, 50, 56

[erw12] CA ERwin Data Modeling. http://erwin.com/, 2012. Acessado em 14/Fev/2013. 43

[exc] Microsoft Excel. http://office.microsoft.com/en-us/excel/. Acessado em 04/05/2012. 8

[Gal06] Avigdor Gal. Why is schema matching tough and what can we do about it? SIGMOD Rec., 35(4):2-5, Dezembro 2006. 13 
[Gar05] Gartner. Gartner says more than 50 percent of data warehouse projects will have limited acceptance or will be failures through 2007. http://www.gartner.com/ press_releases/asset_121817_11.html, 2005. Acessado em 04/05/2012. 1

[GDS14] Anja Gruenheid, Xin Luna Dong e Divesh Srivastava. Incremental record linkage. Proceedings of the VLDB Endowment, 7(9):697-708, 2014. 17

[GFS ${ }^{+}$01] Helena Galhardas, Daniela Florescu, Dennis Shasha, Eric Simon e Cristian-Augustin Saita. Declarative data cleaning: language, model, and algorithms. Em Proceedings of the 27th International Conference on Very Large Data Bases, VLDB'01, páginas 371-380, São Francisco, EUA, 2001. Morgan Kaufmann Publishers Inc. 17

[GFSS00] Helena Galhardas, Daniela Florescu, Dennis Shasha e Eric Simon. AJAX: an extensible data cleaning tool. SIGMOD Rec., 29(2):590-595, Maio 2000. 17

[GMPS13] Floris Geerts, Giansalvatore Mecca, Paolo Papotti e Donatello Santoro. The LLUNATIC data-cleaning framework. Proceedings of the VLDB Endowment, 6(9):625-636, 2013. 17

[GMPS14] Floris Geerts, Giansalvatore Mecca, Paolo Papotti e Donatello Santoro. That's all folks! LLUNATIC goes open source. Proceedings of the VLDB Endowment, 7(13):1565-1568, 2014. 17

[GMR98] Matteo Golfarelli, Dario Maio e Stefano Rizzi. Conceptual design of data warehouses from E/R schema. Em Proceedings of the Thirty-First Annual Hawaii International Conference on System Sciences, HICSS'98, página 334, Kona, HI, EUA, 1998. 9

[GRG08] Paolo Giorgini, Stefano Rizzi e Maddalena Garzetti. GRAnD: A goal-oriented approach to requirement analysis in data warehouses. Decision Support Systems, 45:4-21, 2008. 8

[GSS $\left.{ }^{+} 12\right]$ Thelma T. Gonçalez, Ester C. Sabino, Karen S. Schlumpf, David J. Wright, Silvana C. Leao, Divaldo Sampaio, Pedro L. Takecian, Anna B. F. Proietti, Edward Murphy, Michael P. Busch e Brian Custer. Vasovagal reactions in whole blood donors at 3 REDS-II blood centers in Brazil. Transfusion, 52(5):1070-1078, 2012. 30,82

[Haw80] Douglas M. Hawkins. Identification of Outliers. Monographs on applied probability and statistics. Chapman and Hall, 1980. 20

[HPDW01] Jiawei Han, Jian Pei, Guozhu Dong e Ke Wang. Efficient computation of iceberg cubes with complex measures. Em Proceedings of the 2001 ACM SIGMOD International Conference on Management of Data, SIGMOD'01, páginas 1-12, Santa Barbara, CA, EUA, 2001. 8

[Huy01] Nam Huyn. Scientific OLAP for the biotech domain. Em Proceedings of the 27th International Conference on Very Large Data Bases, VLDB'01, páginas 645-648, Rome, Italy, 2001. 8

[IFT01] Isabel C. Italiano, João E. Ferreira e Osvaldo K. Takai. Aspectos conceituais em data warehouse. Relatório Técnico RT-MAC-2001-08, Instituto de Matemática e Estatística, Universidade de São Paulo, São Paulo, Brasil, 2001. 8

[Inm02] William H. Inmon. Building the Data Warehouse. John Wiley \& Sons, Inc., Nova Iorque, EUA, terceira edição, 2002. 5 
[JKPT04] Christian S. Jensen, Augustas Kligys, Torben Bach Pedersen e Igor Timko. Multidimensional data modeling for location-based services. The VLDB Journal, 13(1):1-21, 2004. 8

[Joh03] James H. Johnson. CHAOS Chronicles v3.0. Relatório técnico, The Standish Group, 2003. 1

[JWK09] Fan Jiang, Ying Wu e Aggelos K. Katsaggelos. Detecting contextual anomalies of crowd motion in surveillance video. Em ICIP, páginas 1117-1120. IEEE, 2009. 56

[KC04] Ralph Kimball e Joe Caserta. The data warehouse ETL toolkit. Wiley, 2004. 7

[Kim96] Ralph Kimball. The data warehouse toolkit. Wiley, Nova Iorque, EUA, 1996. 6, 9, 33

[KTR12] Lars Kolb, Andreas Thor e Erhard Rahm. Dedoop: Efficient deduplication with hadoop. Proceedings of the VLDB Endowment, 5(12):1878-1881, 2012. 17

[Len02] Maurizio Lenzerini. Data integration: a theoretical perspective. Em Proceedings of the twenty-first ACM SIGMOD-SIGACT-SIGART symposium on Principles of database systems, PODS'02, páginas 233-246, Wisconsin, EUA, Junho 2002. 9, 11

[LH03] Choonhwa Lee e Abdelsalam Helal. Context attributes: An approach to enable context-awareness for service discovery. Em SAINT, páginas 22-30. IEEE Computer Society, 2003. 56

[LLL00] Mong L. Lee, Tok W. Ling e Wai L. Low. Intelliclean: a knowledge-based intelligent data cleaner. Em Proceedings of the sixth ACM SIGKDD international conference on Knowledge discovery and data mining, KDD'00, páginas 290-294, Nova Iorque, EUA, 2000. ACM. 17

[Mit97] Tom Mitchell. Machine Learning. McGraw-Hill, primeira edição, 1997. 18

[MMP10] Bruno Marnette, Giansalvatore Mecca e Paolo Papotti. Scalable data exchange with functional dependencies. Proceedings of the VLDB Endowment, 3(1):105-116, Setembro 2010. 2

$\left[\mathrm{MMP}^{+} 11\right]$ Bruno Marnette, Giansalvatore Mecca, Paolo Papotti, Salvatore Raunich e Donatello Santoro. ++Spicy: an open-source tool for second-generation schema mapping and data exchange. Proceedings of the VLDB Endowment, 4(12):1438-1441, Agosto 2011. 2, 13, 14

[MNP10] Chris Mayfield, Jennifer Neville e Sunil Prabhakar. ERACER: A database approach for statistical inference and data cleaning. Em Proceedings of the 2010 ACM SIGMOD International Conference on Management of Data, SIGMOD '10, páginas 75-86, Nova Iorque, NY, EUA, 2010. ACM. 17

[mon] Pentaho Mondrian Project. http://mondrian.pentaho.com/. Acessado em 04/05/2012. 8

[Mon00] Alvaro E. Monge. Matching algorithms within a duplicate detection system. IEEE Techn. Bulletin Data Engineering, 23(4):14-20, 2000. 17

[Moo07] Raymond J. Mooney. Machine learning: Inductive classification lecture. http: //www.cs.utexas.edu/ mooney/cs391L/, 2007. Acessado em 04/05/2012. 19 
[MPR09] Giansalvatore Mecca, Paolo Papotti e Salvatore Raunich. Core schema mappings. Em Proceedings of the 35th ACM SIGMOD International Conference on Management of Data, SIGMOD'09, páginas 655-668, Providence, EUA, Junho 2009. 2

[MPRB09] Giansalvatore Mecca, Paolo Papotti, Salvatore Raunich e Marcello Buoncristiano. Concise and expressive mappings with + Spicy. Proceedings of the VLDB Endowment, 2:1582-1585, Agosto 2009. 2, 13

[MRS08] Christopher D. Manning, Prabhakar Raghavan e Hinrich Schütze. Introduction to Information Retrieval. Cambridge University Press, Nova Iorque, EUA, 2008. 25

[Ng] Andrew Ng. Machine learning: Lecture xv. anomaly detection. https://class. coursera.org/ml-005/lecture/preview. Universidade de Stanford, Plataforma Coursera. 23,76

[PdANL $\left.{ }^{+} 12\right]$ Giuseppina M. Patavino, Cesar de Almeida-Neto, Jing Liu, David J. Wright, Alfredo Mendrone-Junior, Maria I. L. Ferreira, Anna B. F. Carneiro-Proietti, Brian Custer, Joao E. Ferreira, Michael P. Busch e Ester C. Sabino. Number of recent sexual partners among blood donors in Brazil: associations with donor demographics, donation characteristics, and infectious disease markers. Transfusion, 52(1):151-159, 2012. 30

$\left[\mathrm{PHV}^{+} 02\right]$ Lucian Popa, Mauricio A. Hernández, Yannis Velegrakis, Renée J. Miller, Felix Naumann e Howard Ho. Mapping XML and relational schemas with Clio. Em Proceedings of the 18th International Conference on Data Engineering, páginas 498-499, 2002. 13

[pos] PostgreSQL. http://www.postgresql.org/. Acessado em 04/05/2012. 40

[pow12] SAP Sybase PowerDesigner. http://www.sybase.com/products/ modelingdevelopment/powerdesigner/, 2012. Acessado em 14/Fev/2013. 43

[Pre10] Roger S. Pressman. Software Engineering: A Practitioner's Approach. McGraw-Hill Higher Education, sétima edição, 2010. 8

$\left[\mathrm{PVH}^{+} 02\right]$ Lucian Popa, Yannis Velegrakis, Mauricio A. Hernandez, Renée J. Miller e Ronald Fagin. Translating web data. Em Proceedings of the 28th international conference on Very Large Data Bases, VLDB'02, páginas 598-609. VLDB Endowment, 2002. 13

[rai] Ruby on Rails. http://www.rubyonrails.org/. Acessado em 04/05/2012. 40

[Rai08] Vincent Rainardi. Building a Data Warehouse: With Examples in SQL Server. Apress, 2008. 6, 9, 12, 32

[RH01] Vijayshankar Raman e Joseph M. Hellerstein. Potter's Wheel: an interactive data cleaning system. Em Proceedings of the 27th International Conference on Very Large Data Bases, VLDB'01, páginas 381-390, 2001. 17

[rub] Ruby. http://www.ruby-lang.org. Acessado em 04/05/2012. 40

[Sad07] Pramodkumar J. Sadalage. Recipes for Continuous Database Integration. AddisonWesley, 2007. 8, 44 
[Sch96] Bruce Schneier. Applied Cryptography, capítulo 18. John Wiley \& Sons, Inc., Nova Iorque, EUA, segunda edição, 1996. 69

[SCT11] David Schuff, Karen Corral e Ozgur Turetken. Comparing the understandability of alternative data warehouse schemas: an empirical study. Decision Support Systems, 52:9-20, Dezembro 2011. 7

$\left[\mathrm{SGCP}^{+} 12\right]$ Ester C. Sabino, Thelma T. Gonçalez, Anna B. F. Carneiro-Proietti, Moussa Sarr, Joao E. Ferreira, Divaldo Sampaio, Nanci A. Salles, David J. Wright, Brian Custer e Michael P. Busch. Human immunodeficiency virus prevalence, incidence, and residual risk of transmission by transfusions at Retrovirus Epidemiology Donor Study-II blood centers in Brazil. Transfusion, 52(4):870-879, 2012. 30

[SMR ${ }^{+}$94] Diane M. Strong, Stuart E. Madnick, Thomas Redman, Arie Segev e Richard Y. Wang. Data quality: a critical research issue for the 1990s and beyond. Em ICIS, páginas 500-501. Association for Information Systems, 1994. 14

[SSS ${ }^{+}$10] Ester C. Sabino, Nanci A. Salles, Moussa Sarr, Angela M. Barreto, Marcio Oikawa, Claudia D. L. Oliveira, Silvana C. Leao, Anna B. F. Carneiro-Proietti, Brian Custer e Michael P. Busch. Enhanced classification of Chagas serologic results and epidemiologic characteristics of seropositive donors at three large blood centers in Brazil. Transfusion, 50(12):2628-2637, 2010. 30

[SWJR07] Xiuyao Song, Mingxi Wu, Christopher Jermaine e Sanjay Ranka. Conditional anomaly detection. IEEE Trans. on Knowl. and Data Eng., 19(5):631-645, Maio 2007. 56

[TF12] Pedro L. Takecian e João E. Ferreira. Methodological guidelines and adaptive statistical data validation to build effective datawarehouses. Em Proceedings of the 27th Brazilian Symposium on Databases - Thesis and Dissertation Workshop, páginas 61-68, São Paulo, Brasil, 2012. 82

[TOB $\left.{ }^{+} 13\right]$ Pedro L. Takecian, Marcio K. Oikawa, Kelly R. Braghetto, Paulo Rocha, Fred Lucena, Katherine Kavounis, Karen S. Schlumpf, Susan Acker, Anna B. F. CarneiroProietti, Ester C. Sabino, Brian Custer, Michael P. Busch e João E. Ferreira. Methodological guidelines for reducing the complexity of data warehouse development for transactional blood bank systems. Decision Support Systems, 55(3):728-739, 2013. 41,82

[VBST08] Vaninha Vieira, Patrick Brézillon, Ana Carolina Salgado e Patricia Azevedo Tedesco. A context-oriented model for domain-independent context management. Revue d'Intelligence Artificielle, 22(5):609-627, 2008. 56

[VdMP $\left.{ }^{+} 11\right]$ Vânia M. P. Vidal, José A. F. de Macêdo, João C. Pinheiro, Marco A. Casanova e Fabio Porto. Query processing in a mediator based framework for linked data integration. International Journal of Business Data Communications and Networking (JBDCN), 7(2):29-47, 2011. 11

[VTS11] Vaninha Vieira, Patricia Tedesco e Ana Carolina Salgado. Designing contextsensitive systems: An integrated approach. Expert Syst. Appl., 38(2):1119-1138, Fevereiro 2011. 56

[WZR05] Liangjiang Wang, Aidong Zhang e Murali Ramanathan. BioStar models of clinical and genomic data for biomedical data warehouse design. Int $J$ Bioinformatics Res Appl, 1:63-80, Abril 2005. 8 
[xqu] XQuery 1.0: An XML query language. http://www.w3.org/TR/xquery/. Acessado em $06 / 05 / 2012.2$

[Yan97] Ling Ling Yan. Accessing heterogeneous data through homogenization and integration mediators. Em Proceedings of the Second IFCIS International Conference on Cooperative Information Systems, COOPIS'97, páginas 130-139. IEEE Computer Society, 1997. 11

[YBEE13] Mohamed Yakout, Laure Berti-Équille e Ahmed K. Elmagarmid. Don’t be SCAREd: Use SCalable Automatic REpairing with maximal likelihood and bounded changes. Em Proceedings of the 2013 ACM SIGMOD International Conference on Management of Data, SIGMOD '13, páginas 553-564, Nova Iorque, NY, EUA, 2013. ACM. 17

[ZD07] Patrick Ziegler e Klaus R. Dittrich. Data integration - problems, approaches and perspectives. Em Conceptual Modelling in Information Systems Engineering, páginas 39-58. Springer, 2007. xi, 9, 10

[Zha13] Ji Zhang. Advancements of outlier detection: A survey. EAI Endorsed Trans. Scalable Information Systems, 1:e2, 2013. 22

[zip] .ZIP File Format Especification. http://www.pkware.com/documents/casestudies/ APPNOTE.TXT. Acessado em 04/01/2014. 59 
